NÚBIA DE SOUZA LOBATO

EFEITO DO TRATAMENTO COM METFORMINA SOBRE ALTERAÇÕES VASCULARES EM MODELO DE RESISTÊNCIA À INSULINA (OBESIDADE EM RATOS) 
NÚBIA DE SOUZA LOBATO

\section{EFEITO DO TRATAMENTO COM METFORMINA SOBRE ALTERAÇÕES VASCULARES EM MODELO \\ DE RESISTÊNCIA À INSULINA \\ (OBESIDADE EM RATOS)}

Dissertação apresentada ao Programa de Pós-graduação em Farmacologia do Instituto de Ciências Biomédicas, da Universidade de São Paulo, para obtenção do Título de Mestre em Ciências. 
NÚBIA DE SOUZA LOBATO

\title{
EFEITO DO TRATAMENTO COM METFORMINA SOBRE ALTERAÇÕES VASCULARES EM MODELO DE RESISTÊNCIA À INSULINA (OBESIDADE EM RATOS)
}

\begin{abstract}
Dissertação apresentada ao Programa de Pós-graduação em Farmacologia do Instituto de Ciências Biomédicas, da Universidade de São Paulo, para obtenção do Título de Mestre em Ciências.
\end{abstract}

Área de Concentração: Farmacologia Orientadora: Prof. Dra. Zuleica Bruno Fortes 


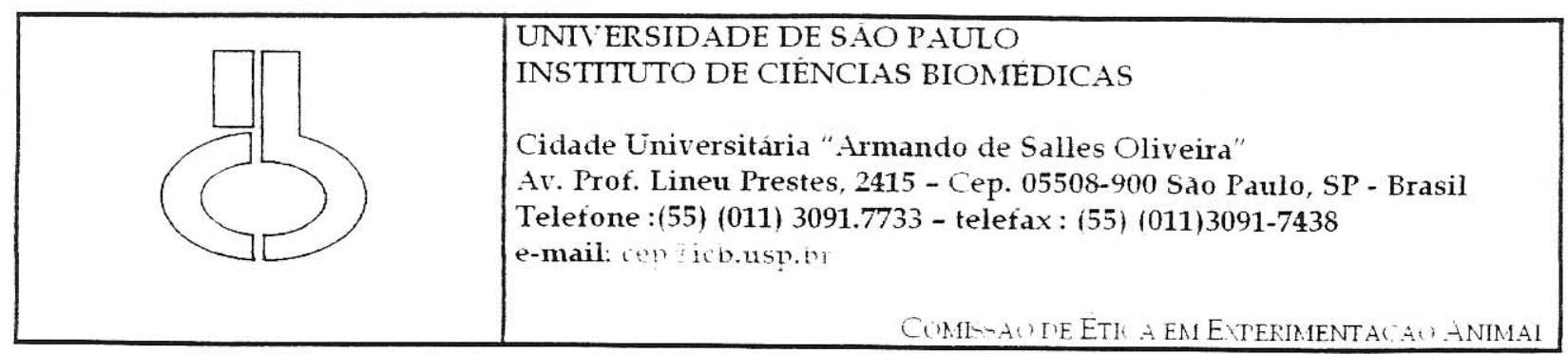

Decl. CEEA.020/2006

\section{DECLARAÇÃO}

Em adendo ao Certificado 007/04/CEEA, aprovo a inclusão do subprojeto intitulado: "Efeito do tratamento com metformina sobre alterações vasculares em modelo de resistência à insulina (obesidade em ratos)" sob a responsabilidade da aluna NÜBIA DE SOUZA LOBATO ao protocolo intitulado: "Reatividade microcirculatória em patologias experimentais. Papel do endotélio", para uso da espécie animal utilizado e métodos semelhantes, mediante solicitação da Profa. Dra. Zuleica Bruno Fortes, responsável pela linha de Pesquisa.

São Paulo, 06 de junho de 2006.

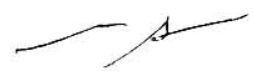

Profa. Dra. Marilia C. Leite Seelaender

Coordenadora da CEEA-ICB/USP 


\section{DEDICATÓRIA}

\section{À minha querida família,}

Meus pais, Neury e Maria Aparecida, pelo amor, incentivo e aceitação incondicional da minha dedicação à pesquisa científica;

Meus irmãos, Nívea Júnior e Luana, pela compreensão e carinho prestados. Mesmo à distância, fizeram chegar, de diversas formas, incentivos e carinhosos cuidados.

\section{Ao Fernando,}

Meu amor, pela paciência, amizade e companheirismo em todos os momentos, dando-me coragem para prosseguir com a confiança necessária para realizar meus sonhos.

\section{À minha orientadora,}

Dra. Zuleica Bruno Fortes, os meus mais profundos agradecimentos pela acolhida em seu laboratório, pela confiança e orientação exemplar, que contribuíram de modo decisivo para minha formação científica. 


\section{AGRADECIMENTOS}

Às professoras do grupo de Hipertensão (Dra. Maria Helena C. Carvalho, Dra. Rita de Cássia A. T. Passaglia, Dra. Dorothy Nigro) pelo apoio e estrutura dos laboratórios.

Às secretárias do departamento de Farmacologia, Selma e Julieta, pelo auxílio com os assuntos burocráticos, e pela amizade.

Aos funcionários do laboratório de hipertensão: Manoel, Ritinha, Martinha, Antônio, Sônia Ba, pela atenção e auxílio prestados.

À funcionária e amiga Rosângela, que me acolheu com bastante carinho quando da minha chegada em São Paulo, me fornecendo ajuda sempre que precisei.

À Cidora, pelos momentos descontraídos que compartilhamos durante todo esse período, e pela atenção prestada me ensinando sempre novas técnicas no laboratório.

À Grazi, pelo carinho, amizade e parceria, até mesmo nos momentos difíceis...

Ao Rodrigo, que se revelou ao longo desse tempo grande amigo e companheiro.

À minha grande amiga Simone Sartoretto pela indescritível solidariedade e afeto inestimável, que se traduziram sempre em grandes momentos.

À Eliana, sou imensamente grata pelo incentivo e colaboração que contribuíram para o enriquecimento do meu trabalho. Não apenas valorizo os comentários e observações críticas com relação aos resultados obtidos, mas também pela amizade.

Expresso meus sinceros agradecimentos aos meus amigos, Fernando Carneiro, Fernanda e Zidônia, que contribuíram para que o sonho da pós-graduação se tornasse realidade.

Aos meus também amigos do laboratório: André, Stephen, Luciana, Juliana, Fernanda, Bia, Maduka, Rossana, Tiago e Eveline, cuja amizade foi de grande importância nessa nova caminhada. 
Devo agradecer também aos companheiros do Departamento de Fisiologia: Ana Paula, Anderson, Camila, Gisele, Hlldebrando (Hild) e João Luís (Ceará), pela amizade, festinhas...

À Fundação de Amparo à Pesquisa do Estado de São Paulo (FAPESP), pelo auxílio financeiro.

Há muito mais a quem agradecer... A todos aqueles que, embora não nomeados, me brindaram com seus inestimáveis apoios em distintos momentos e por suas por suas presenças afetivas, o meu reconhecido e carinhoso MUITO OBRIGADA!!! 


\section{RESUMO}

LOBATO, N. S. Efeito do tratamento com metfomina sobre alterações vasculares em modelo de resistência à insulina (obesidade em ratos). 2008. 128 f. Dissertação (Mestrado em Ciências) - Instituto de Ciências Biomédicas, Universidade de São Paulo, São Paulo, 2008.

Neste estudo avaliamos a participação do óxido nítrico (NO), do fator hiperpolarizante derivado do endotélio (EDHF), dos produtos da ciclooxigenase (COX) e das espécies reativas de oxigênio (EROs), bem como o efeito do tratamento com metformina (Met), nas alterações vasculares em ratos com obesidade induzida por glutamato monossódico (MSG). Os ratos MSG utilizados em nosso estudo apresentaram aumento do índice de Lee, acúmulo de gordura visceral, dislipidemia, resistência à insulina, hiperinsulinemia e aumento da secreção de insulina. $O$ tratamento com Met corrigiu estas alterações. A intolerância à glicose, ausente nos ratos MSG com 16 semanas, foi detectada com 18 semanas e não foi corrigida pela Met. Demonstramos também que a resposta vasoconstritora à NA, aumentada nos ratos MSG, não foi alterada pelo L- nitro arginina metil éster (L-NAME), inibidor da síntese de NO e pelo Tetraetilamônio (TEA), que impede a hiperpolarização, sendo corrigida pela Indometacina (Indo), inibidor da COX. Esses dados indicam que produtos da COX participam do aumento da resposta contrátil à NA. O tratamento com Met corrigiu a resposta aumentada à NA. Essa correção foi revertida pelo LNAME e TEA, sendo mantida com Indo, indicando que o NO e a hiperpolarização participam do efeito da Met. A resposta à acetilcolina (Ach), diminuída nos ratos MSG, foi revertida pelo L-NAME e Indo, e reduzida de modo mais pronunciado pelo TEA. Met corrigiu a resposta vasodilatadora à Ach. A correção foi mantida na presença de L-NAME, Indo e TEA, indicando que a correção da resposta à Ach pela Met não depende do NO, da COX e da hiperpolarização. Ratos MSG com 16 semanas apresentaram hiperresponsividade ao nitroprussiato de sódio (NPS), que foi mantida nos ratos tratados com Met. A diminuída produção de $\mathrm{NO}$ e aumentada geração de EROs observada nos ratos MSG pode explicar as alterações vasculares. Met reduziu a geração de EROs sem corrigir a produção diminuída de NO. Nossos dados indicam que o aumento da resposta vasoconstritora e a diminuição da resposta vasodilatadora dependente de endotélio estão relacionados com alterações na via do NO e da COX, associados com aumento na geração de EROs. Em adição, 
há maior participação do EDHF na resposta vasodilatadora e aumento da resposta do músculo liso vascular ao NO, que podem constituir mecanismo compensatório frente à redução da vasodilatação dependente de NO nos ratos MSG. A metformina restaura a aumentada resposta vasoconstritora e a diminuída resposta vasodilatadora dependente de endotélio, atuando sobre o $\mathrm{NO}$ e o EDHF, e reduzindo a geração de EROs, além de interferir com a resposta do músculo liso vascular promovendo aumentada responsividade ao NO.

Palavras - Chave: Obesidade. Reatividade Vascular. Metformina. 


\section{ABSTRACT}

LOBATO, N. S. Effect of metformin treatment upon vascular alterations in insulin resistance model (rat obesity). 2008. $128 \mathrm{f}$. Master thesis (Science) Instituto de Ciências Biomédicas, Universidade de São Paulo, São Paulo, 2008.

In this present study we evaluated the participation of the nitric oxide (NO), the endothelium derived hyperpolarizing factor (EDHF), the ciclooxygenase (COX) products and the reactive oxygen species (ROS), as well as the effect of metformin (Met) treatment on the vascular alterations in rat model of obesity induced by monosodium glutamate (MSG). MSG rats presented higher Lee index, fat accumulation, dyslipidemia, insulin resistance, hyperinsulinemia and enhanced insulin secretion. Met treatment corrected these alterations. Sixteen-week-old MSG did not present glucose intolerance differing from the 18-week-old MSG group, in which it was present. Met treatment was not able to revert this alteration. We have shown that the response to norepinephrine (NE), enhanced in MSG rats, was maintained by L-nitro arginine methyl ester (L-NAME), a NO synthesis inhibitor and tetraethylamonium (TEA), which prevents hyperpolarization, but was corrected by indomethacin (Indo), a COX inhibitor. These data indicate that the COX products participate in the enhanced response to NE. Met treatment corrected the enhanced response to NE. This correction by Met was reverted by L-NAME and TEA, but was not affected by Indo, indicating that the NO and hyperpolarization participate in the Met effect. The response to acetilcholine (Ach), reduced in MSG rats, was corrected by L-NAME and Indo but worsened by TEA. Met treatment corrected the vasodilation response to Ach. The correction of Ach response by Met was maintained by LNAME, Indo and TEA, indicating that the correction by Met does not depend on NO, COX and hyperpolarization. Sixteen-week-old MSG rats presented hyperresponsiveness to sodium nitroprusside (NPS), which was preserved in the Met-treated group. The reduced production of $\mathrm{NO}$ and enhanced generation of ROS in MSG rats could explain the observed vascular alterations. Met restored the enhanced ROS generation, but did not correct the reduced NO production. Our data indicate that the enhanced response to NE and the reduced vasodilation response endothelium-dependent are related to alterations in the $\mathrm{NO}$ and COX pathways, leading to a higher ROS generation. Furthermore, the greater participation of EDHF 
on the vasodilation response and the enhanced response of vascular smooth muscle to NO could be a compensatory mechanism for the vasodilation NO dependent reduction in MSG rats. Met restores the higher vasocontrictor response and the lower endothelium-dependent vasodilation response, acting on the NO and EDHF, and decreasing the ROS generation, besides its effect on the vascular smooth muscle response, preserving the hyperresponsiveness to NO.

Key words: Obesity. Insulin resistance. Vascular Reactivity. Metformin. 


\section{LISTA DE ILUSTRAÇÕES}

Figura 1. Esquema ilustrativo dos mecanismos gerais de relaxamento e contração vascular dependentes do endotélio 30

Figura 2. Esquema do sistema para estudo da reatividade vascular no leito mesentérico isolado

Figura 3. Oxidação da dihidroetidina por diferentes espécies reativas de oxigênio e seus produtos.

Figura 4. Índice de Lee dos diversos grupos experimentais .50

Figura 5. Peso relativo da gordura retroperitonial e periepididimal dos diversos grupos experimentais.

Figura 6. Peso relativo dos músculos sóleo e EDL dos diversos grupos experimentais

Figura 7. Curva de ganho de peso dos diversos grupos experimentais .53

Figura 8. Dosagem de glicose e insulina dos grupos experimentais .56

Figura 9. Índices HOMA-IR e HOMA- $\beta$ obtidos a partir das glicemias e insulinemias em jejum dos grupos experimentais.

Figura 10. Curvas Glicêmicas e área sob a curva do teste de tolerância à glicose intravenoso dos diversos grupos experimentais. 58

Figura 11. Curva concentração-efeito para o cloreto de potássio no leito arteriolar mesentérico dos grupos experimentais com 16 semanas.

Figura 12. Curva concentração-efeito para o cloreto de potássio no leito arteriolar mesentérico dos grupos experimentais com 18 semanas.

Figura 13. Curva concentração-efeito para a noradrenalina no leito arteriolar mesentérico dos grupos experimentais com 16 semanas. 
Figura 14. Curva concentração-efeito para a noradrenalina no leito arteriolar mesentérico dos grupos experimentais com 18 semanas.

Figura 15. Curva concentração-efeito e resposta máxima vasoconstritora para noradrenalina na presença de L-NAME no leito arteriolar mesentérico dos grupos experimentais com 16 semanas.

Figura 16. Curva concentração-efeito e resposta máxima vasoconstritora para noradrenalina na presença de L-NAME no leito arteriolar mesentérico dos grupos experimentais com 18 semanas.

Figura 17. Curva concentração-efeito e resposta máxima para noradrenalina na presença de TEA no leito arteriolar mesentérico dos grupos experimentais com 16 semanas.

Figura 18. Curva concentração-efeito e resposta máxima para noradrenalina na presença de TEA no leito arteriolar mesentérico dos grupos com 18 semanas.

Figura 19. Curva concentração-efeito e resposta máxima para noradrenalina na presença de Indometacina no leito arteriolar mesentérico dos grupos experimentais com 16 semanas. 76

Figura 20. Curva concentração-efeito e resposta máxima para noradrenalina na presença de Indometacina no leito arteriolar mesentérico dos grupos experimentais com 18 semanas.

Figura 21. Curva concentração-efeito para acetilcolina no leito arteriolar mesentérico dos grupos experimentais com 16 semanas.

Figura 22. Curva concentração-efeito para acetilcolina no leito arteriolar mesentérico dos grupos experimentais com 18 semanas

Figura 23. Curva concentração-efeito e resposta máxima para acetilcolina na presença de L-NAME no leito arteriolar mesentérico dos grupos experimentais com 16 semanas. 
Figura 24. Curva concentração-efeito e resposta máxima para acetilcolina na presença de L-NAME no leito arteriolar mesentérico dos grupos experimentais com 16 semanas.

Figura 25. Curva concentração-efeito e resposta máxima para acetilcolina na presença de TEA no leito arteriolar mesentérico dos grupos experimentais com 16 semanas.

Figura 26. Curva concentração-efeito e resposta máxima para acetilcolina na presença de TEA no leito arteriolar mesentérico dos grupos experimentais com 18 semanas

Figura 27. Curva concentração-efeito e resposta máxima para acetilcolina na presença de Indometacina no leito arteriolar mesentérico dos grupos experimentais com 16 semanas.

Figura 28. Curva concentração-efeito e resposta máxima para acetilcolina na presença de Indometacina no leito arteriolar mesentérico dos grupos experimentais com 18 semanas.

Figura 29. Curva concentração-efeito e resposta máxima para nitroprussiato de sódio no leito arteriolar mesentérico dos grupos experimentais com 16 semanas. 96

Figura 30. Curva concentração-efeito e resposta máxima para o nitroprussiato de sódio no leito arteriolar mesentérico dos grupos experimentais com 18 semanas. 98

Figura 31. Quantificação da produção de NO em artérias mesentéricas dos grupos experimentais com 16 e 18 semanas 100

Figura 32. Quantificação da geração espécies reativas de oxigênio em artérias mesentéricas dos grupos experimentais com 16 e 18 semanas. 101 


\section{LISTA DE TABELAS}

Tabela 1. Perfil lipídico dos grupos experimentais com 16 semanas. .54

Tabela 2. Perfil lipídico dos grupos experimentais com 18 semanas. .55

Tabela 3. Medida da pressão arterial e freqüência cardíaca dos grupos experimentais com 16 e 18 semanas.

Tabela 4. Valores de resposta máxima e sensibilidade ao cloreto de potássio no leito arteriolar mesentérico dos grupos com 16 semanas.

Tabela 5. Valores de resposta máxima e sensibilidade ao cloreto de potássio no leito arteriolar mesentérico dos grupos com 18 semanas.

Tabela 6. Valores de resposta máxima à noradrenalina no leito arteriolar mesentérico dos grupos experimentais com 16 semanas.

Tabela 7. Valores de resposta máxima à noradrenalina no leito arteriolar mesentérico dos grupos com 18 semanas

Tabela 8. Efeito do bloqueio da enzima óxido nítrico sintase sobre a resposta à noradrenalina no leito arteriolar mesentérico dos grupos com 16 semanas.

Tabela 9. Efeito do bloqueio da enzima óxido nítrico sintase sobre a resposta à noradrenalina no leito arteriolar mesentérico dos grupos com 18 semanas.

Tabela 10. Efeito do bloqueio dos canais de potássio sobre a resposta à noradrenalina no leito arteriolar mesentérico dos grupos com 16 semanas. .73

Tabela 11. Efeito do bloqueio inespecífico dos canais de potássio sobre a resposta à noradrenalina no leito arteriolar mesentérico dos grupos com 18 semanas .75

Tabela 12. Efeito do bloqueio da enzima ciclooxigenase com Indometacina sobre a resposta máxima à noradrenalina no leito arteriolar mesentérico dos grupos com 16 semanas. 
Tabela 13. Efeito do bloqueio da enzima ciclooxigenase com Indometacina sobre a resposta máxima à noradrenalina no leito arteriolar mesentérico dos grupos com 18 semanas.

Tabela 14. Resposta Máxima e sensibilidade à acetilcolina no leito arteriolar mesentérico dos grupos com 16 semanas.

Tabela 15. Resposta Máxima e sensibilidade à acetilcolina no leito arteriolar mesentérico dos grupos com 18 semanas.

Tabela 16. Efeito do bloqueio da enzima óxido nítrico sintase com L- NAME sobre a sensibilidade e a resposta máxima à acetilcolina no leito arteriolar mesentérico dos grupos com 16 semanas.

Tabela 17. Efeito do bloqueio da enzima óxido nítrico sintase com L- NAME sobre a sensibilidade e a resposta máxima à acetilcolina no leito arteriolar mesentérico dos grupos com 18 semanas.

Tabela 18. Efeito do bloqueio inespecífico dos canais de potássio ativados por cálcio com TEA sobre a sensibilidade e a resposta máxima à acetilcolina no leito arteriolar mesentérico dos grupos com 16 semanas.

Tabela 19. Efeito do bloqueio inespecífico dos canais de potássio ativados por cálcio com TEA sobre a sensibilidade e a resposta máxima à acetilcolina no leito arteriolar mesentérico dos grupos com 18 semanas.

Tabela 20. Efeito do bloqueio da enzima ciclooxigenase com Indometacina sobre a sensibilidade e a resposta máxima à acetilcolina no leito arteriolar mesentérico dos grupos com 16 semanas.

Tabela 21. Efeito do bloqueio da ciclooxigenase com Indometacina sobre a sensibilidade e a resposta máxima à acetilcolina no leito arteriolar mesentérico dos grupos com 18 semanas.

Tabela 22. Valores de resposta máxima ao nitroprussiato de sódio no leito arteriolar mesentérico dos grupos com 16 semanas.

Tabela 23. Valores de resposta máxima ao nitroprussiato de sódio no leito arteriolar mesentérico dos grupos experimentais com 18 semanas de idade. 


\section{LISTA DE ABREVIATURAS E SIGLAS}

\begin{tabular}{|c|c|}
\hline AA & Ácido araquidônico \\
\hline Ach & Acetilcolina \\
\hline Akt & Proteína quinase $B$ \\
\hline AMPc & Monofosfato de adenosina cíclico \\
\hline AMPK & Proteína quinase ativada pelo monofosfato de adenosina \\
\hline Ang II & Angiotensina II \\
\hline ANOVA & Análise de variância \\
\hline ATP & Trifosfato de adenosina \\
\hline AUC & Área sob a curva \\
\hline $\mathrm{BH}_{4}$ & Tetrahidrobiopterina \\
\hline $\mathrm{Ca}^{2+}$ & Cálcio \\
\hline $\mathrm{CaCl}_{2}$ & Cloreto de Cálcio \\
\hline CCE & Curva concentração-efeito \\
\hline $\mathrm{CO}_{2}$ & Dióxido de carbono \\
\hline $\operatorname{cox}$ & Ciclooxigenase \\
\hline DAF & Diaminofluoresceína \\
\hline DHE & Diidroetidina \\
\hline $\mathrm{dL}$ & Decilítro \\
\hline$E$ & Etídeo \\
\hline $\mathrm{EC}_{50}$ & Concentração que promove $50 \%$ da resposta máxima \\
\hline EDCF & Fatores contráteis derivados do endotélio \\
\hline EDHF & Fator hiperpolarizante derivado do endotélio \\
\hline EDL & Extensor digital longo \\
\hline EDRF & Fatores relaxantes derivados do endotélio \\
\hline EDTA & Ácido etilenodiaminotetracético \\
\hline $\mathrm{EHO}$ & 2-hidróxi-etídeo \\
\hline eNOS & Óxido nítrico sintase endotelial \\
\hline Epm & Erro padrão da média \\
\hline EROs & Espécies reativas de oxigênio \\
\hline ET-1 & Endotelina - 1 \\
\hline FC & Frequência Cardíaca \\
\hline GMPc & Monofosfato cíclico de guanosina \\
\hline
\end{tabular}


Grb2 Proteína ligante do receptor do fator de crescimento 2

HDL Lipoproteína de alta densidade

HOMA Homeostasis Model of Assessment

$\mathrm{H}_{2} \mathrm{O}_{2} \quad$ Peróxido de hidrogênio

Iк $\beta \quad$ Inibidor Kappa $\beta$

IL-6 Interleucina - 6

IVGTT Teste de tolerância

Indo Indometacina

iNOS Óxido nítrico sintase induzível

IRS Substrato do receptor de insulina

$\mathrm{KCL} \quad$ Cloreto de potássio

$\mathrm{KH}_{2} \mathrm{PO}_{4} \quad$ Dihidrogenofosfato de potássio

LDL Lipoproteína de baixa densidade

L-NAME Éster de N-metil-L-arginina

MAPK Proteína quinase ativada por mitógeno

MCP-1 Proteína quimiotáxica para monócitos

Met Metformina

mg Miligrama

$\mathrm{MgSO}_{4} \quad$ Sulfato de magnésio

MSG Glutamato monossódico

$\mathrm{mmHg} \quad$ Milímetro de mercúrio

NA Noradrenalina

$\mathrm{NaCl} \quad$ Cloreto de sódio

NADPH Nicotinamida adenina dinucleotídeo fosfato

$\mathrm{NaHCO}_{3} \quad$ Bicarbonato de sódio

NFк $\beta \quad$ Fator nuclear kappa $\beta$

nNOS Óxido nítrico sintase neuronal

NO Óxido nítrico

NOS Óxido nítrico sintase

NPS Nitroprussiato de sódio

$\mathrm{O}_{2} \quad$ Oxigênio

$\mathrm{O}^{2-} \quad$ Ânion superóxido

$\mathrm{ONOO}^{-} \quad$ Ânion peroxinitrito

PA Pressão arterial 
PAI-1 Inibidor do ativador de plasminogênio

PDK-1 Proteína quinase dependente de fosfoinositídeo-1

$\mathrm{pD}_{2} \quad$ Logaritmo negativo da $\mathrm{EC}_{50}$

$\mathrm{PGF}_{2 \alpha} \quad$ prostaglandina $\mathrm{F}_{2 \alpha}$

$\mathrm{PGI}_{2} \quad$ Prostaciclina

PKB Proteína quinase $B$

PKC Proteina quinase $\mathrm{C}$

PI3-K Fosfatidil inositol -3 quinase

$\mathrm{PLA}_{2} \quad$ Fosfolipase $\mathrm{A}_{2}$

$\mathrm{R}_{\mathrm{MAX}} \quad$ Resposta máxima

Ser Serina

SNC Sistema Nervoso Central

TEA Tetraetilamônio

$\mathrm{TXA}_{2} \quad$ Tromboxano $\mathrm{A}_{2}$

VCAM-1 Molécula de aderência vascular - 1

VLDL Lipoproteína de muito baixa densidade 


\section{SUMÁRIO}

1 INTRODUÇÃO

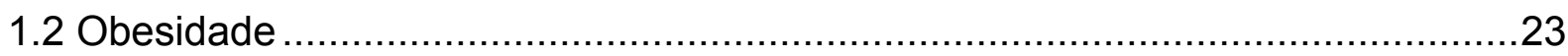

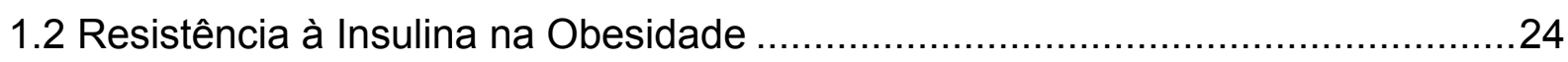

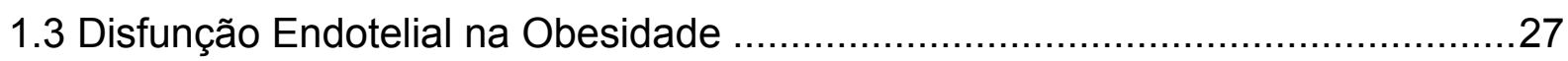

1.4 Obesidade Induzida pelo Glutamato Monossódico …........................................32

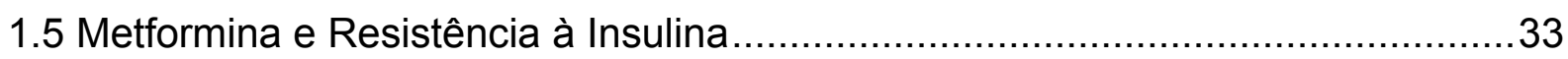

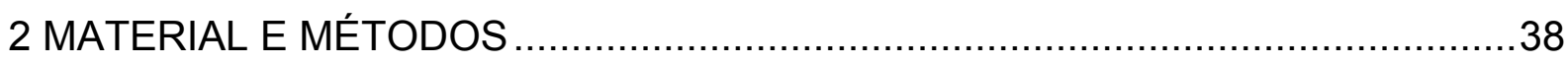

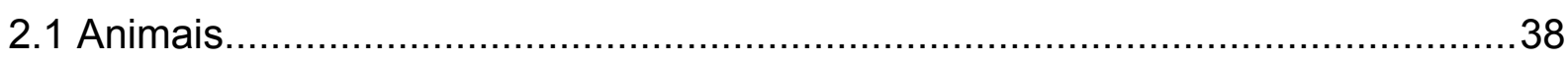

2.2 Indução da Obesidade e Tratamento com Metformina ........................................38

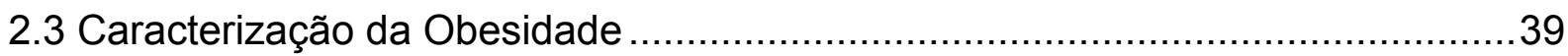

2.4 Determinação dos Parâmetros Biológicos.......................................................39

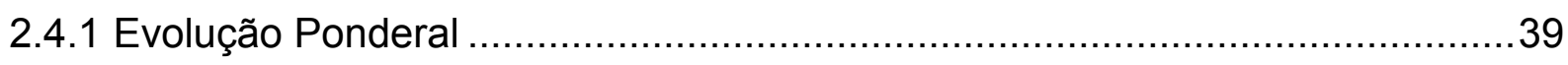

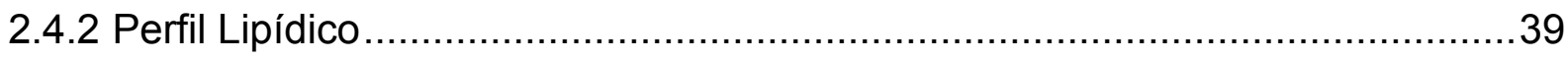

2.4.3 Determinação das Concentrações Séricas de Glicose e Insulina .....................41

2.4.4 Sensibilidade à Insulina e Capacidade Secretória Pancreática .......................41

2.4.5 Teste de Tolerância à Glicose Intravenoso ...............................................42

2.5 Pressão Arterial Caudal e Freqüência Cardíaca ...........................................42

2.6 Reatividade Vascular do Leito Arteriolar Mesentérico Isolado ...........................42

2.6.1 Avaliação da Resposta Vasoconstritora ao Cloreto de Potássio .......................44

2.6.2 Avaliação da Resposta Vasoconstritora à Noradrenalina ..............................44

2.6.3 Avaliação da Resposta Vasodilatadora à Acetilcolina e ao Nitroprussiato de

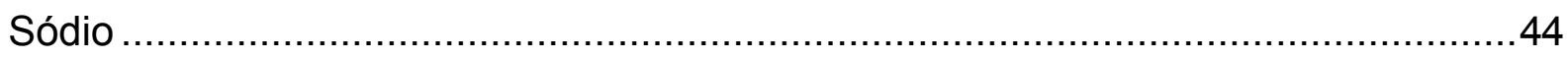

2.6.4 Efeito do Bloqueio da Síntese de NO Sobre a Resposta Contrátil à

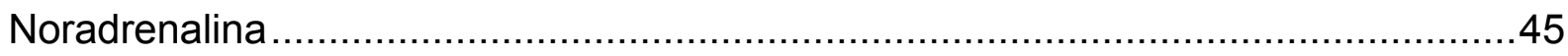

2.6.5 Efeito do bloqueio de Canais de Potássio Sobre a Resposta Contrátil à

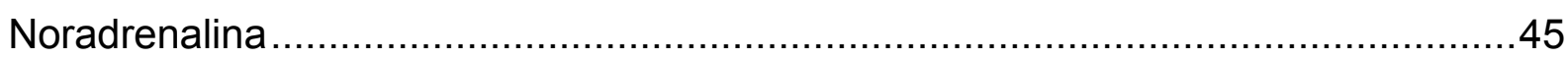

2.6.6 Efeito do bloqueio da COX Sobre a Resposta Contrátil à Noradrenalina.........45

2.6.7 Efeito do Bloqueio da Síntese de NO Sobre a Resposta Vasodilatadora à

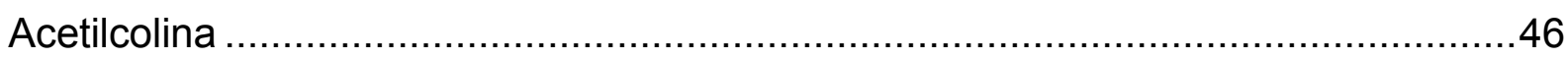

2.6.8 Efeito do Bloqueio de Canais de Potássio Sobre a Resposta à Acetilcolina ....46

2.6.9 Efeito do Bloqueio da COX Sobre a Resposta Vasodilatadora à Acetilcolina ...47

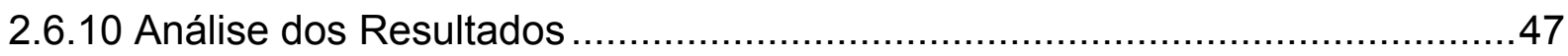

2.7 Medida da Produção de NO em Artérias Mesentéricas ...................................48

2.8 Estudo da Geração de EROs em Artérias Mesentéricas ....................................48

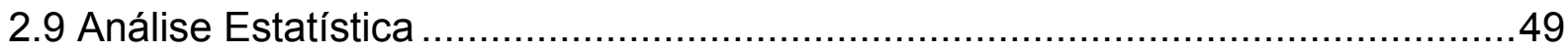

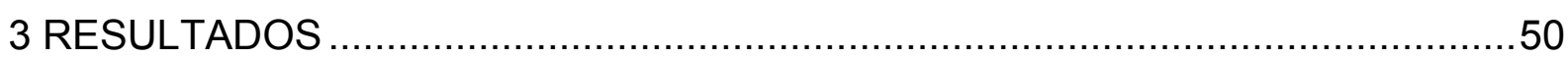


3.1 Caracterização da Obesidade .50

3.1.1 Determinação do Índice de Lee, Peso Relativo das Gorduras Periepididimal e



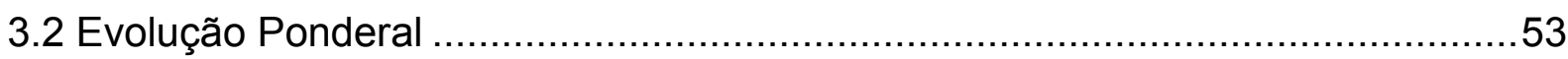

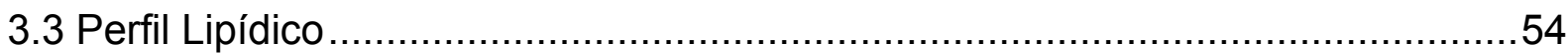

3.4 Determinação das Concentrações de Glicose e Insulina ....................................56

3.5 Sensibilidade à Insulina e Capacidade Secretória Pancreática...........................57

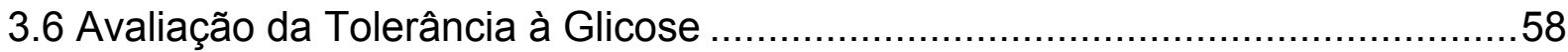

3.7 Pressão Arterial Caudal e Freqüência Cardíaca .............................................59

3.8 Reatividade do Leito Arteriolar Mesentérico Isolado e Perfundido ......................60

3.8.1 Avaliação da Resposta Vasoconstritora ao Cloreto de Potássio ......................60

3.8.2 Avaliação da Resposta Vasoconstritora à Noradrenalina ..............................64

3.8.3 Papel do NO na Modulação da Resposta Vasoconstritora à Noradrenalina ....68

3.8.4 Papel dos Canais de Potássio na Modulação da Resposta Vasoconstritora à

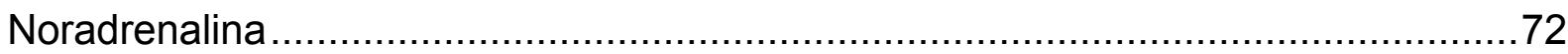

3.8.5 Participação dos Produtos da COX na Modulação da Resposta Vasoconstritora

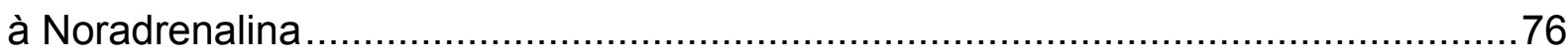

3.8.6 Avaliação da Resposta Relaxante Dependente do Endotélio .........................80

3.8.7 Participação do NO na Resposta Vasodilatadora Dependente do Endotélio ..84

3.8.8 Participação dos Canais de Potássio na Resposta Vasodilatadora Dependente

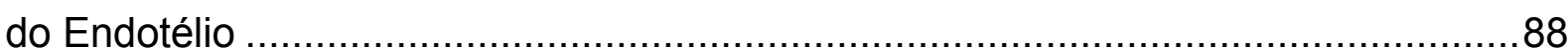

3.8.9 Participação dos Produtos da COX na Resposta Vasodilatadora Dependente

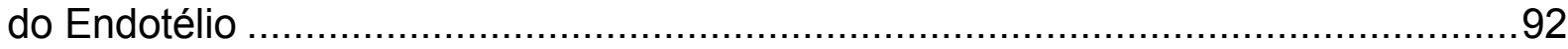

3.8.10 Avaliação da Resposta Relaxante Independente do Endotélio ......................96

3.9 Produção de NO em Artérias Mesentéricas .....................................................100

3.10 Geração de EROs Oxigênio em Artérias Mesentéricas....................................101



4.1 Metformina e os Distúrbios Metabólicos na Obesidade Induzida por MSG.......102

4.2 Efeito da Obesidade e do Tratamento com Metformina Sobre a Reatividade

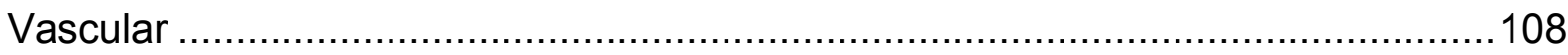

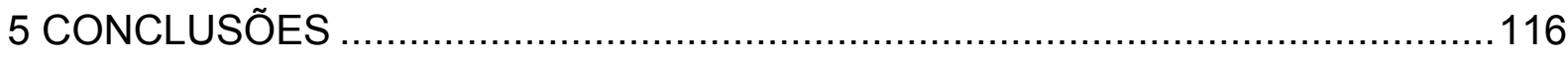

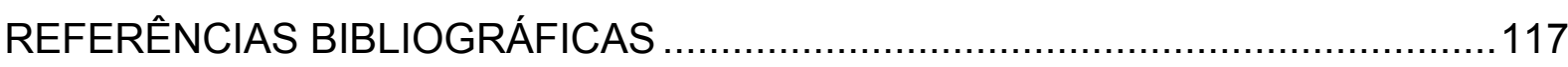




\section{INTRODUÇÃO}

\subsection{Obesidade}

A obesidade e as doenças que surgem como conseqüência desta condição, tais como diabetes tipo 2, hipertensão e doenças cardiovasculares, estão aumentando de modo significativo a morbidade e mortalidade em todo o mundo (WILD et al., 2004).

O número de indivíduos obesos já atingiu cerca de 2,1 bilhões, o que contribuiu para o aumento nos problemas de saúde associados com morbidade e mortalidade, em virtude da predisponência à hipertensão arterial, à dislipidemia, à doença cardiovascular aterosclerótica e ao diabetes mellitus (LI et al., 2005). A associação da obesidade com estas condições patológicas foi designada por Reaven (1988) como "Síndrome X", e como característica comum a estas alterações foi detectada a presença de resistência à insulina. A "Síndrome X", conhecida atualmente como "Síndrome metabólica" ou "Síndrome da Resistência à Insulina", afeta um em cada quatro adultos acima de 40 anos (KELISHADI, 2007).

O aumento marcante na prevalência de obesidade tornou esta condição reconhecida como um dos mais sérios problemas de saúde pública (ZIMMET et al., 2001), com conseqüências econômicas e sociais que afetam a população mundialmente (POWERS et al., 2007).

Estudos epidemiológicos demonstram que a prevalência de obesidade, principalmente entre indivíduos jovens, em países em desenvolvimento, como é o caso do Brasil, tem aumentado significantemente em relação a países industrializados. Dados da Sociedade Brasileira de Endocrinologia e Metabolismo mostram que 18 milhões de brasileiros são obesos e cerca de 70 milhões apresentam sobrepeso. Aliado a isto, estimativas indicam que em 2030, cerca de 366 milhões de pessoas terão diabetes, o que corresponde a mais do que o dobro de indivíduos estimados terem diabetes no ano de 2000 (170 milhões) (WILD et al., 2004). Tendo-se em vista o aumento observado na prevalência de obesidade em praticamente todos os países tanto industrializados quanto em desenvolvimento, e a importância da obesidade como um fator de risco para o diabetes, o número de casos de diabetes em 2030 pode ser consideravelmente maior. 
A obesidade é uma condição fisiopatológica crônica de origem multifatorial, sendo definida como excesso da massa de tecido adiposo em relação à massa magra, que pode ocorrer de modo regional ou generalizado (VEJA, 2002). Esta condição coincide com aumento de peso, embora possa ocorrer aumento da quantidade e porcentagem de gordura em indivíduos de peso normal (MONTEIRO, 1998). Os mecanismos fisiopatológicos que levam ao sobrepeso e ao acúmulo excessivo de tecido adiposo estão apenas parcialmente elucidados. Sabe-se que ela surge como conseqüência do modo através do qual o corpo regula a ingestão, 0 gasto e o estoque energético. Além disso, fatores biológicos, comportamentais e ambientais podem interagir e afetar o balanço energético, contribuindo para o desenvolvimento da obesidade (HILL, 2006).

\subsection{Resistência à Insulina na Obesidade}

O papel chave da resistência à insulina na fisiopatologia da "Síndrome X" foi confirmado através de estudos demonstrando que indivíduos que apresentam resistência à insulina, e que não são obesos, apresentam a mesma prevalência de patologias associadas à obesidade quando comparados a indivíduos obesos (MYKKANEN et al., 1997). Conseqüentemente, o papel da resistência à insulina e das alterações fisiopatológicas associadas a esta condição ganhou considerável importância.

A insulina é considerada o hormônio anabólico mais potente e é essencial para o desenvolvimento apropriado dos tecidos, o crescimento e a manutenção dos níveis normais de glicose corporal. Ela é secretada pelas células $\beta$ das ilhotas de Langerhans pancreáticas em resposta ao aumento nos níveis circulantes de glicose e aminoácidos que ocorre após uma refeição. A insulina regula a homeostase glicêmica, reduzindo a produção de glicose hepática (via diminuição na gliconeogênese e glicogenólise) e aumentando a captação de glicose, inicialmente no músculo esquelético e tecido adiposo. Nestes locais a captação de glicose depende da translocação do transportador de glicose GLUT4 para a superfície celular, estimulada pela insulina. A insulina atua também sobre o metabolismo lipídico, aumentando a síntese de lipídios no fígado e tecido adiposo e diminuindo a liberação de ácidos graxos e triglicerídeos por estes tecidos (WILCOX, 2005). 
A sinalização intracelular da insulina inicia-se com a sua ligação à subunidade $\alpha$ do receptor de insulina, estimulando a autofosforilação da região intracelular da subunidade $\beta$. Uma vez ativado, o receptor de insulina fosforila em tirosina membros da família dos substratos dos receptores de insulina (IRS-1/2/3/4), levando à ativação de complexas vias de sinalização, que por sua vez regulam diversas funções celulares. A fosforilação de IRS cria sítios de reconhecimento para moléculas contendo domínios com homologia a Shc (proteínas que possuem homologia com a Src), tais como a subunidade regulatória p85 da fosfatidilinositol 3quinase (PI3-K) e fosfatase fosfotirosina (SHP2) (WHITE, 1998; PESSIN e SALTIEL, 2000). As proteínas ajusantes conhecidas da PI3-K são a proteína quinase $B(P K B)$ ou AKt, que é ativada por fosforilação em serina e treonina, e as isoformas atípicas da PKC ( $\zeta$ e $\lambda)$ (KOHN et al., 1996; BANDYOPADHYAY et al., 1997).

Além da ativação da PI3-K, que culmina em muitas de suas ações metabólicas, a insulina estimula a mitogen-activated protein quinase (MAPK). Essa via inicia-se com a fosforilação das proteínas IRS e/ou Shc, que interagem com a proteína ligante do receptor do fator de crescimento 2 (Grb2), molécula que também apresenta domínios com homologia a Src 2 (SH2). Esta via de sinalização da insulina geralmente regula ações biológicas relacionadas ao crescimento, mitogênese e diferenciação celular (SALTIEL e KAHN, 2001).

A insulina também apresenta importantes ações vasculares, dentre as quais a mais importante é a estimulação da produção de NO pelo endotélio, através de uma via dependente de fosforilação, que é distinta dos mecanismos dependentes de cálcio utilizados pelos receptores acoplados à proteína G, como exemplo a Ach. Estas ações no endotélio levam à vasodilatação e aumento do fluxo sanguíneo, favorecendo a captação de glicose pelo músculo esquelético. As ações da insulina, deste modo, representam um papel central no acoplamento da homeostase metabólica à homeostase hemodinâmica. A via de sinalização da insulina no endotélio estimulando a produção de NO envolve a ativação da PI3-K com fosforilação e ativação da proteína quinase dependente de fosfoinositídeo-1 (PDK1), que fosforila e ativa a Akt, ativando diretamente a enzima óxido nítrico sintase endotelial (eNOS) em Ser1177, o que resulta em aumento da sua atividade e subseqüente produção de NO. Além da via de sinalização dependente de PI3-K que regula as ações vasodilatadoras, a insulina ativa a via de sinalização dependente de MAPK estimulando a secreção de endotelina-1 (ET-1) e a expressão de PAI-1, 
VCAM-1 e E-selectina. Em condições fisiológicas a atividade da via PI3K/Akt/NO é maior do que a MAPK/ET-1, com o desequilíbrio entre estas duas vias podendo levar a alterações nas ações vasculares e também metabólicas da insulina (MUNIYAPPA et al., 2007).

A resistência à insulina é definida como efeito diminuído da insulina sobre a captação, metabolismo e armazenamento de glicose, em virtude da diminuição da sensibilidade de tecidos periféricos à ação metabólica deste hormônio (AVOGARO et al., 2005). Nesta condição, a captação de glicose estimulada pela insulina encontra-se diminuída no músculo esquelético e no tecido adiposo, além de haver prejuízo na supressão da produção de glicose hepática (FORMIGUEIRA et al., 2004; GREENFIELD e CAMPBELL, 2004). A hiperinsulinemia compensatória é um sinal evidente de perda da homeostase glicêmica nesta condição.

Embora esteja bem estabelecido que a obesidade está associada com resistência às ações celulares da insulina (SALTIEL e KAHN, 2001), assim como no diabetes tipo 2, a resistência à insulina na obesidade é uma desordem complexa. Múltiplas vias endócrinas, inflamatórias e neurais são simultaneamente prejudicadas e podem modular vias de sinalização intrínsecas à célula e também funcionais em tecidos como o fígado, tecido adiposo e músculo, além do sistema imune e sistema nervoso, levando à resistência à insulina (QATANANI e LAZAR, 2007).

No músculo e no tecido adiposo de humanos e roedores obesos, já foi demonstrada expressão e/ ou atividade aumentada de diversas proteínas tirosina fosfatases, responsáveis por finalizar a sinalização propagada através da fosforilação da tirosina quinase, iniciada pela insulina. Esta alteração contribui para a redução da expressão de diversas moléculas envolvidas na sinalização da ação insulínica nestes locais (FORMIGUEIRA et al., 2004), podendo desta forma ter participação na gênese da resistência à insulina.

Estudos clínicos e experimentais sugerem a existência de uma relação causaefeito entre obesidade e resistência à insulina, tendo-se em vista que ganho/perda de peso está intimamente correlacionado com diminuição/aumento da sensibilidade à insulina, respectivamente (FREIDENBERG et al., 1988). De fato, o tecido adiposo pode contribuir para a resistência à insulina na obesidade, visto que não atua apenas como um órgão de armazenagem de energia, mas também como órgão endócrino que participa ativamente da homeostase corporal através da liberação de ácidos graxos livres não esterificados e glicerol, hormônios e uma variedade de 
proteínas ativas biologicamente chamadas adipocinas (FORMIGUEIRA et al., 2004; SCHERER, 2006).

$\mathrm{Na}$ obesidade ocorre disfunção do tecido adiposo branco, com aumento da liberação de adipocinas pró-inflamatórias, e redução das adipocinas antiinflamatórias, alterando a homeostase energética e a função vascular, aumentando assim, o risco para doenças cardiovasculares e diabetes tipo 2 (MATSUZAWA, 2006). Produtos como a interleucina-6 (IL-6), proteína quimiotáxica para monócitos (MCP)-1 e produtos de macrófagos e outras células que estão presentes no tecido adiposo, têm sua liberação aumentada nesta condição e podem contribuir para a gênese da resistência à insulina.

Estudos também demonstraram que os ácidos graxos livres não esterificados podem ter papel importante na modulação da sensibilidade à insulina, sendo considerados como importante elo entre obesidade, resistência à insulina e diabetes tipo 2 (BODEN, 1997). Na maioria dos pacientes obesos as concentrações plasmáticas de ácidos graxos livres estão elevadas, inicialmente devido ao aumento na lipólise promovida pela expansão da massa de tecido adiposo associada à perda do balanço energético, produzindo resistência à insulina hepática e periférica (DELARUE e MAGNAN, 2007).

\subsection{Disfunção Endotelial na Obesidade}

O endotélio vascular, principal responsável pela manutenção da homeostase hemodinâmica, também sofre alterações decorrentes da resistência à insulina e obesidade. A disfunção endotelial, caracterizada pela alteração na atividade vascular dependente de NO é uma característica bem estabelecida em estados de resistência à insulina como obesidade, diabetes mellitus e síndrome metabólica (KIM et al., 2006), e está relacionada à maior risco de desenvolvimento de aterosclerose, doença coronariana e hipertensão arterial.

Estudos clínicos realizados visando examinar o efeito da resistência à insulina sobre a reatividade vascular em humanos obesos com e sem diabetes mellitus, demonstraram redução de 40 a $50 \%$ da vasodilatação dependente de endotélio quando comparados ao grupo controle. Além disso, a capacidade da insulina aumentar a vasodilatação dependente de endotélio por modulação da produção ou 
liberação de NO encontrava-se notadamente prejudicada nestes indivíduos. Estas observações levaram os autores a concluir que a obesidade e a resistência à insulina, independentemente de outros fatores de risco, estão associadas com alterações da função endotelial (STEINBERG et al., 1996). As alterações metabólicas como a glicotoxicidade, a lipotoxicidade e também a produção descontrolada de citocinas pró-inflamatórias, independentemente, têm sido associados à gênese da disfunção endotelial associada à obesidade e resistência à insulina (KIM et al., 2006). Entretanto, os mecanismos envolvidos nestas alterações vasculares presentes na obesidade ainda não foram completamente elucidados.

As células endoteliais vasculares representam importante papel na manutenção da homeostase cardiovascular. Além de proporcionar uma barreira física entre o lúmen e a parede do vaso, o endotélio regula ativamente o tônus vascular basal e a reatividade vascular em condições fisiológicas, respondendo a forças mecânicas e a mediadores neurohumorais, além de liberar uma variedade de fatores contráteis e relaxantes (FURCHGOTT e VANHOUTTE, 1989). Frente a estímulos específicos as células endoteliais podem liberar fatores relaxantes derivados do endotélio (EDRFs) (MONCADA et al., 1988), como também fatores contráteis derivados do endotélio (EDCFs) (FURCHGOTT e VANHOUTTE, 1989). Os EDRFs incluem o NO, a prostaciclina $\left(\mathrm{PGI}_{2}\right)$ e o fator hiperpolarizante derivado do endotélio (EDHF). Os EDCFs compreendem a angiotensina II (Ang II), a ET-1, espécies reativas de oxigênio (EROs) e prostanóides vasoconstritores (Figura 1) (FÉLETOU e VANHOUTTE, 1999; DE VRIESE et al., 2000). Em condições fisiológicas, o tônus vascular é garantido pelo equilíbrio exercido por estes fatores, especialmente os produtos da COX, em conjunto com o $\mathrm{NO}$ e o EDHF. O desequilíbrio na produção e/ou liberação dos fatores envolvidos no relaxamento e na contração vasculares, com aumento de EDCFs e/ou diminuição dos EDRFs, caracteriza a disfunção endotelial (MATHER et al., 2002).

A prostaciclina foi o primeiro EDRF descrito. Ela é formada a partir do ácido araquidônico ( $A A)$, considerado a principal fonte de eicosanóides, que incluem as prostaglandinas, tromboxano e leucotrienos. O AA é encontrado esterificado principalemente nos fosfolipídeos das membranas celulares e é liberado por estímulos químicos ou mecânicos (MONCADA et al., 1976). Quando livre, é metabolizado por diversas vias, dentre elas a via das ciclooxigenases de ácidos graxos (COX). Existem duas isoformas de COX: a COX1, uma enzima constitucional 
e a COX2, enzima induzida principalmente em células inflamatórias. No endotélio vascular, a $\mathrm{PGI}_{2}$, formada pela ação da prostaciclina-sintase, é um dos principais metabólicos gerados pela liberação de $A A$ e ativação da $\operatorname{COX}$. $A P_{2}$ é rapidamente liberada pelo endotélio após estímulos, como Ach, bradicinina, hipóxia tecidual e estresse hemodinâmico. Estes estímulos promovem aumento do $\mathrm{Ca}^{2+}$ intracelular nas células endoteliais, resultando na ativação da enzima fosfolipase $A_{2}$ $\left(\mathrm{PLA}_{2}\right)$, que gera $\mathrm{AA}$ a partir de fosfolipídeos de membrana plasmática. O AA é então metabolizado pela via das ciclooxigenases, dando origem à $\mathrm{PGI}_{2}(\mathrm{Mc} \mathrm{GIFF}, 1991)$.

Os efeitos promovidos pela $\mathrm{PGI}_{2}$ no músculo liso vascular envolvem ativação da adenilato ciclase e aumento na geração de monofosfato cíclico de adenosina $(A M P c)$ intracelular. Esse mecanismo de transução de sinais promove o relaxamento das células do músculo liso vascular (HECKER, 2000).

Entre os EDRFs, o NO tem papel crucial na regulação do tônus vascular. O NO é formado a partir do metabolismo do aminoácido L-arginina através da enzima NOS. Foram descritas três isoformas da NOS: NOS neuronal (nNOS), enzima constitutiva existente em células neuronais; NOS induzíveil (iNOS), enzima expressa em resposta a estímulos patológicos, em macrófagos, neutrófilos, células de músculo liso vascular e células endoteliais; e NOS endotelial (eNOS), também cosiderada uma enzima constitutiva, encontrada em plaquetas, osteoblastos, osteoclastos e células endoteliais. Esta isoforma da NOS produz NO constantemente para manter o tônus vascular e também pode ser estimulada por alguns agonistas. A eNOS, em presença de NADPH (nicotinamida adenina dinucleotídeo fosfato), complexo $\mathrm{Ca}^{2+} /$ calmodulina e tetrahidrobiopterina, oxida a Larginina, transformando-a em L-citrulina e NO (MONCADA e HIGGINS, 2006).

Uma vez produzido, o NO é liberado pelo endotélio e difunde-se para as células do músculo liso vascular, ativando a guanilato ciclase solúvel ao combinar-se com o grupo heme dessa enzima. Ocorre, então, uma elevação nos níveis intracelulares de monofosfato cíclico de guanosina (GMPc) (VANHOUTTE et al., 1989), que age sobre proteínas-quinases e fosfodiesterases dependentes de GMPc, resultando em redução da concentração de cálcio intracelular e consequente vasodilatação (HECKER, 2000).

A síntese de NO endotelial em condições fisiológicas é controlada por estímulos mecânicos, sendo importantes o fluxo e a tensão de cisalhamento (shear stress). Além disso, esse controle pode ocorrer através da ativação de receptores 
para agentes vasodilatadores, como a Ach, e a bradicinina, cuja ocupação também aumenta o $\mathrm{Ca}^{2+}$ intracelular, estimulando a síntese de NO pelo endotélio.

Outra substância liberada pelo endotélio, que contribui para o relaxamento dependente de endotélio, tanto em artérias de condutância quanto na microcirculação, é o EDHF (COHEN et al., 1995). Embora não tenha ainda sido identificado, sabe-se que após sua formação nas células endoteliais e difusão para as células do músculo liso vascular, o EDHF promove hiperpolarização e consequente relaxamento. Esse mecanismo parece acontecer principalmente através da ativação de canais de $\mathrm{K}^{+}$e inibição de canais de $\mathrm{Ca}^{2+}$ dependentes de voltagem (HECKER, 2000).

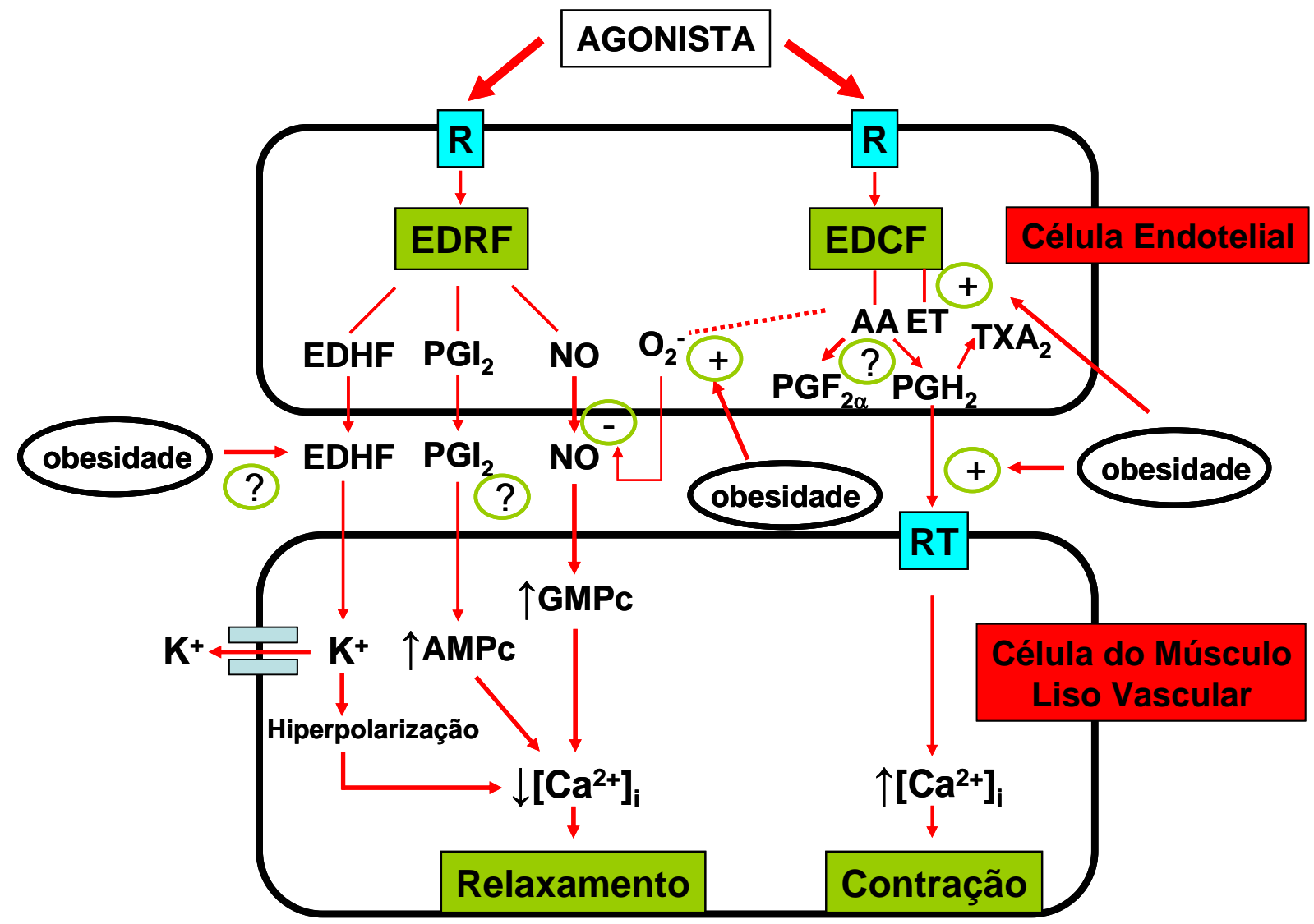

Figura 1 - Esquema ilustrativo dos mecanismos gerais de relaxamento e contração vascular dependentes do endotélio. Adaptado de De Vriese et al., (2000).

$\mathrm{R}$, receptor; EDRF, fator relaxante derivado do endotélio; EDHF, fator hiperpolarizante derivado do endotélio; $\mathrm{PGI}_{2}$, prostaciclina; $\mathrm{NO}$, óxido nítrico; EDCF, fator contrátil derivado do endotélio; $A A$, ácido araquidônico; $\mathrm{PGH}_{2}$, prostaglandina $\mathrm{H}_{2} ; \mathrm{TXA}_{2}$, tromboxano $\mathrm{A}_{2} ; \mathrm{PGF}_{2 \alpha}$, prostaglandina $\mathrm{F}_{2 \alpha} ; \mathrm{O}_{2}{ }^{-}$, ânion superóxido; RT, receptor de tromboxano. 
Embora diversos estudos tenham demonstrado a contribuição do EDHF na disfunção endotelial em condições como o diabetes tipo 2 (De VRIESE et al., 2000), pouco se sabe sobre seu papel nas alterações presentes na obesidade.

Alguns mecanismos têm sido propostos para explicar a disfunção endotelial presente na obesidade. A perda da função modulatória do endotélio parece ter participação crítica no desenvolvimento destas alterações vasculares em indivíduos obesos. A disfunção endotelial presente na obesidade, tem sido atribuída a alterações na geração e/ou liberação dos mediadores envolvidos no relaxamento (STEINBERG et al.,1996), especialmente o NO, e na contração vascular em reposta a estímulo por agentes vasoconstritores como os produtos do AA (MATHER et al., 2002). Entretanto, pouco se sabe sobre a participação dos outros fatores liberados pelo endotélio e que apresentam importante papel na modulação do tônus vascular, sobre as alterações presentes nesta condição.

Estudos demonstram também o importante papel do estresse oxidativo no desenvolvimento da disfunção endotelial na obesidade, sendo este considerado como o principal mecanismo através do qual a resistência à insulina causa disfunção endotelial. A diminuição da vasodilatação dependente de endotélio na obesidade é acompanhada de redução da biodisponibilidade do NO, que pode estar associada à maior produção de espécies reativas de oxigênio (ROS), tais como os ânions superóxido $\left(\mathrm{O}^{2-}\right)$, que inativam o NO (SCHIFFRIN et al., 2004). Um estudo clínico demonstrou que a diminuição da resposta vasodilatadora dependente de endotélio em indivíduos obesos foi atribuída, ao menos em parte, ao estresse oxidativo, tendose em vista que a co-infusão de vitamina $C$ melhorou, embora não tenha normalizado completamente, a resposta endotelial à Ach (PERTICONE et al., 2001).

Outra fonte de EROs é o chamado desacoplamento da eNOS, uma condição na qual esta enzima responsável pela síntese de NO é privada da L-arginina ou da tetrahidrobiopterina (BH4), um importante cofator para a atividade normal da eNOS, o que leva à geração de ânions superóxido $\left(\mathrm{O}_{2}^{-}\right)$e peróxido de hidrogênio $\left(\mathrm{H}_{2} \mathrm{O}_{2}\right)$ no lugar do NO. Esta condição ocorre na disfunção endotelial, com aumento na produção de $\mathrm{O}_{2}^{-}$e formação de peroxinitrito (ONOO$\left.{ }^{-}\right)$, um mediador chave da peroxidação lipídica, envolvido em lesões ateroscleróticas. Recentemente demonstrou-se que o gene que codifica a enzima eNOS tem expressão aumentada em mulheres obesas. O aumento da atividade eNOS pode levar ao estresse oxidativo devido ao estado desacoplado desta enzima (ENGELI et al., 2004), 
confirmando as observações anteriores sobre a importância do estresse oxidativo na gênese da disfunção endotelial na obesidade.

Em resumo, apesar de estar bem estabelecido que a obesidade está intimamente associada à disfunção endotelial, tanto em humanos como em modelos experimentais, os mecanismos que levam ao desenvolvimento destas alterações ou como os fatores liberados pelo endotélio podem contribuir para o desenvolvimento das mesmas, não estão completamente esclarecidos.

\subsection{Obesidade Induzida pelo Glutamato Monossódico (MSG)}

Diversos modelos de obesidade experimental têm sido propostos a fim de investigar a patogênese, bem como os aspectos metabólicos e vasculares envolvidos na obesidade. Os estudos em modelos animais têm sido bastante úteis no estabelecimento das causas e conseqüências da doença e podem, também, ter participação importante no desenvolvimento de procedimentos mais efetivos para prevenção e tratamento desta condição.

Pode-se induzir experimentalmente um modelo de obesidade utilizando a administração de glutamato monossódico (MSG) no período neonatal em ratos. Os animais recém-nascidos são mais sensíveis à ação do MSG, uma vez que a barreira hematoencefálica não se apresenta totalmente formada (KIZER et al., 1977).

O aminoácido neurotransmissor glutamato possui propriedades neurotóxicas que, indiretamente provocam lesões no sistema nervoso central (SNC), ao afetarem neurônios glutamatérgicos localizados principalmente na área pré-óptica e do núcleo arqueado do hipotálamo e nos neurônios colinérgicos do núcleo arqueado (HOLZWARTH-MCBRIDE et al., 1976), prejudicando a sinalização de leptina e insulina nesta região. As alterações neuroendócrinas e metabólicas decorrentes do tratamento neonatal com MSG foram muito estudadas.

Este modelo experimental de obesidade foi inicialmente descrito por Olney (1969). Os mecanismos pelos quais o tratamento com MSG provoca obesidade não estão totalmente compreendidos, entretanto, vários estudos têm estabelecido que neste modelo há uma desordem de origem multifatorial, associada com uma variedade de alterações neuroendócrinas e metabólicas, que contribuem para o desenvolvimento de hiperinsulinemia e resistência à insulina (OLNEY, 1969; 
NEMEROFF, 1977; SARTIN et al. 1985; MAITER et al. 1991; MACHO et al. 2000). Além disso, sabe-se que, quando adultos, os animais apresentam significativa diminuição dos níveis do hormônio do crescimento $(\mathrm{GH})$, hipogonadismo, esterilidade, hipercorticosteronemia (OLNEY, 1969), hiperleptinemia, resistência à insulina, menor atividade da proteína translocadora de glicose GLUT-4, menor atividade do tecido adiposo marrom e maior deposição de gordura visceral (HIRATA et al., 1997). Dentre as hipóteses sugeridas na gênese destas alterações estão, distúrbios autonômicos, como hiperatividade parassimpática (LUCINEI BALBO et al., 2000) e hipoatividade simpática (MORRIS et al., 1998; DULLOO e YOUNG, 1991) e ainda diminuição na termogênese (MESSINA et al., 2005).

As alterações na função neuronal hipotalâmica observadas nos ratos MSG promovem aumento da atividade do eixo hipotálamo-pituitária-adrenal (MACHO et al., 2000), o qual parece ser o principal componente responsável pelo desenvolvimento da obesidade neste modelo. Está bem estabelecido existir um crosstalk entre o tecido adiposo e a atividade do eixo hipotálamo-pituitária-adrenal, que representa papel central no controle da ingestão alimentar, do metabolismo de glicose e lipídeos, bem como do balanço energético (LARSEN et al., 1994). Embora esteja bem estabelecido que a obesidade humana constitua uma desordem de origem multifatorial, estudos sugerem que alterações no eixo hipotálamo-pituitáriaadrenal estão envolvidas no desenvolvimento desta condição, em particular a obesidade com acúmulo de gordura visceral (MARIN et al., 1992; PASQUALI et al., 1966; ROSMOND et al., 1998).

No que diz respeito à adequação de modelos experimentais para o estudo da obesidade, embora nenhum deles simule com exatidão a obesidade humana em virtude da grande da grande complexidade desta desordem, o modelo de obesidade induzido por MSG apresenta características que são encontradas na obesidade humana, tais como: resistência à insulina, dislipidemia e aumento de gordura visceral (MARMO et al., 1994; HIRATA et al., 1997), podendo assim ser considerado como modelo adequado de obesidade experimental. 


\subsection{Metformina e Resistência à Insulina}

A fisiopatologia da obesidade está intimamente relacionada à do diabetes tipo 2. A maior parte dos pacientes diabéticos é obesa e a obesidade por si só resulta em resistência à insulina, dislipidemia e disfunção vascular. Além do aumento de gordura corporal total, o acúmulo de gordura intra-abdominal ou visceral presente na obesidade, aumenta 10-11 vezes o risco de desenvolvimento de diabetes tipo 2 e doenças cardiovasculares (LI et al., 2005).

Tanto o diabetes tipo 2 quanto a obesidade estão relacionados com a presença de resistência à insulina e hiperinsulinemia compensatória, alterações metabólicas que ocorrem no sentido de agravar a doença aterosclerótica. Neste sentido, as recomendações da Associação Americana de Diabetes para o cuidado de pacientes com diabetes tipo 2 incluem intervenções que melhorem a sensibilidade à insulina. Estudos demonstraram que intervenções no estilo de vida em pacientes obesos podem reduzir ou retardar a incidência de diabetes tipo 2 , assim como intervenções farmacológicas com agentes antidiabéticos (TUOMILEHTO et al., 2001).

As intervenções para o controle da resistência à insulina e desordens metabólicas relacionadas incluem inicialmente mudanças no estilo de vida, com redução da ingestão calórica e atividades físicas, a fim de diminuir os níveis de glicose, melhorar o perfil lipídico e induzir perda de peso (FONSECA, 2003). O tratamento com antidiabéticos orais é indicado para pacientes com diabetes mantidos sob dieta alimentar, com glicemia em jejum acima de $140 \mathrm{mg} / \mathrm{dL}$ e, geralmente, são indicados quando a combinação de dieta e prática de atividade física se torna insuficiente para normalizar os níveis glicêmicos.

Dentre os antidiabéticos orais se destacam os secretagogos de insulina, com efeitos diretos sobre a produção de insulina pelas células $\beta$ pancreáticas, compreendendo as sulfoniluréias e as glinidas. As sulfoniluréias constituem a terapia oral de primeira escolha para pacientes diabéticos que não apresentam sobrepeso, uma vez que o ganho de peso usualmente ocorre com o seu uso. Os receptores de sulfoniluréias são parte integrante da estrutura dos canais de $\mathrm{K}+$ dependentes de ATP $\left(\mathrm{K}_{\mathrm{ATP}}\right)$. A ligação das sulfoniluréias aos receptores presentes nas células $\beta$ promove fechamento dos canais de potássio, despolarização da membrana celular e conseqüente influxo de cálcio através de canais dependentes de voltagem, 
promovendo a secreção das vesículas contendo insulina. As glinidas são secretagogos que promovem a secreção rápida de insulina logo após as refeições, reduzindo a hiperglicemia pós-prandial comum em pacientes nos estágios iniciais do diabetes tipo 2. Existem também drogas antidiabéticas que retardam a absorção de carboidratos, alterando assim a liberação mediada pela glicose, de hormônios intestinais que aumentam a secreção de insulina. Um exemplo é a acarbose, um inibidor competitivo da a-glicosidase, enzima responsável pela digestão de polissacarídeos complexos a monossacarídeos (para revisão ver BAILEY, 2007).

A resistência à insulina é uma alteração metabólica característica nos pacientes diabéticos, entretanto, as alterações na ação deste hormônio não estão restritas apenas à suas ações sobre o metabolismo da glicose, ocorrendo também em outros aspectos do metabolismo intermediário. Portanto, as alterações da ação da insulina nos tecidos-alvo são de grande interesse terapêutico no diabetes tipo 2. Neste sentido, as tiazolidinedionas, bem como as biguanidas, relacionadas como drogas sensibilizadoras de insulina, atuam diretamente contra a resistência à insulina. As tiazolidinedionas melhoram a sensibilidade à insulina através da estimulação do receptor que quando ativado induz proliferação de peroxisomo- $\vee$ (PPAR-y), expresso no tecido adiposo e, em menor grau no músculo e fígado. Seu efeito primário consiste principalmente em aumentar a captação de glicose via GLUT-4 no músculo esquelético (KRENTZ e BAILEY, 2005).

A biguanida metformina é um dos agentes anti-hiperglicemiantes mais comumente utilizados para o tratamento da resistência à insulina em pacientes com diabetes tipo 2. Ela age por diversos mecanismos extra-hepáticos, aumentando a sensibilidade do organismo à ação da insulina endógena e controlando a resistência à insulina por mecanismos dependentes e independentes de insulina. Apesar de não ter seu mecanismo de ação ainda totalmente elucidado, sabe-se que a principal ação da metformina em pacientes com diabetes é inibir a produção de glicose hepática, primariamente por reduzir a gliconeogênese hepática, em parte através da potencialização da ação da insulina, resultando assim em diminuição das concentrações de glicose no sangue, com conseqüente redução da hiperinsulinemia (SEUFERT et al., 2004). Pode, também, como efeito secundário, aumentar a captação de glicose estimulada pela insulina no músculo esquelético. Efeitos dependentes da ação da insulina podem envolver aumento discreto da atividade tirosina quinase da subunidade $\beta$ do receptor de insulina e potencialização da via de 
sinalização pós-receptor. Concentrações maiores de metformina podem aumentar o metabolismo anaeróbico independentemente da ação da insulina, atuando sobre a cadeia respiratória mitocôndrial (DETAILLE et al., 2005).

Embora as biguanidas tenham se tornado disponíveis para a terapia do diabetes tipo 2 na década de 50 , os mecanismos pelos quais ela melhorava a sensibilidade à insulina permaneceram desconhecidos até achados que demonstraram que a metformina ativa a proteína quinase ativada pelo monofosfato de adenosina (AMPK) no músculo esquelético e no fígado (ZHOU et al., 2001), estimulando o transporte de glicose e ácidos graxos no músculo independentemente da insulina.

A AMPK pertence à família de enzimas que são ativadas em conseqüência do estresse celular resultante da depleção de ATP, agindo assim como reguladora da homeostase energética celular e sistêmica (SCHIMMACK et al., 2006). Uma vez ativada, a AMPK funciona no sentido de restaurar o ATP celular, inibindo os processos consumo e estimulando processos de geração de energia. Seus efeitos incluem estímulo para o transporte de glicose e ácidos graxos no músculo por um mecanismo independente da insulina. A fosforilação e conseqüente inibição acetilcoenzima A carboxilase, enzima que catalisa a etapa limitante da reação de síntese de lipídeos, promove aumento na oxidação de ácidos graxos no músculo, fígado, e tecido adiposo, inibindo a síntese de colesterol e triglicérides (KEMP et al., 1999).

A ativação da AMPK parece ser a etapa crítica na redução, mediada pela metformina, da produção de glicose hepática e do aumento na captação de glicose pelo músculo esquelético, constituindo, desta forma, o principal regulador do metabolismo de glicose e lipídios e o mediador chave dos efeitos benéficos da metformina (CHENG et al., 2005). Os estudos realizados com esta enzima indicam que a mesma possa constituir um importante alvo no tratamento farmacológico do diabetes tipo 2.

Além da ação anti-hiperglicêmica que justifica seu uso no tratamento do diabetes tipo 2, estudos recentes demonstram que a metformina controla e previne as complicações diabéticas na microcirculação de ratos resistentes à insulina, melhorando a reatividade vascular através de efeito direto sobre o endotélio e sobre o músculo liso vascular. Estes efeitos parecem ser relacionados à melhora do relaxamento vascular mediado pelo NO (KATAKAM et al., 2000), que pode ocorrer como conseqüência da diminuição da captação de cálcio e conseqüente diminuição 
do conteúdo de cálcio intracelular (DOMINGUEZ et al., 1996) e por redução da produção de espécies reativas de oxigênio (OUSLIMANI et al., 2005).

Utilizando o modelo experimental de diabetes tipo 2 induzido por estreptozotocina, foi demonstrado recentemente em nosso laboratório que a metformina restaura a resposta de arteríolas e vênulas a vasodilatadores dependentes de endotélio, mediadores ou não da resposta inflamatória e a agentes vasodilatadores independentes de endotélio independentemente da correção das alterações metabólicas (SARTORETTO et al., 2005), sugerindo efeito direto desta droga sobre o sistema vascular.

De fato, estudos têm demonstrado redução na mortalidade relacionada a doenças cardiovasculares em usuários de metformina quando comparados com usuários de outros agentes antidiabéticos (JOHNSON et al., 2002), sugerindo que a metformina pode apresentar efeitos protetores cardiovasculares adicionais além de suas propriedades anti-hiperglicemiantes. Entretanto, os mecanismos envolvidos nestes efeitos ainda não estão totalmente elucidados.

Recentemente, em experimentos conduzidos in vivo utilizando a microcirculação mesentérica de ratos obesos-MSG em nosso laboratório observouse que a resposta dos microvasos a agentes vasodilatadores dependentes do endotélio está reduzida (TOLEDO, 2005), semelhantemente ao que ocorre em outros modelos de resitência à insulina, como no diabetes tipo 2 . O mecanismo envolvido nessas alterações não foi esclarecido.

Considerando que a obesidade está associada com resistência à insulina e que este estado é caracterizado por alterações na reatividade vascular, é importante verificar se essas alterações ocorrem em outras preparações que permitam aprofundar os mecanismos responsáveis pelas mesmas.

Portanto, o objetivo do presente trabalho foi avaliar a participação do sistema do NO, do EDHF, da via da ciclooxigenase e do estresse oxidativo como fatores envolvidos na fisiopatologia das alterações vasculares presentes na obesidade induzida experimentalmente em ratos, bem como o efeito do tratamento com metformina sobre estas alterações. Apresentamos os estudos referentes à caracterização das alterações metabólicas e vasculares dos ratos com 16 semanas de idade, período em que a obesidade e resistência à insulina encontra-se bem estabelecida, bem como as alterações em ratos com 18 semanas submetidos ou não ao tratamento com metformina. 


\section{MATERIAL E MÉTODOS}

\subsection{Animais}

Foram utilizados ratos neonatos da linhagem Wistar, provenientes do biotério do Departamento de Farmacologia do Instituto de Ciências Biomédicas. Os ratos foram mantidos durante todo o período experimental em caixas de polipropileno, acondicionadas em ambiente com temperatura controlada de $22 \pm 2^{\circ} \mathrm{C}$ e ciclo claroescuro de $12 \mathrm{~h}$, com livre acesso à água e alimento. Os ratos foram divididos em três grupos experimentais:

I) Controles com 16 e 18 semanas;

II) Obesos-MSG com 16 e 18 semanas (MSG);

III) Obesos-MSG tratados com metformina (MSG-Met);

O protocolo para uso de animais em experimentação esta de acordo com os Princípios Éticos na Experimentação Animal adotado pelo Colégio Brasileiro de Experimentação Animal (COBEA) e foi aprovado pela Comissão de Ética em Experimentação Animal (CEEA) do ICB.

\subsection{Indução da Obesidade e Tratamento com Metformina}

Os ratos receberam injeções subcutâneas de MSG (4mg/g de peso corporal) nos dias 2, 3, 4, 5 e 6 após o nascimento (RODRIGUEZ-SIERRA et al., 1980). Ratos do grupo controle receberam igual volume de solução fisiológica $0,9 \%$. Os ratos adultos, com 16 e 18 semanas de idade, foram utilizados para os protocolos descritos.

Ratos do grupo MSG com 16 semanas de idade foram tratados com dose única diária de metformina (Glifage ${ }^{\circledR}$; Merk, Brasil), $300 \mathrm{mg} / \mathrm{kg}$ de peso corpóreo, diluída em água, por gavagem durante 15 dias. Os respectivos controles receberam água. 


\subsection{Caracterização da Obesidade}

Para a caracterização e confirmação da eficácia do tratamento com MSG, a obesidade foi avaliada pela determinação do Índice de Lee [peso corporal 1/3 (g)/comprimento naso-anal (cm)], do peso relativo (g/100 g peso corporal) das gorduras periepididimal e retroperitonial e da massa magra (músculos sóleo e EDL). Durante todos os protocolos experimentais o acúmulo de gordura retroperitonial e periepididimal foi avaliado.

\subsection{Determinação dos Parâmetros Biológicos}

\subsubsection{Evolução Ponderal}

Os ratos foram pesados semanalmente, desde a $1^{\text {a }}$ semana após a injeção de MSG até a $18^{a}$ semana, para a avaliação da evolução ponderal.

\subsubsection{Perfil Lipídico}

Para a determinação do perfil lipídico, os ratos foram submetidos à privação alimentar de 05 horas (período das 07 - 12:00h) e anestesiados com pentobarbital sódico (Hypnol 3\% ${ }^{\circledR}$, Fontover, Brasil) (40 mg/kg de peso corporal) por via intraperitonial e em seguida submetidos à laparotomia e exposição da artéria aorta descendente. Amostras de $3,0 \mathrm{~mL}$ de sangue foram coletadas e em seguida centrifugadas a $3000 \mathrm{rpm}$ por cinco minutos. O soro foi separado e utilizado para as determinações descritas a seguir.

\subsubsection{Determinação do Colesterol Sérico}

O colesterol total foi determinado pelo método enzimático COE/COD/POD $\left(C E L M^{\circledR}\right)$, utilizando-se alíquotas de $10 \mu \mathrm{L}$ de soro, coletado como descrito no item 2.4.2. Neste método o colesterol-oxidase catalisa a oxidação do colesterol 
produzindo o peróxido de hidrogênio. Este, através de uma reação oxidativa catalisada pela peroxidase, reage com a 4-aminoantipirina e fenol produzindo a antipirilquinonimina vermelha, cuja intensidade de cor é proporcional à concentração de colesterol na amostra. Os resultados foram expressos em mg/dL.

\subsubsection{Determinação de Triglicerideos Séricos}

Os triglicerideos foram determinados pelo método enzimático da glicerol-3fosfato-oxidase (GPO-POD) (CELM ${ }^{\circledR}$ ), utilizando-se alíquotas de $10 \mu \mathrm{L}$ de soro coletado. Neste método os triglicerídeos sofrem ação de lipases resultando na molécula de glicerol, e este é posteriormente convertido a glicerol-3-fosfato. A glicerol-3-fosfato-oxidase catalisa a oxidação do glicerol-3-fosfato produzindo o peróxido de hidrogênio. Este, através de uma reação oxidativa catalisada pela peroxidase, reage com a 4-aminoantipirina e fenol produzindo a antipirilquinonimina vermelha, cuja intensidade de cor é proporcional à concentração de triglicerídeos na amostra. Os resultados foram expressos em $\mathrm{mg} / \mathrm{dL}$.

\subsubsection{Determinação Sérica de HDL Colesterol}

As LDLs e as VLDLs foram precipitadas seletivamente pelo ácido fosfotúngstico. No sobrenadante, separado por centrifugação, restaram as HDLs e realizou-se a determinação do colesterol ligado às mesmas, utilizando o sistema enzimático COP-POD $\left(\mathrm{CELM}^{\circledR}\right)$, com alíquotas de $500 \mu \mathrm{L}$ de soro. Os resultados foram expressos em $\mathrm{mg} / \mathrm{dL}$.

\subsubsection{Cálculo da Concentração Sérica de VLDL Colesterol}

A partir da concentração sérica de triglicerídes, determinada pelo método enzimático da glicerol-3-fosfato-oxidase (GPO-POD, CELM ${ }^{\circledR}$ ), descrito anteriormente, foram calculadas as concentrações de VLDL colesterol, utilizando o seguinte cálculo: VLDL Colesterol $(\mathrm{mg} / \mathrm{dL})=$ Triglicérides $(\mathrm{mg} / \mathrm{dL}) / 5$ 


\subsubsection{Cálculo da Concentração Sérica de LDL Colesterol}

A partir das concentrações séricas de HDL colesterol, determinado utilizando o sistema enzimático COP-POD (CELM $\left.{ }^{\circledR}\right)$, e VLDL, descritos anteriormente, foram calculadas as concentrações de LDL colesterol, utilizando o seguinte cálculo:

LDL Colesterol $(\mathrm{mg} / \mathrm{dL})=$ Colesterol Total $(\mathrm{HDL}$ Colesterol + VLDL Colesterol)

$\checkmark \quad$ Para os testes a seguir, os ratos foram mantidos em privação alimentar de 4 horas (período das 07 - 11:00h) e anestesiados com pentobarbital sódico (Hypnol $3 \%{ }^{\circledR}$, Fontover, Brasil) (40 mg/kg de peso corporal) por via intraperitonial.

\subsubsection{Determinação das Concentrações Séricas de Glicose e Insulina}

Amostras de sangue foram coletadas da aorta abdominal. O soro, separado por centrifugação a $3000 \mathrm{rpm}$, por $10 \mathrm{~min}$, foi estocado a $-80^{\circ} \mathrm{C}$, em alíquotas para dosagem de glicose e insulina. A concentração de glicose sanguínea foi determinada pelo método enzimático-colorimétrico glicose-oxidase (Kit glicose $\mathrm{E}$ enzimática, CELM ${ }^{\circledR}$, São Paulo, Brasil). A concentração de insulina no soro foi determinada por radioimunoensaio (RIE) (Rat insulin RIA Kit, Linco, USA).

2.4.4 Avaliação da Sensibilidade à Insulina pelo Índice HOMA-IR e da Capacidade Secretória Pancreática pelo Índice HOMA- $\beta$

A sensibilidade à insulina foi avaliada semanalmente a partir da $12^{\mathrm{a}}$ semana e os ratos foram utilizados nos experimentos com 16 semanas, idade onde a resistência à insulina foi detectada. A sensibilidade à insulina e a função da célula $\beta$ foram avaliadas pelo índice HOMA-IR (Homeostasis Model Assessment) e Índice HOMA- $\beta$, respectivamente (MATTHEWS et al., 1985), e que levam em consideração a insulina e a glicemia em jejum, através das seguintes fórmulas matemáticas:

HOMA-IR= Insulina em jejum x Glicemia em jejum / 22,5

HOMA- $\beta=(\%)$ da função da célula $\beta=20 \times$ insulina plasmática (mU/L)/[glicose plasmática $(\mathrm{mmol} / \mathrm{L}) \times 3,5]$. 


\subsubsection{Teste de Tolerância à Glicose Intravenoso (IVGTT)}

Foi coletada uma gota de sangue caudal correspondendo à glicemia basal (T0) e em seguida administrada dose única de glicose $(0,75 \mathrm{~g} / \mathrm{kg}$ de peso corporal) por via intravenosa, sendo coletadas amostras de sangue nos tempos 5, 10, 20, 30 e 60 minutos após a injeção de glicose, correspondendo a T5, T10, T20, T30 e T60. A glicemia foi determinada através de glicosímetro e fitas (Advantage ${ }^{\circledR}$, Roche, Brasil).

\subsection{Determinação da Pressão Arterial Caudal e da Freqüência Cardíaca}

A pressão arterial caudal dos ratos acordados foi determinada por método indireto, através da pletismografia de cauda. Dois dias antes da primeira medida de pressão arterial caudal os ratos foram submetidos a um período de adaptação que envolvia o aquecimento dos animais em estufa especial por 10 minutos a $40{ }^{\circ} \mathrm{C}$ e a contenção em cilindro de acrílico, com abertura para o focinho e cauda, por cinco minutos. Este procedimento foi realizado uma vez ao dia durante dois dias.

Após o procedimento de adaptação foram determinados os níveis pressóricos dos ratos. Para isso os ratos foram aquecidos por 10 minutos a $40{ }^{\circ} \mathrm{C}$ e colocados no cilindro de contenção. Um oclusor e um sensor foram ajustados à porção proximal da cauda do rato, acoplados ao esfigmomanômetro elétrico PE-399 conectado a um sistema de transdução (PowerLab 4/S, AD Instrument Pty Ltda). O valor final da pressão arterial caudal de cada animal representa a média aritmética de três medidas seqüenciais.

\subsection{Reatividade Vascular do Leito Arteriolar Mesentérico Isolado}

Os ratos foram anestesiados com solução de hidrato de cloral $(450 \mathrm{mg} / \mathrm{kg})$ por via subcutânea. Ao atingirem o nível cirúrgico foram submetidos a laparotomia e tiveram o mesentério cuidadosamente exposto. A artéria mesentérica superior foi canulada com cateter de polietileno (PE-10 Hemo Técnico® - São Paulo, Brasil) introduzido cerca de 1,5 a 2,0 cm distante da aorta abdominal e o leito mesentérico foi perfundido, com fluxo constante de $2 \mathrm{~mL} / \mathrm{min}$ com Krebs Henseleit mantido com 
$\mathrm{pH}$ em torno de 7,4 e saturado com $95 \%$ de $\mathrm{O}_{2}$ e $5 \%$ de $\mathrm{CO}_{2}$, mantida a $37,0 \pm 0,5$ ${ }^{\circ} \mathrm{C}$. A solução de Krebs Henseleit apresenta a seguinte composição (em mmol/L): $\mathrm{NaCl}, 113 ; \mathrm{KCl}, 4,7 ; \mathrm{CaCl}_{2}, 2,5, \mathrm{NaHCO}_{3}, 25 ; \mathrm{MgSO}_{4}, 1.1 ; \mathrm{KH}_{2} \mathrm{PO}_{4}, 1,1 ; \mathrm{EDTA}, 0.03$; glicose, 5,5 (Mc GREGOR, 1965; CARVALHO et al., 1987).

O mesentério, já perfundido, foi removido do rato, separado da alça intestinal e colocado em cuba de vidro aquecida a $37^{\circ} \mathrm{C}$. Alterações da pressão de perfusão foram medidas por transdutor de pressão (BP Transducer ${ }^{\circledR}, A D$ Instruments, EUA) e registradas em um sistema de aquisição digital (Power Lab ${ }^{\circledR}, A D$ Instruments, EUA) e utilizadas como medida de contração e relaxamento $(\mathrm{mmHg})$ induzida pelas drogas vasoconstritoras e vasodilatadoras, respectivamente sobre o leito arteriolar mesentérico (Figura 1).

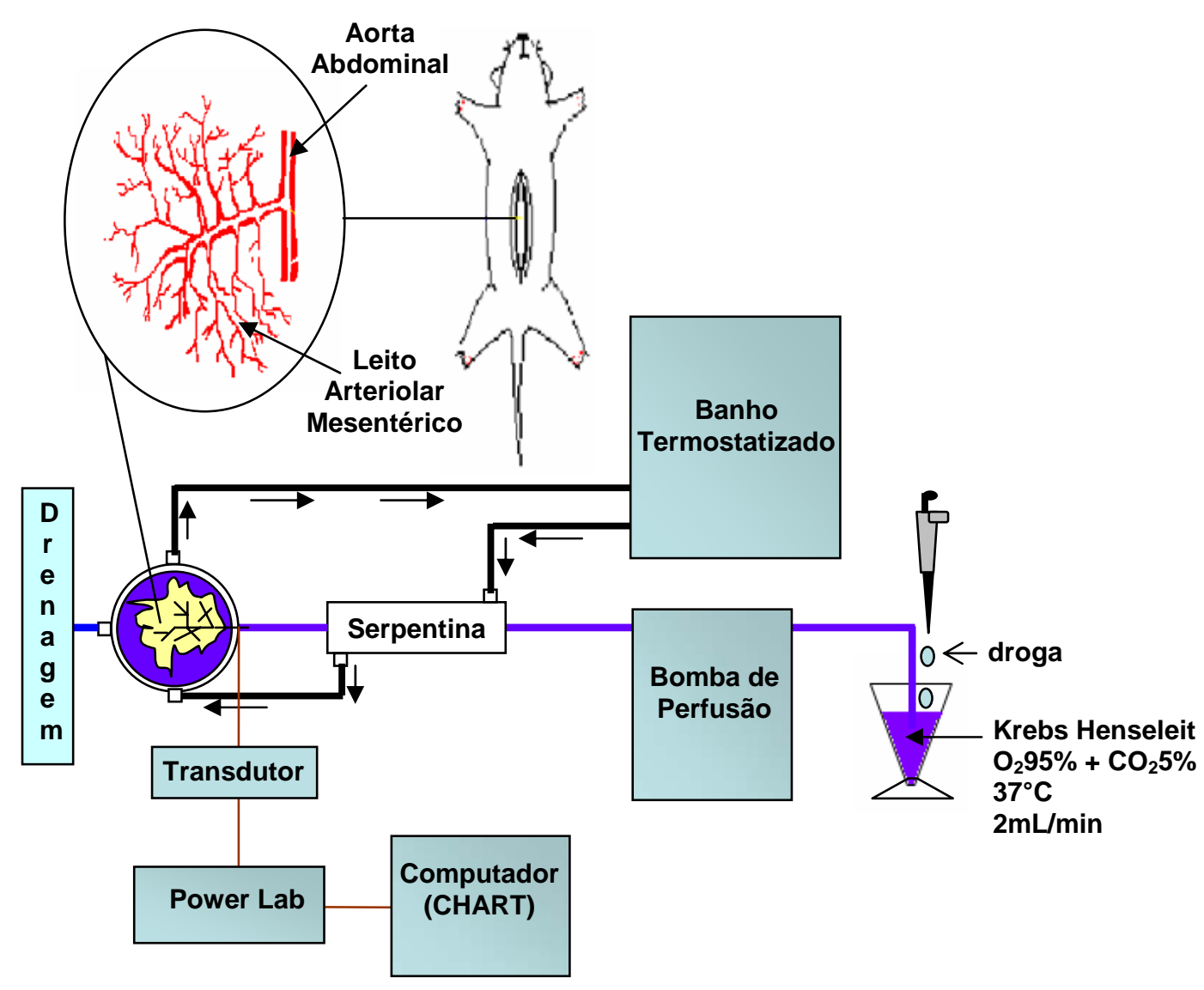

Figura 2 - Esquema do sistema para estudo da reatividade vascular no leito mesentérico isolado. 


\subsubsection{Avaliação da Resposta Vasoconstritora ao Cloreto de Potássio}

Após o período de estabilização de 40 minutos, as preparações foram perfundidas com solução de $\mathrm{KCL}$ em concentrações crescentes $\left(5 \times 10^{-3} \mathrm{M}\right.$ a $225 \times 10^{-3}$ $M)$, gerando uma curva concentração efeito (CCE), com intervalos de 5 minutos entre cada concentração, tempo necessário para a estabilização da resposta contrátil.

\subsubsection{Avaliação da Resposta Vasoconstritora à Noradrenalina}

Após o período de estabilização de 40 minutos, as preparações foram perfundidas com solução de NA em concentrações crescentes $\left(10^{-7} \mathrm{M}\right.$ a $\left.10^{-4} \mathrm{M}\right)$, gerando uma curva concentração-efeito (CCE), com intervalos de 3 minutos entre cada concentração. A perfusão foi realizada na presença de desipramina $\left(10^{-8} \mathrm{M}\right)$ para inibir a recaptação de NA pelos neurônios adrenérgicos presentes no leito mesentérico.

\subsubsection{Avaliação da Resposta Vasodilatadora à Acetilcolina e ao Nitroprussiato de} Sódio

Após período de estabilização de 40 minutos a preparação foi perfundida com solução de NA para produzir pré-contração (medida como aumento na pressão de perfusão) em concentrações que promovem $80 \%$ da resposta máxima nos dois grupos experimentais, estabelecidas previamente na CCE para NA (10-5 M - MSG e $3 \times 10^{-5} \mathrm{M}$ - Controle). Após 10 minutos do início da pré-contração, o leito arteriolar mesentérico foi perfundido com Ach $\left(10^{-9} \mathrm{M}-3 \times 10^{-5} \mathrm{M}\right)$ ou NPS $\left(10^{-9} \mathrm{M}-3 \times 10^{-5} \mathrm{M}\right)$ em concentrações crescentes, gerando uma curva CCE, com intervalos de 3 minutos entre cada concentração. A Ach e o NPS foram diluídos em Krebs-Henseleit contendo desipramina e NA nas concentrações descritas acima. 


\subsubsection{Efeito do Bloqueio da Síntese de Óxido Nítrico Sobre a Resposta Contrátil à}

Noradrenalina

Para avaliar o papel do NO na modulação da resposta contrátil à NA do leito arteriolar mesentérico dos ratos Cont, MSG e MSG-Met, as preparações foram perfundidas com nitro L-arginina metil éster (L-NAME - $100 \mu \mathrm{M}$ ) (XAVIER et al., 2004), um inibidor não seletivo da síntese de NO, por 30 minutos após o período de estabilização. A preparação foi então perfundida com solução de NA em concentrações crescentes $\left(10^{-7} \mathrm{M}\right.$ a $\left.3 \times 10^{-4} \mathrm{M}\right)$, gerando uma CCE, com intervalos de 3 minutos entre cada concentração. A perfusão de NA foi realizada na presença de desipramina e L-NAME.

2.6.5 Efeito do Bloqueio de Canais de Potássio Sobre a Resposta Contrátil à Noradrenalina

Para avaliar o papel do componente EDHF na modulação da resposta contrátil à NA do leito arteriolar mesentérico dos ratos Cont, MSG e MSG-Met, as preparações foram perfundidas com tetraetilamônio (TEA) (2 mM) (XAVIER et al., 2004), bloqueador inespecífico de canais de potássio, por 30 minutos após o período de estabilização. A preparação foi então perfundida com solução de NA em concentrações crescentes $\left(10^{-7} \mathrm{M}\right.$ a $\left.3 \times 10^{-4} \mathrm{M}\right)$, gerando uma CCE, com intervalos de 3 minutos entre cada concentração. A perfusão de NA foi realizada na presença de desipramina e TEA.

\subsubsection{Efeito do Bloqueio da Ciclooxigenase Sobre a Resposta Contrátil à} Noradrenalina

Para avaliar o papel dos produtos da COX na resposta contrátil à NA do leito arteriolar mesentérico dos ratos Cont, MSG e MSG-Met, as preparações foram perfundidas com Indometacina (10 $\mathrm{MM}$ ) (XAVIER et al., 2004), um inibidor não seletivo da COX, por 30 minutos após o período de estabilização. A preparação foi então perfundida com solução de NA em concentrações crescentes $\left(10^{-7} \mathrm{M}\right.$ a $3 \times 10^{-4}$ 
$M)$, gerando uma CCE, com intervalos de 3 minutos entre cada concentração. $A$ perfusão de NA foi realizada na presença de desipramina e Indometacina.

\subsubsection{Efeito do Bloqueio da Síntese de Óxido Nítrico Sobre a Resposta} Vasodilatadora à Acetilcolina

Para avaliar o componente do relaxamento vascular induzido pela Ach mediado pelo NO no leito arteriolar mesentérico, após período de estabilização de 40 minutos as preparações foram perfundidas com solução contendo L-NAME (100 $\mu \mathrm{M})$ por 30 minutos. Em seguida, as preparações foram perfundidas com solução de NA para produzir pré-contração (medida como aumento na pressão de perfusão), em concentrações que promovem $80 \%$ da resposta máxima nos dois grupos experimentais, estabelecidas previamente na CCE para NA na presença deste bloqueador ( $3 \times 10^{-6} \mathrm{M}$ - MSG e $10^{-5} \mathrm{M}$ - Controle e MSG-Met). Após 10 minutos do início da pré-contração, o leito arteriolar mesentérico foi perfundido com Ach concentrações crescentes $\left(10^{-9} \mathrm{M}\right.$ a $\left.3 \times 10^{-5} \mathrm{M}\right)$, gerando uma CCEC, com intervalos de 3 minutos entre cada concentração. A Ach foi diluída em Krebs-Henseleit contendo desipramina, NA e L-NAME nas concentrações descritas acima.

2.6.8 Efeito do Bloqueio de Canais de Potássio Sobre a Resposta Vasodilatadora à Acetilcolina

Para avaliar o componente do relaxamento vascular induzido pela Ach mediado pelo EDHF no leito arteriolar mesentérico, após período de estabilização de 40 minutos as preparações foram perfundidas com solução contendo TEA (2 mM) por 30 minutos. Em seguida, as preparações foram perfundidas com solução de NA para produzir pré-contração (medida como aumento na pressão de perfusão), em concentrações que promovem $80 \%$ da resposta máxima nos dois grupos experimentais, estabelecidas previamente na CCE para NA na presença deste bloqueador ( $3 \times 10^{-6} \mathrm{M}$ - MSG e MSG-Met, $10^{-5} \mathrm{M}$ - Controle). Após 10 minutos do início da pré-contração, o leito arteriolar mesentérico foi perfundido com Ach concentrações crescentes $\left(10^{-9} \mathrm{M}\right.$ a $\left.3 \times 10^{-5} \mathrm{M}\right)$, gerando uma CCEC, com intervalos 
de 3 minutos entre cada concentração. A Ach foi diluída em Krebs-Henseleit contendo desipramina, NA e TEA nas concentrações descritas acima.

\subsubsection{Efeito do Bloqueio da Ciclooxigenase Sobre a Resposta Vasodilatadora à} Acetilcolina

Para avaliar o papel dos produtos da COX no relaxamento muscular induzido pela Ach do leito arteriolar mesentérico dos ratos Cont, MSG e MSG-Met, as preparações foram perfundidas com Indometacina $(10 \mu \mathrm{M})$, um inibidor não seletivo da COX, por 30 minutos após o período de estabilização. Em seguida, as preparações foram perfundidas com solução de NA para produzir pré-contração (medida como aumento na pressão de perfusão), em concentrações que promovem $80 \%$ da resposta máxima nos dois grupos experimentais, estabelecidas previamente na CCEC para NA na presença deste bloqueador $\left(3 \times 10^{-5} \mathrm{M}\right.$ no três grupos experimentais). Após 10 minutos do início da pré-contração, o leito arteriolar mesentérico foi perfundido com Ach concentrações crescentes $\left(10^{-9} \mathrm{M}\right.$ a $\left.3 \times 10^{-5} \mathrm{M}\right)$, gerando uma CCE, com intervalos de 3 minutos entre cada concentração. A Ach foi diluída em Krebs-Henseleit contendo desipramina, NA e Indometacina nas concentrações descritas acima.

\subsubsection{Análise dos Resultados}

Os resultados das curvas de relaxamento à Ach e NPS foram expressos como porcentagem de relaxamento à pré-contração com noradrenalina. Os resultados de contração foram expressos como variação da pressão de perfusão média, obtidos pela subtração da resposta máxima contrátil pela pressão basal de perfusão. As CCE aos diferentes agonistas tiveram calculados e expressos valores de resposta máxima $(R \max )$ e de $\mathrm{pD}_{2}$ (-Log $\left.\mathrm{EC}_{50}\right)$, que representa o valor da concentração que produz $50 \%$ da Rmax. Para tal, foram realizadas análises de regressão não-linear, obtidas obtidas a partir das CCE utilizando o programa GraphPad Prim Software (San Diego, CA, USA). 


\subsection{Medida da Produção de Óxido Nítrico em Artérias Mesentéricas - Diaminofluoresceína}

O NO foi medido utilizando-se diacetato de 4,5 diaminofluoresceína (DAF-2), um marcador fluorescente sensível ao NO (KOJIMA et al., 1998). Os ratos foram anestesiados, o mesentério foi exposto e as artérias mesentéricas foram rapidamente dissecadas, congeladas e cobertas com meio de congelamento. Utilizando-se um criostato (Leica, Alemanha), cortes transversais das arteérias (20 $\mu \mathrm{m}$ ) foram obtidos, coletados em lâminas de vidro e incubados a $37^{\circ} \mathrm{C}$ com DAF-2 (8 $\mu \mathrm{M}$ ) em tampão fosfato $(0,1 \mathrm{M}, \mathrm{pH} 7,4)$ contendo $\mathrm{CaCl}_{2}(0,45 \mathrm{mM})$. Após 30 minutos, os cortes foram estimulados com $100 \mu \mathrm{M}$ de acetilcolina. Os cortes controles receberam o mesmo volume de tampão fosfato com $\mathrm{CaCl}_{2}$. Após 60 minutos da estimulação, imagens digitais foram capturadas de um microscópio (Nikon E1000, Japão) equipado com epifluorescência. As imagens foram analisadas com o programa Image ${ }^{\circledR}$ (NIH, EUA), medindo-se a densidade óptica média da fluorescência observada. Esta densidade foi avaliada em pelo menos três locais em cada imagem e de artérias obtidas de diferentes ratos. Em um grupo adicional de experimentos, verificamos o efeito de $1 \mathrm{mM}$ de L-NAME (um inibidor não-seletivo da NOS) na produção de NO, seguindo o mesmo protocolo experimental. As artérias foram incubadas com L-NAME no momento em que o DAF-2 foi adicionado.

\subsection{Estudo da Geração de Espécies Reativas de Oxigênio em Artérias Mesentéricas - Dihidroetidina}

A geração de espécies reativas de oxigênio (EROs) foi determinada utilizando um método qualitativo que envolve a dihidroetidina (DHE), um precursor não fluorescente do brometo de etídio. Na presença de EROs, a hidretidina é oxidada dentro da célula, produzindo os compostos fluorescentes etídeo (E) e 2-hidróxi etídeo (EHO), que têm afinidade pelo DNA nuclear. A formação do etídeo deve-se principalmente a oxidação da DHE pelo ânion superóxido, enquanto o 2-hidróxi etídeo é formado pela oxidação da DHE por outras espécies reativas de oxigênio como a água oxigenada (Figura 2). 
Os ratos foram anestesiados, o mesentério foi exposto e as artérias mesentéricas foram rapidamente dissecadas, imersas em meio de congelamento e congeladas. Utilizando-se um criostato (Leica, Alemanha), cortes transversais das artérias $(20 \mu \mathrm{m})$ foram obtidos e colocados em lâminas silanizadas. Os cortes foram incubados com $100 \mu \mathrm{L}$ de dihidroetidina 2,5 $\mu \mathrm{M}\left(60 \mathrm{~min}\right.$, a $\left.37^{\circ} \mathrm{C}\right)$ em câmara úmida e protegidos da luz. Após este período as lâminas foram observadas em microscópio óptico (ZEISS) equipado com filtro para rodamina e câmera fotográfica, utilizando uma objetiva para fluorescência com aumento de 400X. A localização da geração de espécies reativas foi realizada visualmente em três áreas diferentes de cada corte da artéria onde se observou regiões onde haviam núcleos marcados com fluorescência vermelha proveniente dos produtos de oxidação da DHE.

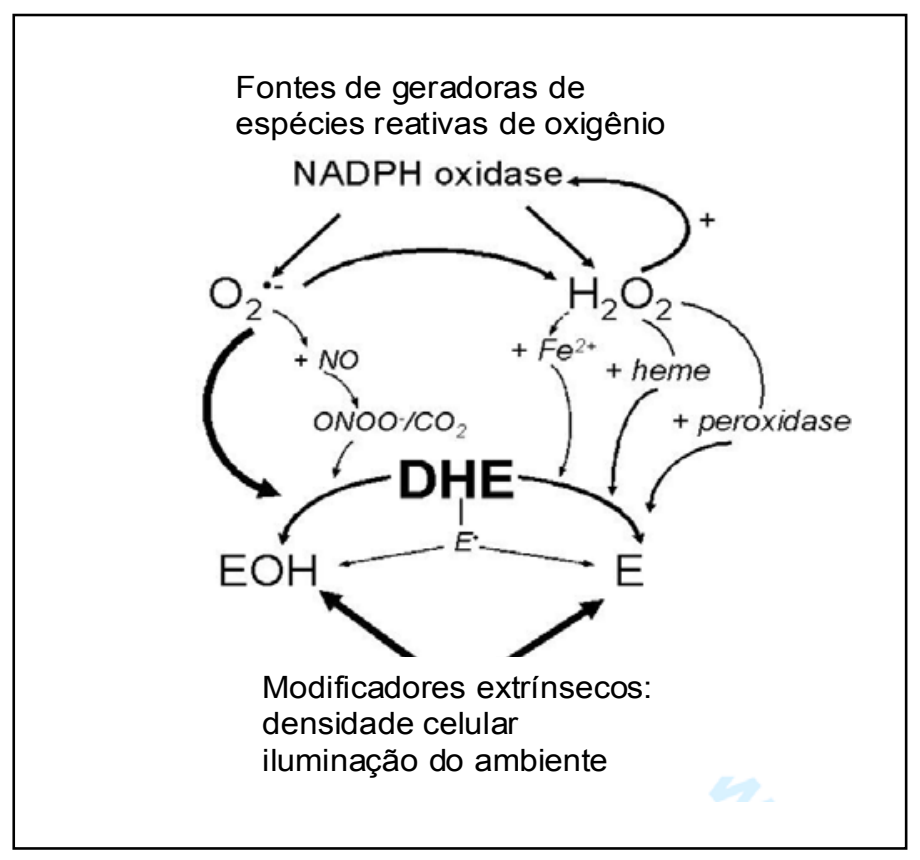

Figura 3 - Oxidação da dihidroetidina (DHE) por diferentes espécies reativas de oxigênio e seus produtos: etídeo $(\mathrm{E})$ e 2-hidróxietideo $(\mathrm{EOH})$.

\subsection{Análise Estatística}

Os resultados foram expressos como média \pm erro padrão da média (epm). As análises estatísticas foram realizadas utilizando-se o teste "t" de Student no caso de comparação de duas médias ou análise de variância de uma via (ANOVA) seguido do teste de Bartlett para a homogeneidade das variâncias e teste de múltiplas comparações Tukey-Kramer para o caso de comparação de mais de duas médias. $O$ nível de significância mínima aceitável foi $p<0,05$. 


\section{RESULTADOS}

\subsection{Caracterização da Obesidade}

3.1.1 Determinação do Indice de Lee, Peso Relativo das Gorduras Periepididimal e Retroperitonial e da Massa Magra

O tratamento de ratos neonatos com MSG induziu obesidade, caracterizada pelo aumento do índice de Lee (Figura 4A) e do peso relativo das gorduras periepididimal e retroperitonial (Figuras $5 \mathrm{~A}$ e $5 \mathrm{~B}$ ), sem alterar a massa magra (Figura $5 \mathrm{~A}, 5 \mathrm{~B})$, após 16 semanas de idade. O mesmo foi observado nos ratos MSG com 18 semanas e o tratamento com metformina promoveu redução significativa do índice de Lee e do peso relativo das gorduras periepididimal e retroperitonial, entretanto, sem reverter estes parâmetros aos níveis do grupo Controle (Figuras 3B, 5C, 5D, 6C e 6D).

A)

B)
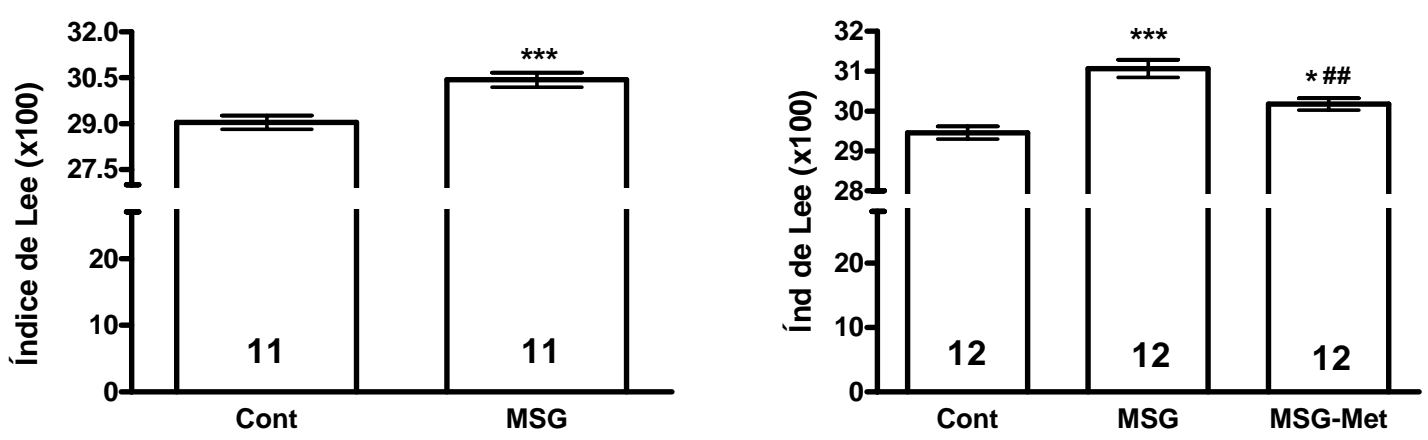

Figura 4 - Índice de Lee [(peso corporal ${ }^{1 / 3}(\mathrm{~g}) /$ comprimento naso-anal (cm)], dos grupos controle (Cont), obeso-MSG (MSG) com 16 semanas (A) e dos grupos Cont, MSG e obesos-MSG tratados com metformina (MSG-Met) com 18 semanas de idade (B). Cada barra representa a média \pm epm. O número de ratos utilizados em cada grupo encontra-se dentro das barras.

${ }^{*} p<0,05$ vs Cont; ${ }^{* * *} p<0,001$ vs controle e MSG-Met; ${ }^{\# \#} p<0,01$ vs MSG. 


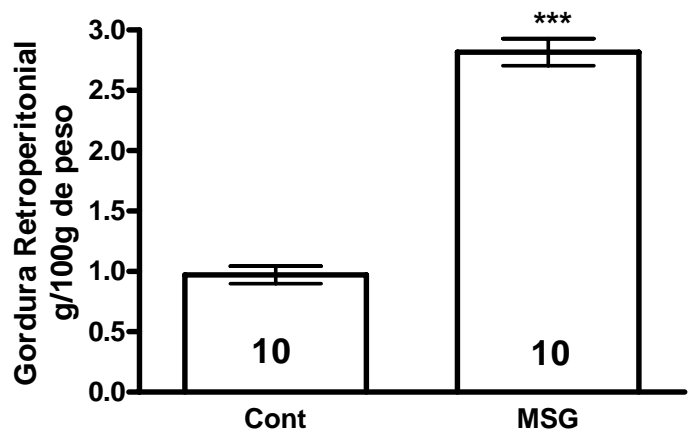

C)

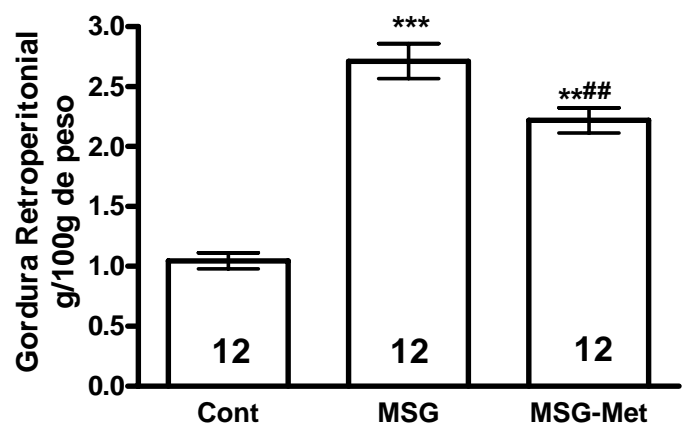

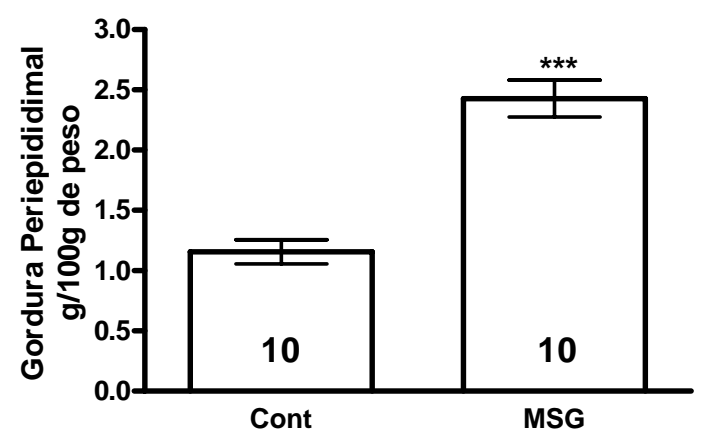

D)

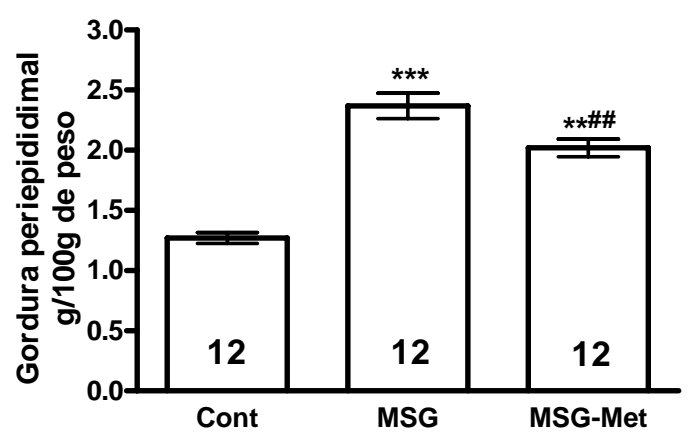

Figura 5 - Peso relativo da gordura retroperitonial e periepididimal dos grupos controle (Cont), obeso-MSG (MSG) com 16 semanas (A e B) e dos grupos Cont e MSG e obeso-MSG tratado com metformina (MSG-Met) com 18 semanas (C e D). Cada barra representa a média \pm epm. O número de ratos utilizados em cada grupo encontra-se dentro das barras.

${ }^{* *} p<0,01$ vs controle; ${ }^{* * *} p<0,001$ vs controle; ${ }^{\# \#} p<0,01$ vs MSG. 
A)

B)
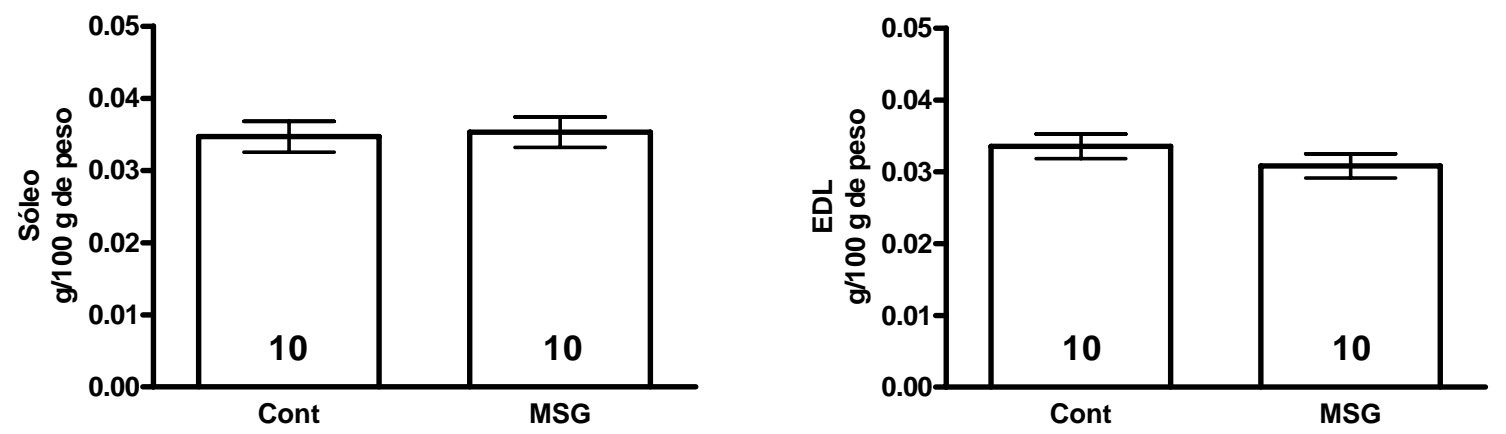

C)

D)
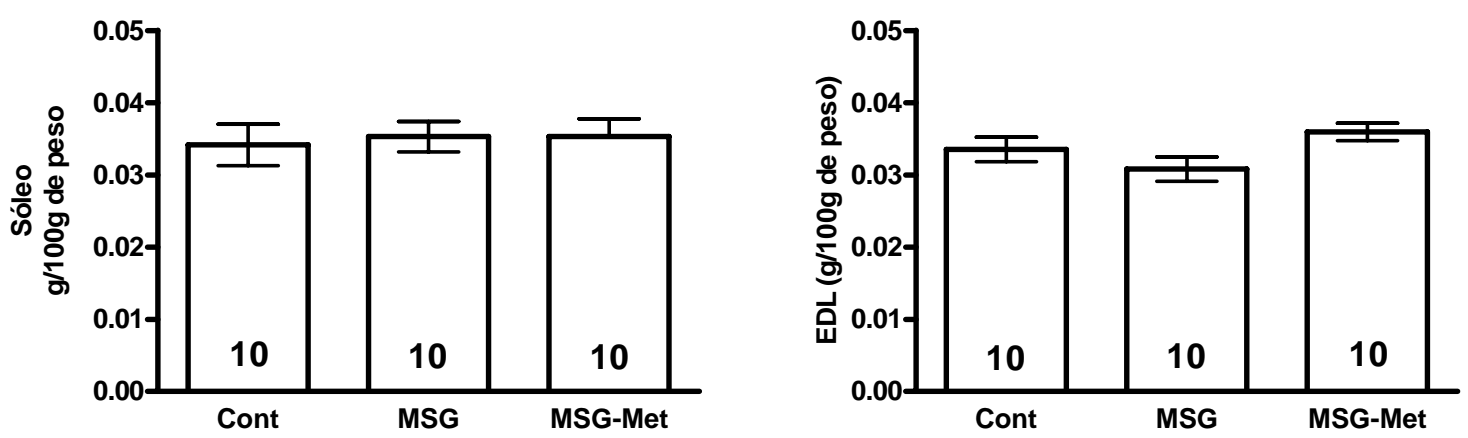

Figura 6 - Peso relativo dos músculos sóleo e EDL (extensor digital longo) dos grupos controle (Cont), obeso-MSG (MSG) com 16 semanas (A e B) e dos grupos Cont e MSG e obeso-MSG tratado com metformina (MSG-Met) com 18 semanas (C e D). Cada barra representa a média \pm epm. O número de ratos utilizados em cada grupo encontra-se dentro das barras. 


\subsection{Evolução Ponderal}

O peso corporal nas primeiras semanas de vida foi semelhante entre os grupos. No entanto, os ratos MSG e MSG-Met apresentaram redução significativa do ganho de peso corporal em relação aos controles, a partir da $9^{a}$ semana após a injeção de MSG até a $18^{\mathrm{a}}$ semana de idade (Figura 7). O peso dos ratos MSG-Met foi significantemente menor quando comparado ao grupo MSG na $18^{\text {a }}$ semana de vida. Os resultados foram expressos em curva de ganho de peso.

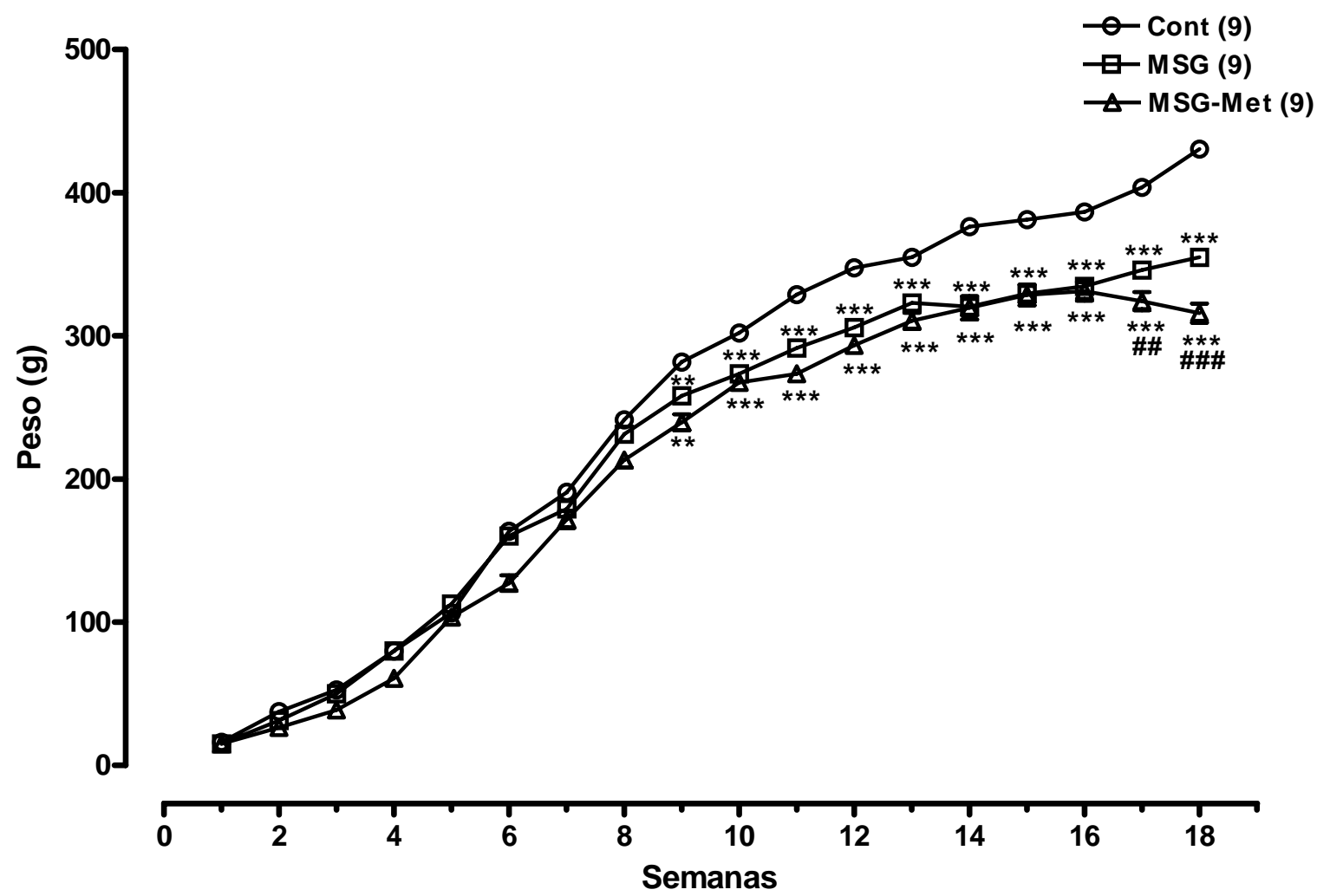

Figura 7 - Curva de ganho de peso dos grupos controle (Cont), obeso-MSG (MSG) e obeso-MSG tratado com metformina (MSG-Met). A medida foi realizada no primeiro dia de cada semana de vida dos ratos. Cada ponto representa a média semanal \pm epm. O número de ratos utilizados em cada grupo encontra-se entre parênteses.

${ }^{* *} p<0,01$ vs controle; ${ }^{* * *} p<0,001$ vs controle; ${ }^{\#} p<0,01$ vs MSG; ${ }^{\# \#} p<0,001$ vs MSG. 


\subsection{Perfil Lipídico}

3.3.1 Dosagem do Colesterol Total, HDL Colesterol, Triglicérides, LDL Colesterol e VLDL Colesterol

Não houve diferença nas concentrações séricas de colesterol total e HDL colesterol entre os grupos Controle e MSG. Entretanto, as concentrações de triglicérides, LDL colesterol e VLDL colesterol estão significativamente aumentadas em ratos MSG com 16 semanas (Tabela 1). Os ratos MSG com 18 semanas de idade apresentaram aumento significativo nos níveis de colesterol total, triglicérides, LDL colesterol e VLDL colesterol quando comparados ao grupo Cont. O tratamento com metformina restaurou todos estes parâmetros. Não houve alteração nos níveis de HDL colesterol entre estes grupos (Tabela 2).

Tabela 1 - Perfil lipídico dos ratos controles e obesos-MSG (MSG) com 16 semanas de idade.

\begin{tabular}{ccc}
\hline \hline & Controle & MSG \\
\hline Colesterol Total & $71,6 \pm 4,3$ & $64,4 \pm 3,2$ \\
& $(8)$ & $(9)$ \\
Triglicérides & $48,8 \pm 11,6$ & $123,8 \pm 18,3^{* *}$ \\
& $(8)$ & $(10)$ \\
HDL-colesterol & $35,6 \pm 2,2$ & $37,4 \pm 1,9$ \\
& $(9)$ & $(9)$ \\
LDL-colesterol & $45,4 \pm 3,8$ & $61,6 \pm 4,8^{*}$ \\
& $(8)$ & $(9)$ \\
VLDL-colesterol & $9,7 \pm 2,3$ & $24,8 \pm 3,6^{* *}$ \\
\hline \hline
\end{tabular}

Cada valor representa a média \pm epm.

O número de ratos utilizados em cada grupo encontra-se entre parênteses.

${ }^{*} p<0,05$ vs Cont, ${ }^{* *} p<0,01$ vs Cont. 
Tabela 2 - Perfil lipídico dos ratos controles e obesos-MSG (MSG) e obesos-MSG tratados com metformina com 18 semanas de idade.

\begin{tabular}{cccc}
\hline \hline & Cont & MSG & MSG-Met \\
\hline Colesterol Total & $74,8 \pm 4,2$ & $108,7 \pm 8,0^{* *}$ & $59,8 \pm 3,1$ \\
& $(6)$ & $(6)$ & $(6)$ \\
Triglicérides & $40,7 \pm 8,0$ & $124,7 \pm 9,9^{* * *}$ & $68,6 \pm 10,0$ \\
& $(7)$ & $(7)$ & $(7)$ \\
HDL-colesterol & $43,4 \pm 2,0$ & $35,2 \pm 2,8$ & $44,0 \pm 2,1$ \\
& $(7)$ & $(7)$ & $(7)$ \\
LDL-colesterol & $48,5 \pm 2,9$ & $74,0 \pm 4,6^{* *}$ & $50,6 \pm 6,1$ \\
& $(7)$ & $(7)$ & $(7)$ \\
VLDL-colesterol & $7,6 \pm 1,5$ & $24,4 \pm 2,0^{* * *}$ & $13,6 \pm 2,6$ \\
& $(7)$ & $(7)$ & $(7)$ \\
\hline \hline
\end{tabular}

Cada valor representa a média \pm epm.

O número de ratos utilizados em cada grupo encontra-se entre parênteses.

${ }^{* *} p<0,01$ vs controle e MSG-Met; ${ }^{* *} p<0,001$ vs controle e MSG-Met. 


\subsection{Determinação das Concentrações de Glicose e Insulina}

A glicemia basal após privação alimentar de 4 horas foi semelhante entre os grupos Cont e MSG com 16 semanas, porém, a concentração de insulina no soro dos ratos MSG foi significantemente maior quando comparada à do grupo Cont (Figura 8A e C). Estas características se mantiveram entre os grupos Controle e MSG com 18 semanas, e o tratamento com metformina corrigiu a hiperinsulinemia no grupo MSG (Figura 8B e D).

A)

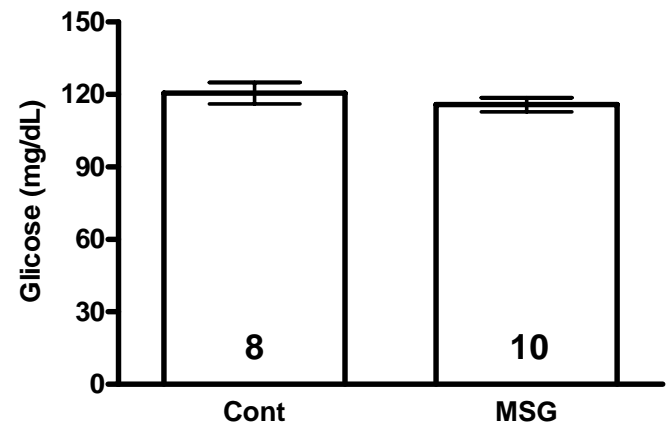

C)

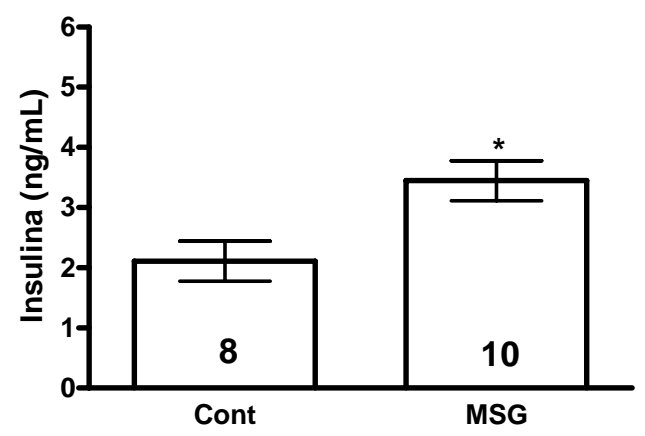

B)

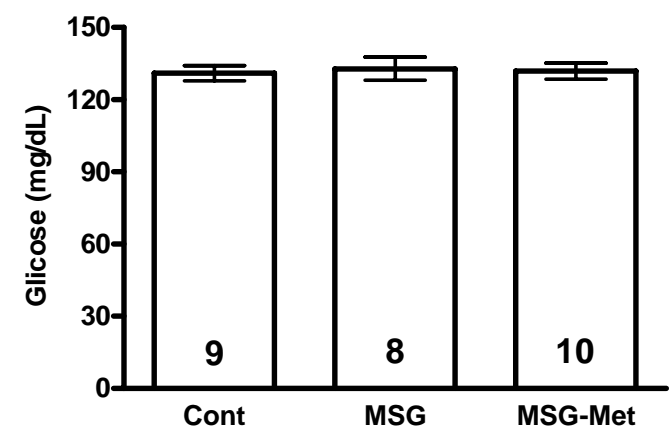

D)

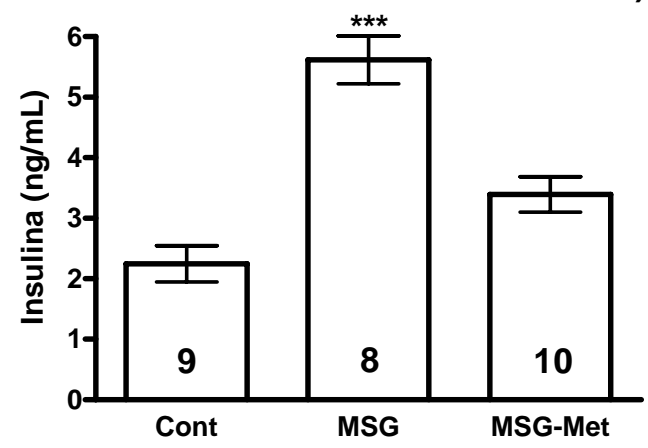

Figura 8 - Dosagem de glicose e insulina dos grupos controle (Cont), obeso-MSG (MSG) com 16 semanas (A e C) e dos grupos Cont, MSG e obeso-MSG tratado com metformina (MSG-Met) com 18 semanas (B e D). Os ratos submetidos ao teste estavam em restrição alimentar prévia de 4 horas (07:00 - 11:00). Cada ponto representa a média \pm epm. O número de ratos utilizados em cada grupo encontra-se dentro das barras.

${ }^{*} p<0,05$ vs Cont; ${ }^{* * *} p<0,001$ vs Cont e MSG-Met. 


\subsection{Avaliação da Sensibilidade à Insulina e da Capacidade Secretória Pancreática}

Os ratos MSG com 16 semanas apresentaram resistência à insulina, avaliada através do índice HOMA-IR, associada com aumento da capacidade secretória pancreática, estimada pelo HOMA- $\beta$ (Figura 9A e B), quando comparados ao grupo Cont. Resultados semelhantes foram observados com os grupos de 18 semanas e o tratamento com metformina corrigiu a resistência à insulina e restaurou a função pancreática no grupo MSG-Met (Figura 9C e D).

A)

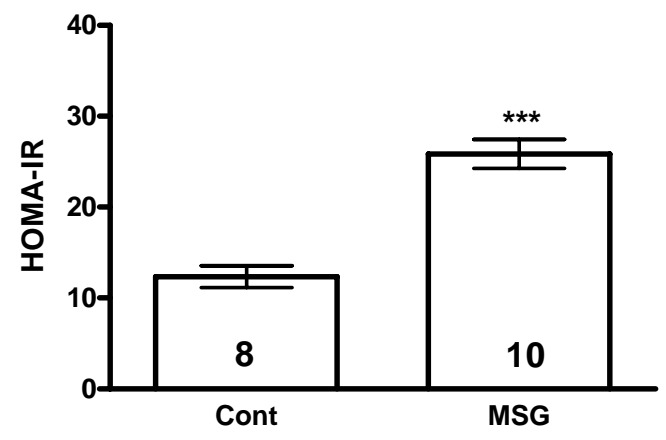

C)

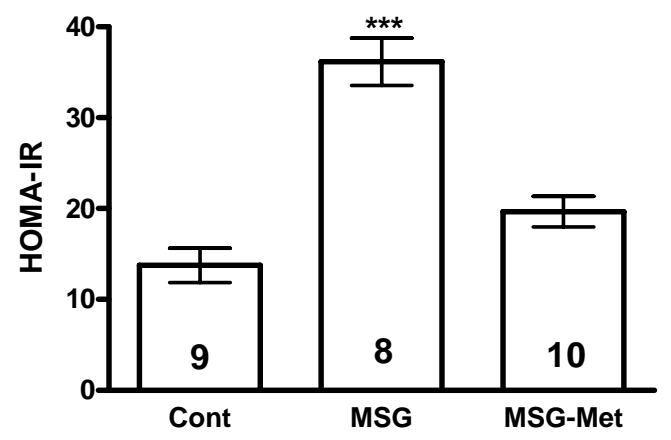

B)

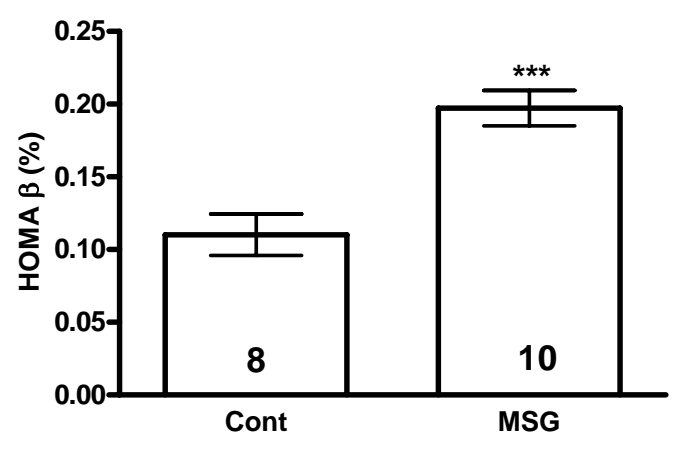

D)

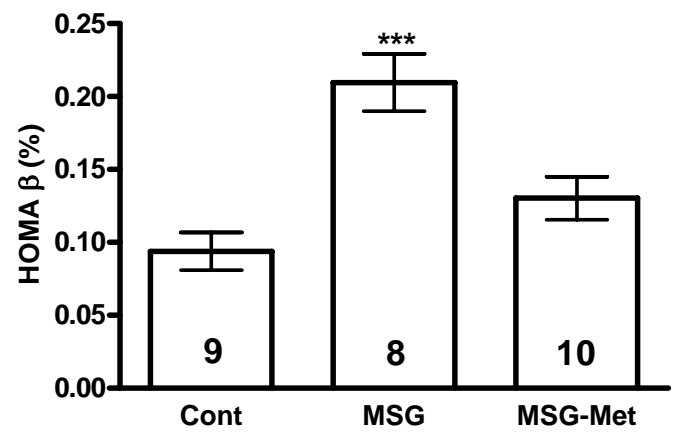

Figura 9 - Índices HOMA-IR e HOMA- $\beta$ obtidos a partir das glicemias e insulinemias em jejum dos grupos controle (Cont), obeso-MSG (MSG) com 16 semanas (A) e dos grupos Cont, MSG e obeso-MSG tratado com metformina (MSG-Met) com 18 semanas (B). Cada barra representa a média \pm epm. O número de ratos utilizados em cada grupo encontra-se dentro das barras.

${ }^{* * *} p<0,001$ vs controle e MSG-Met. 


\subsection{Avaliação da Tolerância à Glicose}

No teste de tolerância à glicose endovenoso, a glicemia basal T0 (antes da injeção intravenosa de glicose-0,75 mg/kg) não diferiu entre os grupos Cont e MSG com 16 semanas bem como entre os grupos com 18 semans de idade. O pico máximo de glicemia ocorreu após 5 minutos da sobrecarga de glicose, com um declínio nas concentrações sanguíneas após este tempo (T5). A área sob a curva da concentração de glicose sanguínea foi semelhante entre os grupos Controle e MSG com 16 semanas (Figura 10A e B). Por outro lado, os ratos do grupo MSG com 18 semanas de idade apresentaram aumento significativo da área sob a curva da concentração de glicose sanguínea e o tratamento com metformina não corrigiu esta alteração (Figura 10C e D).

A)

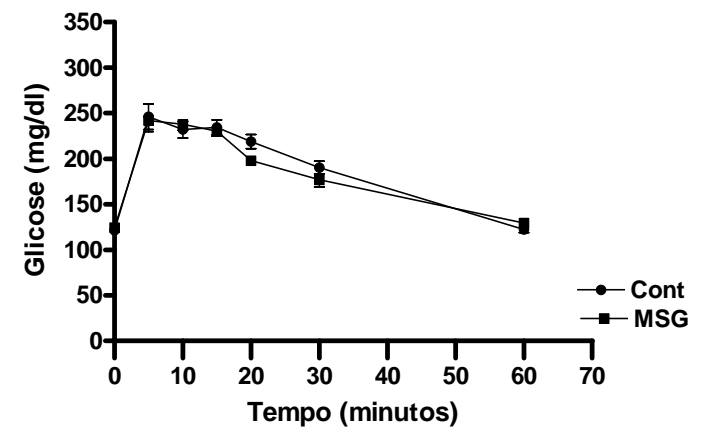

C)

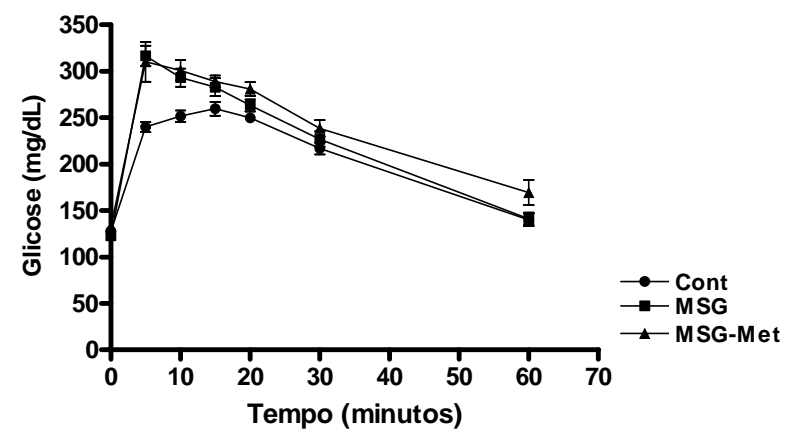

B)

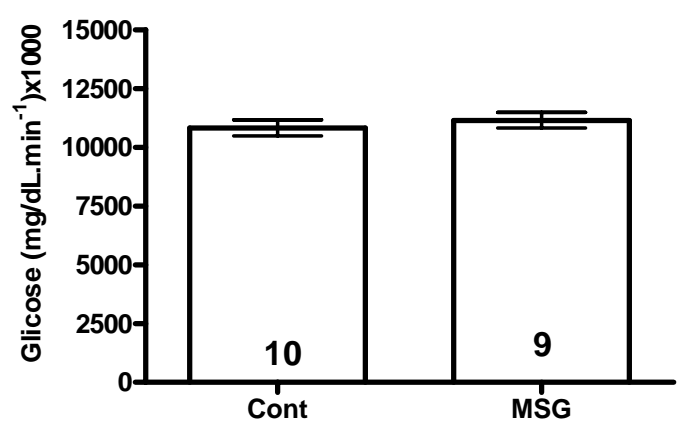

D)

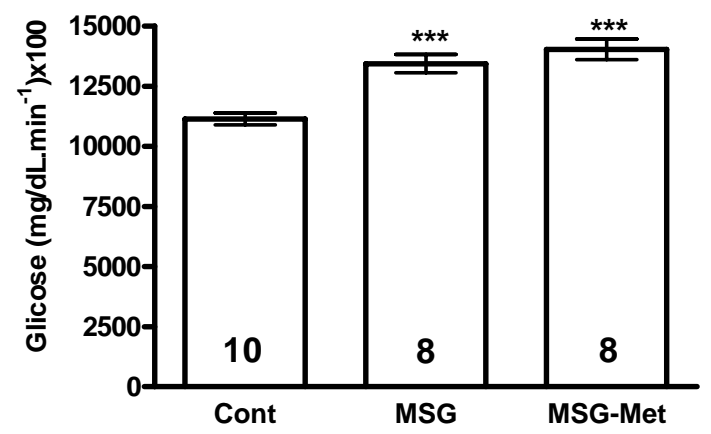

Figura 10 - Curvas Glicêmicas e área sob a curva, obtidas no teste de tolerância à glicose intravenoso (IVGTT) dos grupos controle (Cont), obeso-MSG (MSG) com 16 semanas (A e B) e dos grupos Cont, MSG e obeso-MSG tratado com metformina (MSG-Met) com 18 semanas (C e D). Os ratos submetidos ao teste receberam sobrecarga de glicose $(750 \mathrm{mg} / \mathrm{kg}$ de peso corporal, IV) após restrição alimentar prévia de 5 horas $(07: 00$ - 12:00). Cada ponto representa a média $\pm \mathrm{epm}$. O número de ratos utilizados em cada grupo encontra-se dentro das barras.

${ }^{* * *} p<0,001$ vs Cont. 


\subsection{Pressão Arterial Caudal e Freqüencia Cardíaca}

Não houve diferença significativa nos níveis de pressão arterial e freqüência cardíaca entre os ratos MSG e controles com 16, semelhantemente ao observado nos grupos com 18 semanas de idade (Tabela 3 ).

Tabela 3 - Medida da pressão arterial (PA) e freqüência cardíaca ( $F C$ ) nos ratos controles, obesos-MSG (MSG) com 16 semanas, e dos controles, obesos-MSG (MSG) e MSG tratados com metformina (MSG-Met) com 18 semanas de idade.

\begin{tabular}{|c|c|c|c|c|c|c|}
\hline & \multicolumn{2}{|c|}{ Controle } & \multicolumn{2}{|c|}{ MSG } & \multicolumn{2}{|c|}{ MSG-Met } \\
\hline & $\mathrm{PA}(\mathrm{mmHg})$ & FC (bpm) & PA (mmHg) & FC (bpm) & PA (mmHg) & FC (bpm) \\
\hline $\begin{array}{c}16 \\
\text { semanas }\end{array}$ & $\begin{array}{c}113,2 \pm 1,5 \\
(10)\end{array}$ & $\begin{array}{c}319,6 \pm 7,3 \\
(10)\end{array}$ & $\begin{array}{c}108,0 \pm 2,7 \\
(10)\end{array}$ & $\begin{array}{c}326,0 \pm 16,4 \\
(10)\end{array}$ & - & - \\
\hline $\begin{array}{c}18 \\
\text { semanas }\end{array}$ & $\begin{array}{c}115,5 \pm 1,8 \\
(10)\end{array}$ & $\begin{array}{c}328,1 \pm 2,4 \\
(10)\end{array}$ & $\begin{array}{c}122,3 \pm 2,3 \\
(10)\end{array}$ & $\begin{array}{c}348,3 \pm 12,8 \\
(10)\end{array}$ & $\begin{array}{c}117,9 \pm 1,6 \\
(10)\end{array}$ & $\begin{array}{c}324,8 \pm 7,0 \\
(10)\end{array}$ \\
\hline
\end{tabular}




\subsection{Reatividade do Leito Arteriolar Mesentérico Isolado e Perfundido}

Para manter uma visualização clara dos gráficos, optamos por não representar as diferenças estatísticas entre os grupos nas curvas concentraçãoefeito. Tais diferenças estão representadas nos gráficos de barra e nas tabelas.

\subsubsection{Avaliação da Resposta Vasoconstritora ao Cloreto de Potássio}

A resposta vasoconstritora induzida pelo $\mathrm{KCL}$ foi de similar magnitude no leito arteriolar mesentérico dos grupos estudados com 16 (Figura 11, Tabela 4), bem como com 18 semanas de idade. O tratamento com metformina não interferiu nesta resposta (Figura $12 \mathrm{~B}$, Tabela 5).

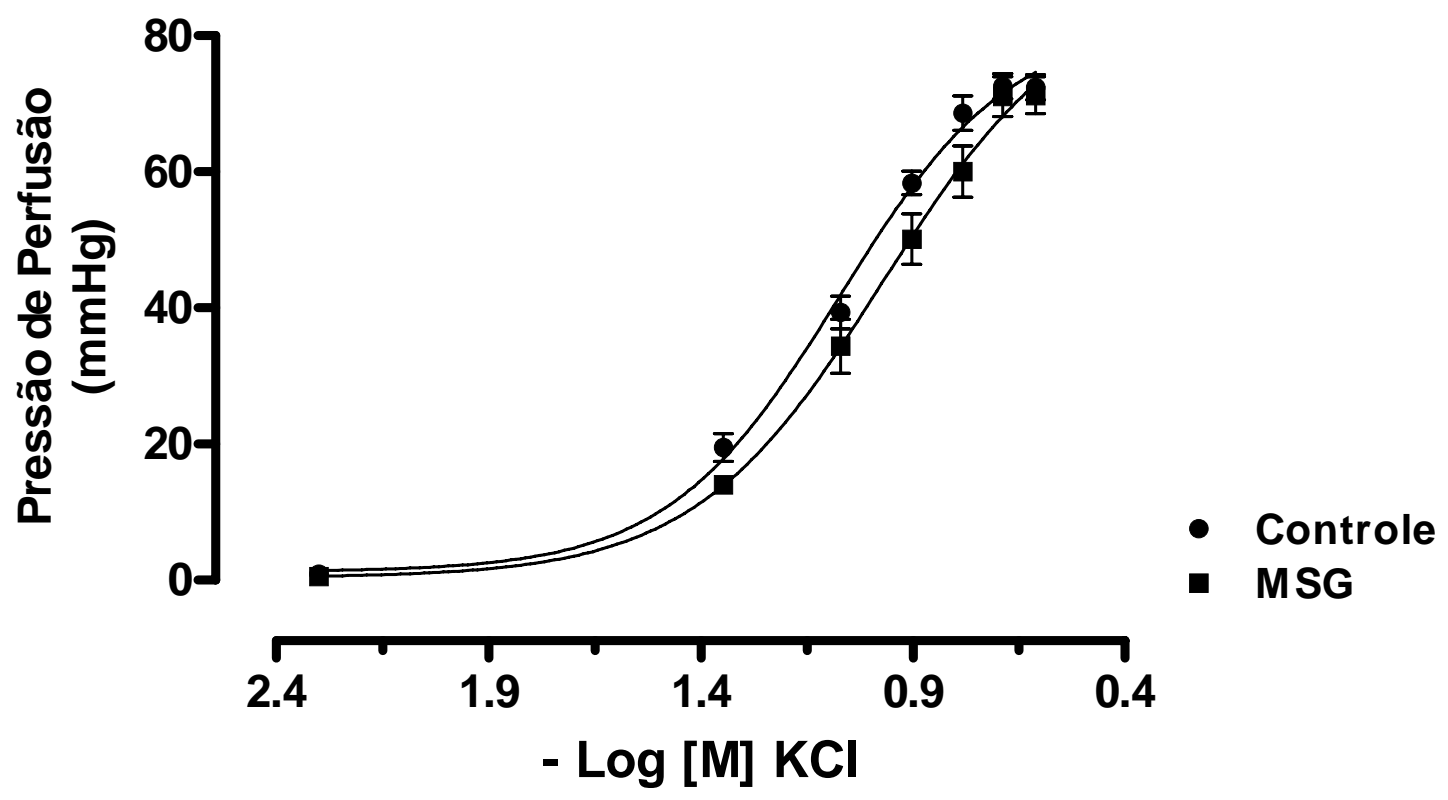

Figura 11 - Curva concentração-efeito para o cloreto de potássio (KCL) no leito arteriolar mesentérico isolado de ratos Wistar controles (Cont), e obesos-MSG (MSG) com 16 semanas de idade. Cada ponto representa a média \pm epm. 
Tabela 4 - Resposta máxima e sensibilidade ao cloreto de potássio (KCL) no leito arteriolar mesentérico de ratos controles e obesos-MSG (MSG) com 16 semanas de idade.

\begin{tabular}{ccccc}
\hline \hline & \multicolumn{3}{c}{ Controle } & \multicolumn{2}{c}{ MSG } \\
\hline & $\mathrm{R}_{\mathrm{MAX}}$ & $\mathrm{pD}_{2}$ & $\mathrm{R}_{\mathrm{MAX}}$ & $\mathrm{pD}_{2}$ \\
& $79,8 \pm 2,9$ & $1,07 \pm 0,04$ & $83,2 \pm 2,1$ & $0,96 \pm 0,05$ \\
$\mathrm{KCL}$ & $(7)$ & $(7)$ & $(7)$ & $(7)$ \\
\hline \hline
\end{tabular}

Os valores de $R_{\text {MAX }}$ (Resposta máxima) representam a média \pm epm.

EC50- concentração que promove $50 \%$ da $\mathrm{R}_{\mathrm{MAX}}$.

O número de ratos utilizados em cada grupo encontra-se entre parênteses. 


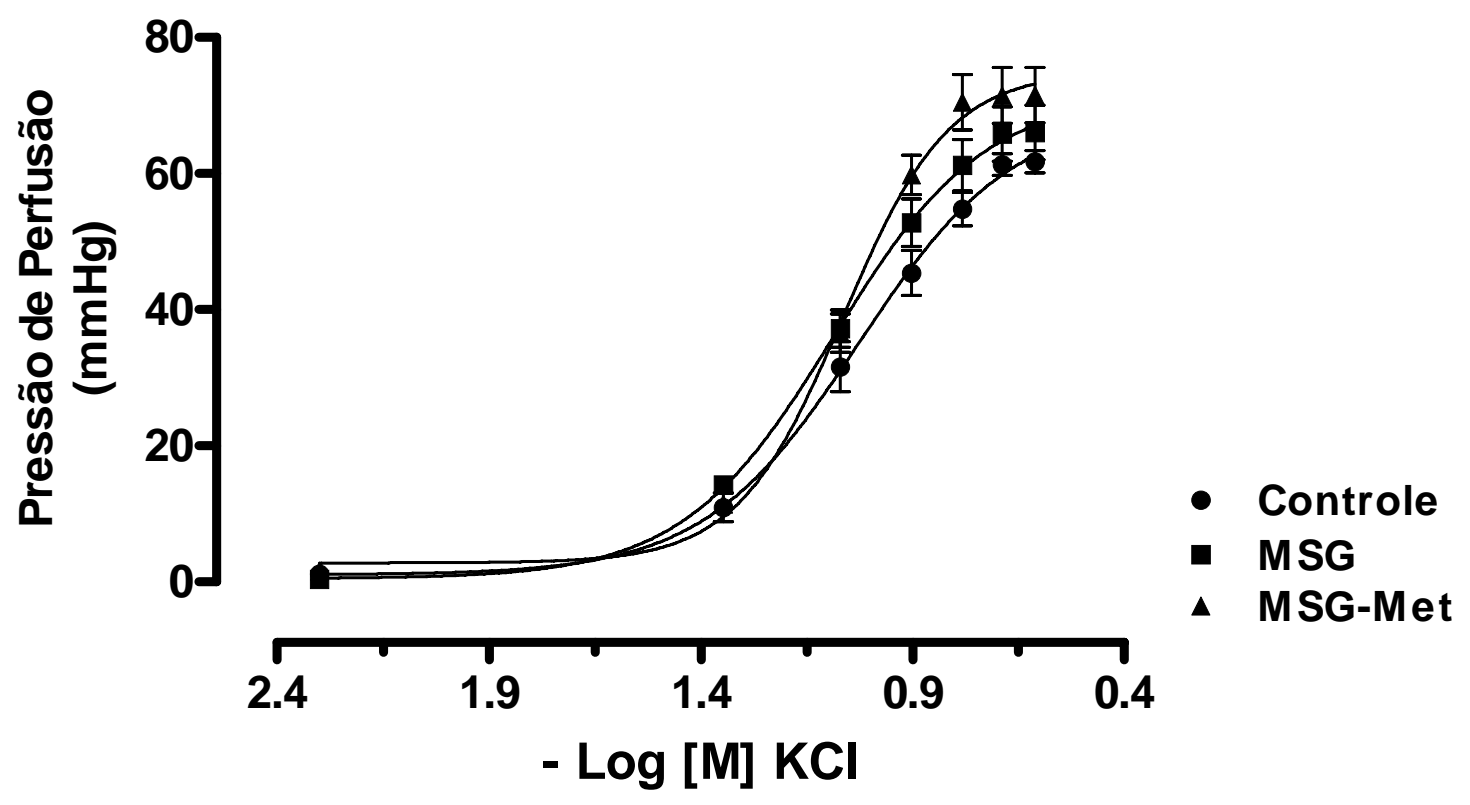

Figura 12 - Curva concentração-efeito para o cloreto de potássio (KCL) no leito arteriolar mesentérico isolado de ratos Wistar controles (Cont), obesos-MSG (MSG) e MSG tratados com metformina (MSG-Met) com 18 semanas de idade. Cada ponto representa a média \pm epm. 
Tabela 5 - Resposta máxima e sensibilidade ao cloreto de potássio (KCL) no leito arteriolar mesentérico de ratos controles, obesos-MSG (MSG) e MSG tratados com metformina (MSG-Met) com 18 semanas de idade.

\begin{tabular}{ccccccc}
\hline \hline & \multicolumn{2}{c}{ Controle } & \multicolumn{2}{c}{ MSG } & \multicolumn{2}{c}{ MSG-Met } \\
\hline & $\mathrm{R}_{\mathrm{MAX}}$ & $\mathrm{pD}_{2}$ & $\mathrm{R}_{\mathrm{MAX}}$ & $\mathrm{pD}_{2}$ & $\mathrm{R}_{\mathrm{MAX}}$ & $\mathrm{pD}_{2}$ \\
$\mathrm{KCL}$ & $75,2 \pm 4,1$ & $0,99 \pm 0,04$ & $76,2 \pm 5,7$ & $1,05 \pm 0,05$ & $78,6 \pm 6,1$ & $1,06 \pm 0,03$ \\
& $(7)$ & & $(7)$ & $(7)$ & $(7)$ & $(7)$ \\
\hline \hline
\end{tabular}

Os valores de $\mathrm{R}_{\mathrm{MAX}}$ (Resposta máxima) representam a média \pm epm.

EC50- concentração que promove $50 \%$ da $\mathrm{R}_{\mathrm{MAX}}$.

$\mathrm{O}$ número de ratos utilizados em cada grupo encontra-se entre parênteses. 


\subsubsection{Avaliação da Resposta Vasoconstritora à Noradrenalina}

O leito arteriolar mesentérico dos ratos MSG apresentou aumento da resposta máxima contrátil à NA quando comparado ao grupo Controle com 16 semanas de idade (Figura 13A e B, Tabela 6). Esta alteração se manteve nos ratos MSG com 18 semanas e foi corrigida pelo tratamento com metformina (Figura 14A e B, Tabela 7).

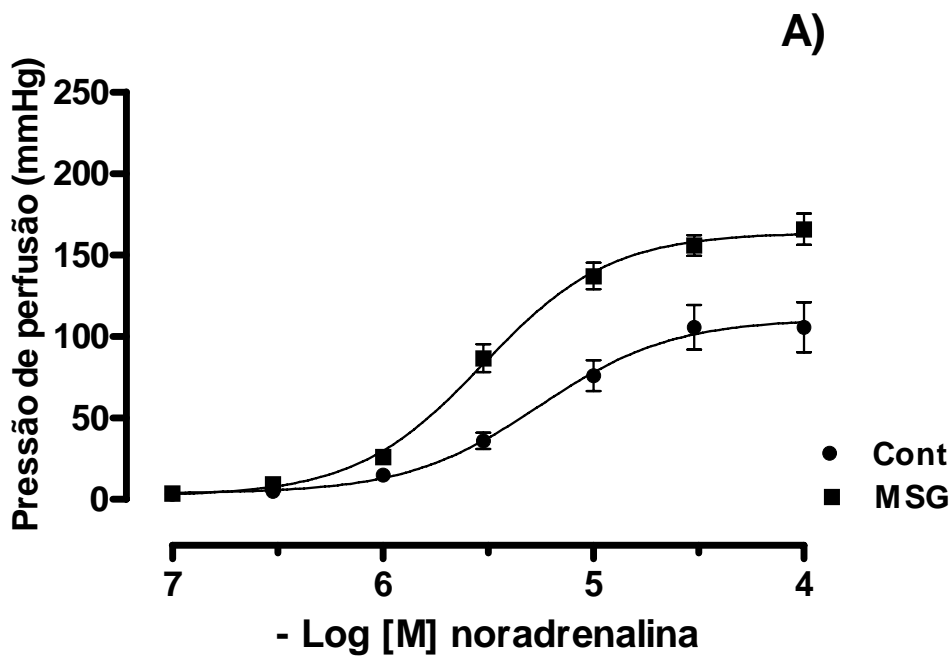

B)

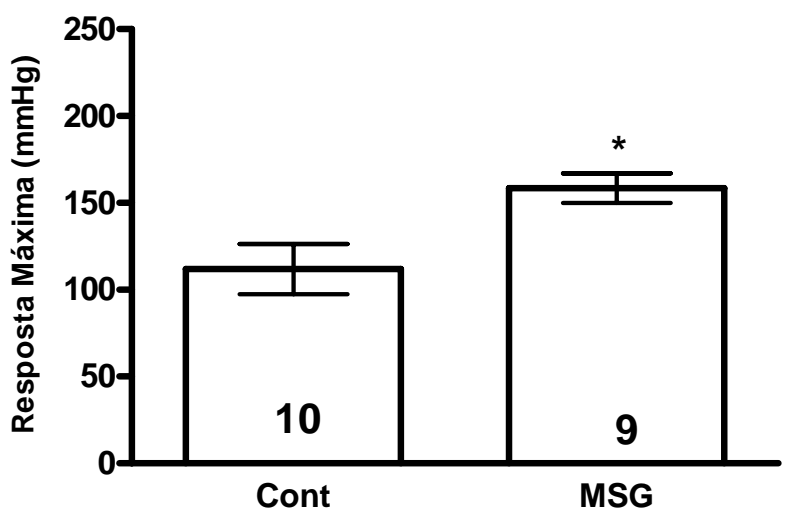

Figura 13 - Curva concentração-efeito (A) e resposta máxima (B) para noradrenalina no leito arteriolar mesentérico isolado de ratos Wistar controles (Cont), e obesosMSG (MSG) com 16 semanas de idade. Cada ponto representa a média \pm epm. O número de ratos utilizados em cada grupo encontra-se no interior das barras. ${ }^{*} p<0,05$ vs Cont. Os sinais de significância foram omitidos nos gráficos por motivo de clareza. As diferenças estão representadas no diagrama de barras. 
Tabela 6 - Valores de resposta máxima à noradrenalina (NA) do leito arteriolar mesentérico de ratos controles e obesos-MSG (MSG) com 16 semanas de idade.

\begin{tabular}{ccccc}
\hline \hline \multicolumn{2}{c}{ Controle } & & \multicolumn{2}{c}{ MSG } \\
\hline & $\mathrm{R}_{\mathrm{MAX}}$ & $\mathrm{pD}_{2}$ & $\mathrm{R}_{\mathrm{MAX}}$ & $\mathrm{pD}_{2}$ \\
NA & $107,2 \pm 13,6$ & $\mathrm{ND}$ & $156,2 \pm 9,0^{*}$ & $\mathrm{ND}$ \\
& $(10)$ & & $(9)$ & \\
& & & & \\
\hline \hline
\end{tabular}

Os valores de $R_{\text {MAX }}$ (Resposta máxima) representam a média \pm epm.

$\mathrm{ND}=$ não foi determinada o pD2 por ter havido diferença significativa na resposta máxima. O número de ratos utilizados em cada grupo encontra-se entre parênteses. * $p<0,05$ vs Controle; 


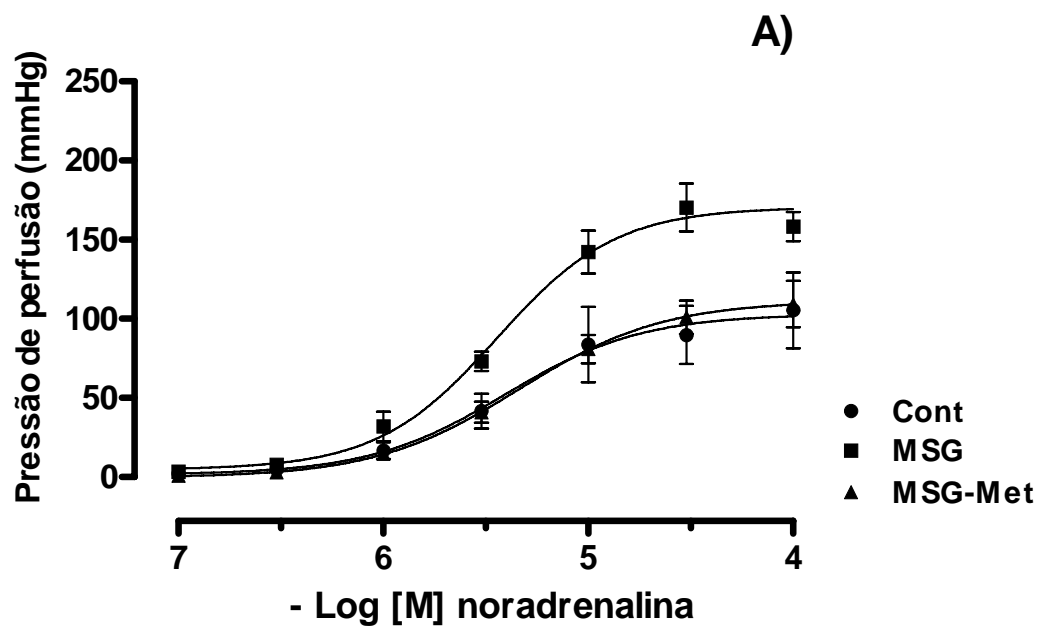

B)

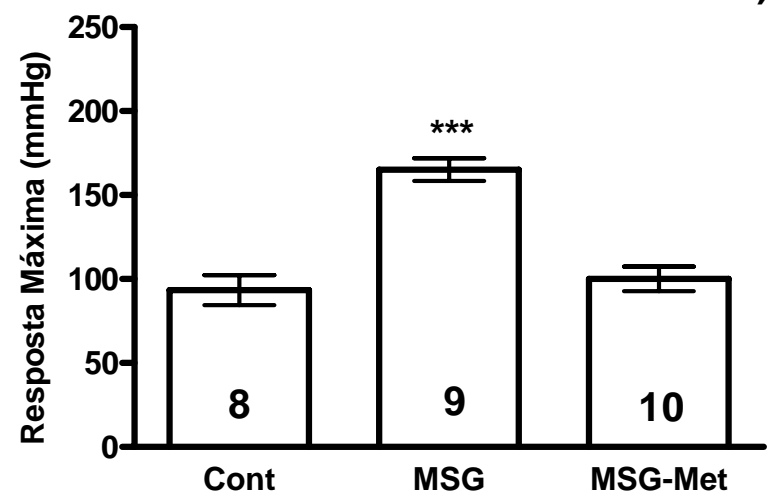

Figura 14 - Curva concentração-efeito (A) e resposta máxima (B) para noradrenalina no leito arteriolar mesentérico isolado de ratos Wistar controles (Cont), obesosMSG (MSG) e MSG tratados com metformina (MSG-Met) com 18 semanas de idade. Cada ponto representa a média \pm epm. O número de ratos utilizados em cada grupo encontra-se dentro das barras.

${ }^{* * *} p<0,001$ vs Cont e MSG-Met.

Os sinais de significância foram omitidos nos gráficos por motivo de clareza. As diferenças estão representadas no diagrama de barras. 
Tabela 7 - Valores de resposta máxima à noradrenalina (NA) do leito arteriolar mesentérico de ratos controles, obesos-MSG (MSG) e MSG tratados com metformina (MSGMet) com 18 semanas de idade.

\begin{tabular}{ccccccc}
\hline \hline & \multicolumn{2}{c}{ Controle } & \multicolumn{2}{c}{ MSG } & \multicolumn{2}{c}{ MSG-Met } \\
& $\mathrm{R}_{\mathrm{MAX}}$ & $\mathrm{pD}_{2}$ & $\mathrm{R}_{\mathrm{MAX}}$ & $\mathrm{pD}_{2}$ & $\mathrm{R}_{\mathrm{MAX}}$ & $\mathrm{pD}_{2}$ \\
& & & & & & \\
NA & $93,4 \pm 9,0$ & $\mathrm{ND}$ & $165,1 \pm 6,8^{* \star *}$ & $\mathrm{ND}$ & $100,0 \pm 7,3$ & $\mathrm{ND}$ \\
& $(8)$ & & $(9)$ & & $(10)$ & \\
\hline \hline
\end{tabular}

Os valores de $\mathrm{R}_{\mathrm{MAX}}$ (Resposta máxima) representam a média \pm epm.

$\mathrm{ND}=$ não foi determinada o pD2 por ter havido diferença significativa na resposta máxima.

$\mathrm{O}$ número de ratos utilizados em cada grupo encontra- se dentro das barras.

${ }^{* * *} p<0,001$ vs Controle e MSG-Met. 
3.8.3 Papel do Óxido Nítrico na Modulação da Resposta Vasoconstritora à Noradrenalina

O aumento da resposta contrátil à NA manteve-se nos ratos MSG com 16 semanas após o bloqueio da síntese de NO com L-NAME (Figura 15A e B, Tabela 8), de modo semelhante ao observado nos ratos MSG com 18 semanas de idade. A correção promovida pela metformina foi revertida na presença deste bloqueio. (Figura 16A e B, Tabela 9).

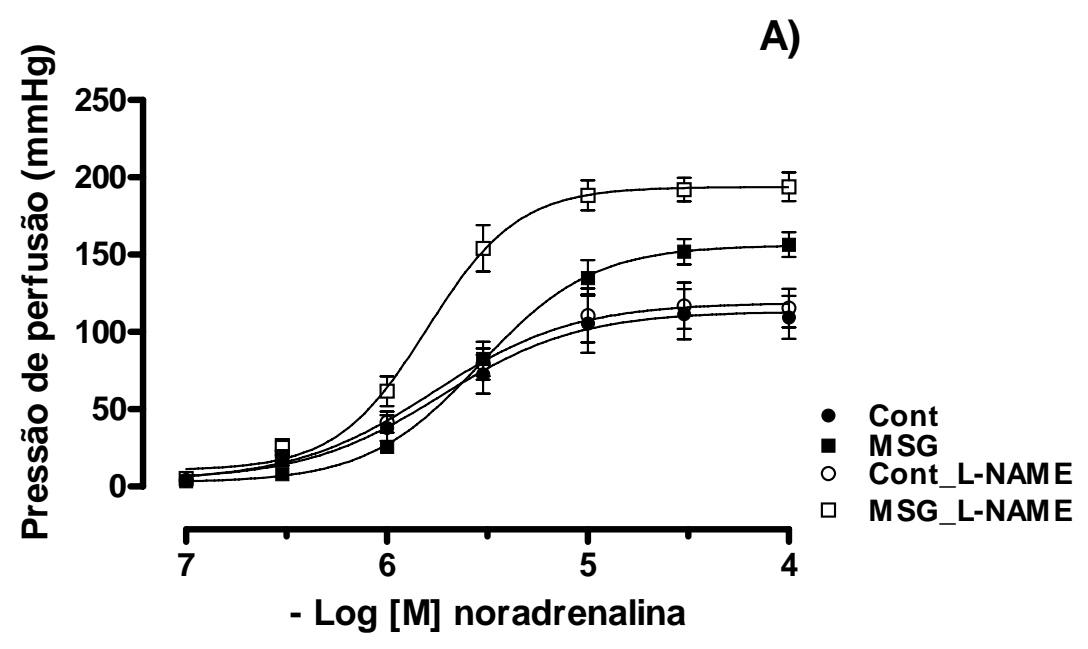

B)

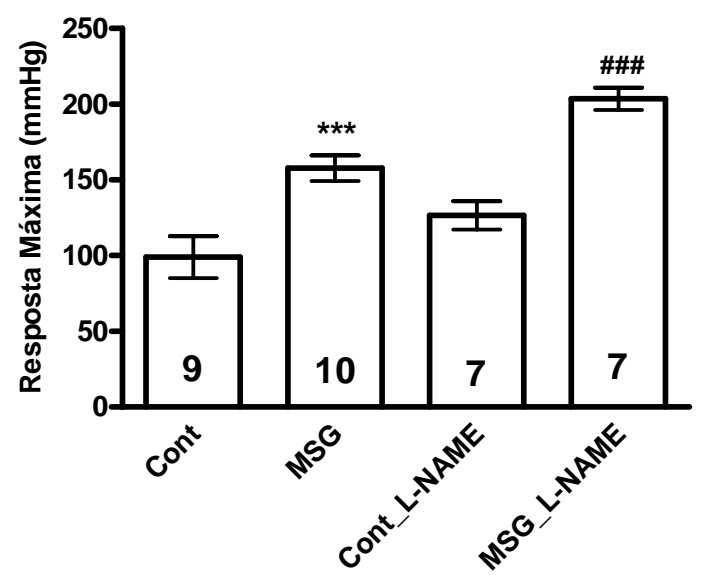

Figura 15 - Curva concentração-efeito (A) e resposta máxima vasoconstritora para noradrenalina (B) com e sem o bloqueio da síntese de óxido nítrico com LNAME $(100 \mu \mathrm{M})$ no leito arteriolar mesentérico isolado de ratos Wistar controles (Cont) e obesos-MSG (MSG) com 16 semanas de idade. Cada ponto representa a média $\pm \mathrm{epm}$. $\mathrm{O}$ número de ratos utilizados em cada grupo encontra-se dentro das barras. " $p<0,001$ vs Cont; $p<0,001$ vs Cont_L-NAME. Os sinais de significância foram omitidos nos gráficos por motivo de clareza. As diferenças estão representadas no diagrama de barras. 


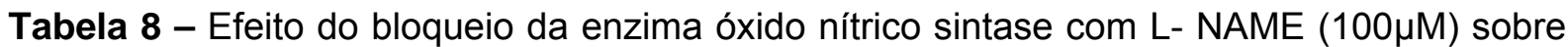
a resposta máxima à noradrenalina (NA) no leito arteriolar mesentérico de ratos controles e obesos-MSG (MSG) com 16 semanas de idade.

\begin{tabular}{ccccc}
\hline \hline \multicolumn{4}{c}{ Controle } & \multicolumn{3}{c}{ MSG } \\
\hline NA & $\mathrm{R}_{\mathrm{MAX}}$ & $\mathrm{pD}_{2}$ & $\mathrm{R}_{\mathrm{MAX}}$ & $\mathrm{pD}_{2}$ \\
& $99,03 \pm 13,9$ & $\mathrm{ND}$ & $157,8 \pm 8,4^{* * *}$ & $\mathrm{ND}$ \\
$\mathrm{NA}$ & $(9)$ & & $(10)$ & \\
+ & $126,6 \pm 9,4$ & $\mathrm{ND}$ & $203,6 \pm 7,4^{\# \# \#}$ & $\mathrm{ND}$ \\
L-NAME & $(7)$ & & $(7)$ & \\
\hline \hline
\end{tabular}

Os valores de $R_{\text {MAX }}$ (Resposta máxima) representam a média \pm epm.

$\mathrm{ND}=$ não foi determinada o pD2 por ter havido diferença significativa na resposta máxima. $\mathrm{O}$ número de ratos utilizados em cada grupo encontra-se entre parênteses.

$p<0,001$ vs Controle; ${ }^{\# \#} p<0,001$ vs Cont_L-NAME. 


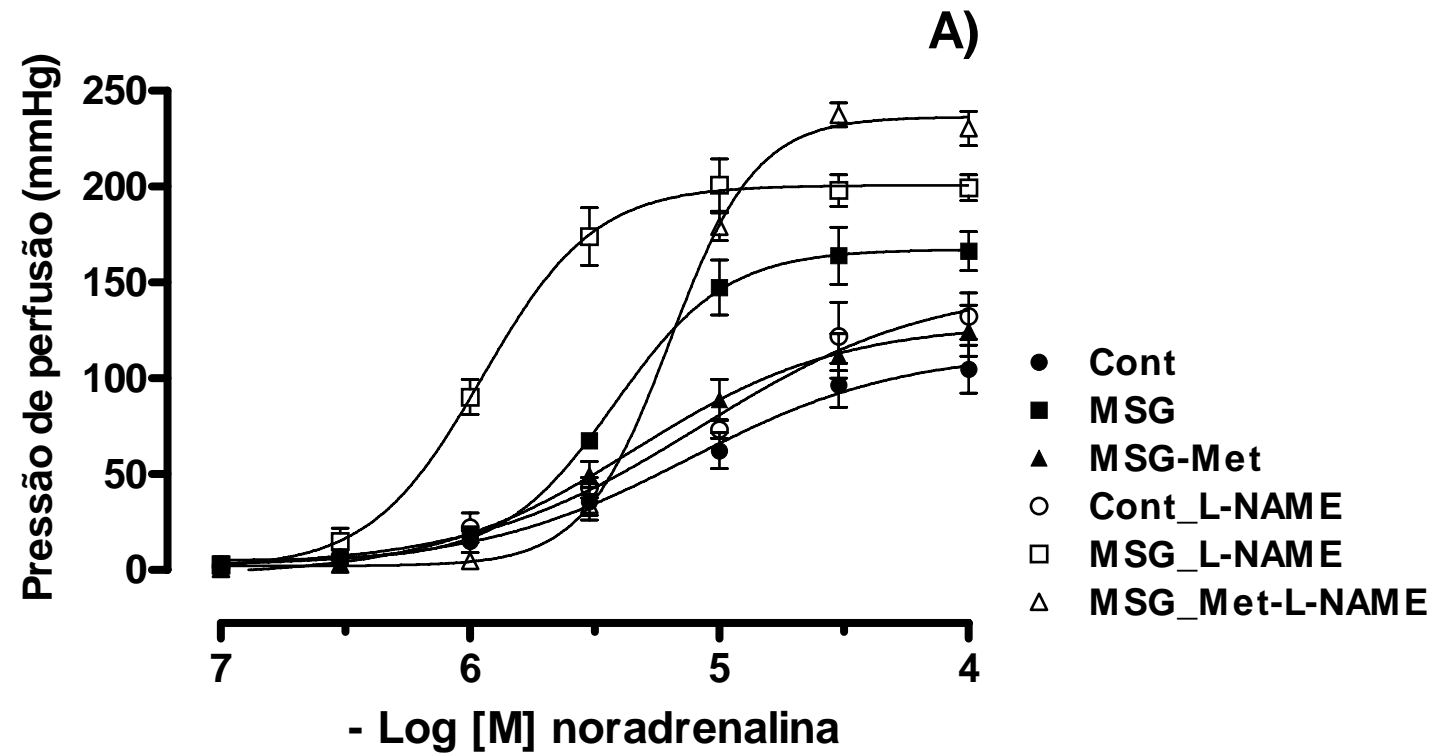

B)

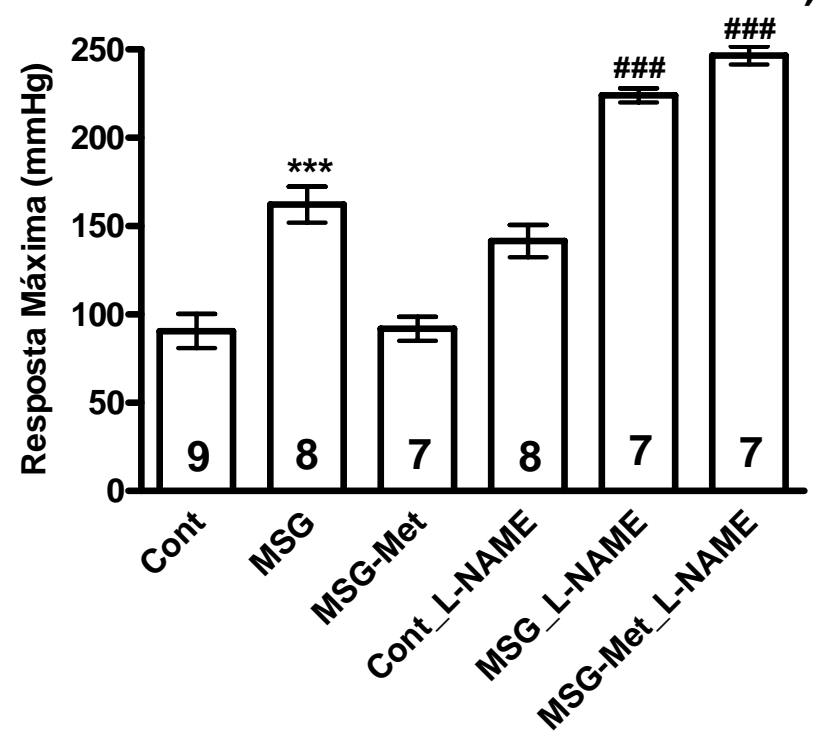

Figura 16 - Curva concentração-efeito (A) e resposta máxima vasoconstritora para noradrenalina (B) com e sem o bloqueio da síntese de óxido nítrico com LNAME $(100 \mu \mathrm{M})$ no leito arteriolar mesentérico isolado de ratos Wistar controles (Cont), obesos-MSG (MSG) e MSG tratados com metformina (MSGMet) com 18 semanas de idade. Cada ponto representa a média \pm epm. $O$ número de ratos utilizados em cada grupo encontra-se dentro das barras. ${ }^{* * *} p<0,001$ vs Cont e MSG-Met; ${ }^{\# \# \# ~} p<0,001$ vs Cont_L-NAME.

Os sinais de significância foram omitidos nos gráficos por motivo de clareza. As diferenças estão representadas no diagrama de barras. 
Tabela 9 - Efeito do bloqueio da enzima óxido nítrico sintase com L- NAME (10 $\mu \mathrm{M})$ sobre a resposta máxima à noradrenalina (NA) no leito arteriolar mesentérico de ratos controles, obesos-MSG (MSG) e MSG tratados com metformina (MSG-Met) com 18 semanas de idade.

\begin{tabular}{ccccccc}
\hline \hline & \multicolumn{2}{c}{ Controle } & MSG & \multicolumn{2}{c}{ MSG-Met } \\
\hline & $\mathrm{R}_{\mathrm{MAX}}$ & $\mathrm{pD}_{2}$ & $\mathrm{R}_{\mathrm{MAX}}$ & $\mathrm{pD}_{2}$ & $\mathrm{R}_{\mathrm{MAX}}$ & $\mathrm{pD}_{2}$ \\
$\mathrm{NA}$ & $90,6 \pm 9,7$ & $\mathrm{ND}$ & $162,2 \pm 10,2^{* * *}$ & $\mathrm{ND}$ & $91,9 \pm 6,7$ & $\mathrm{ND}$ \\
& $(9)$ & & $(8)$ & & $(7)$ & \\
NA & $141,6 \pm 9,1$ & $\mathrm{ND}$ & $224,1 \pm 4,0^{\# \#}$ & $\mathrm{ND}$ & $246,7 \pm 5,2^{\# \#}$ & $\mathrm{ND}$ \\
+ & $(8)$ & & $(7)$ & & $(7)$ & \\
L-NAME & & & & & & \\
\hline \hline
\end{tabular}

Os valores de $R_{\text {MAX }}$ (Resposta máxima) representam a média \pm epm.

$\mathrm{ND}=$ não foi determinada o pD2 por ter havido diferença significativa na resposta máxima. $\mathrm{O}$ número de ratos utilizados em cada grupo encontra-se entre parênteses.

${ }^{* *} p<0,001$ vs Cont e MSG-Met; ${ }^{\# \#} p<0,001$ vs Cont_L-NAME. 
3.8.4 Papel dos Canais de Potássio na Modulação da Resposta Vasoconstritora à Noradrenalina

$\mathrm{O}$ bloqueio dos canais de $\mathrm{K}^{+}$com TEA manteve o aumento da resposta contrátil à NA nos ratos MSG com 16 semanas (Figura 17A e B, Tabela 10). Resultado semelhante foi observado no grupo de 18 semanas, com a correção promovida pela metformina sendo revertida na presença deste bloqueio (Figura 18A e B, Tabela 11).

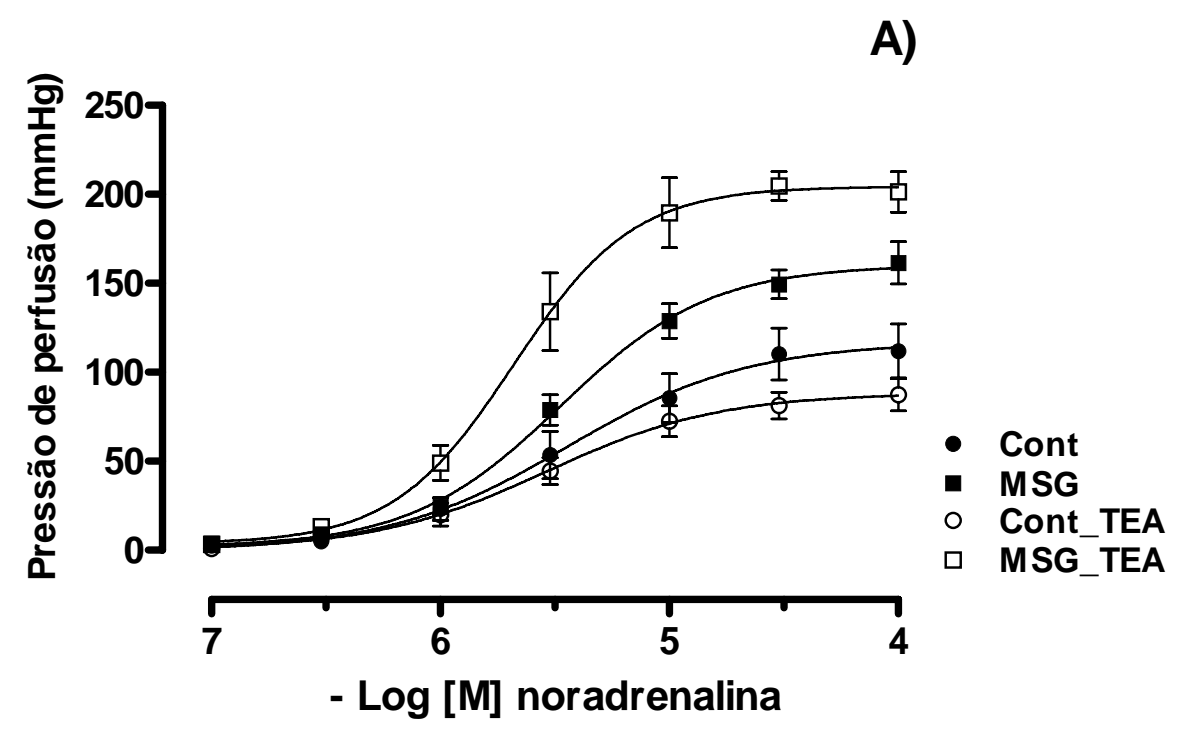

B)

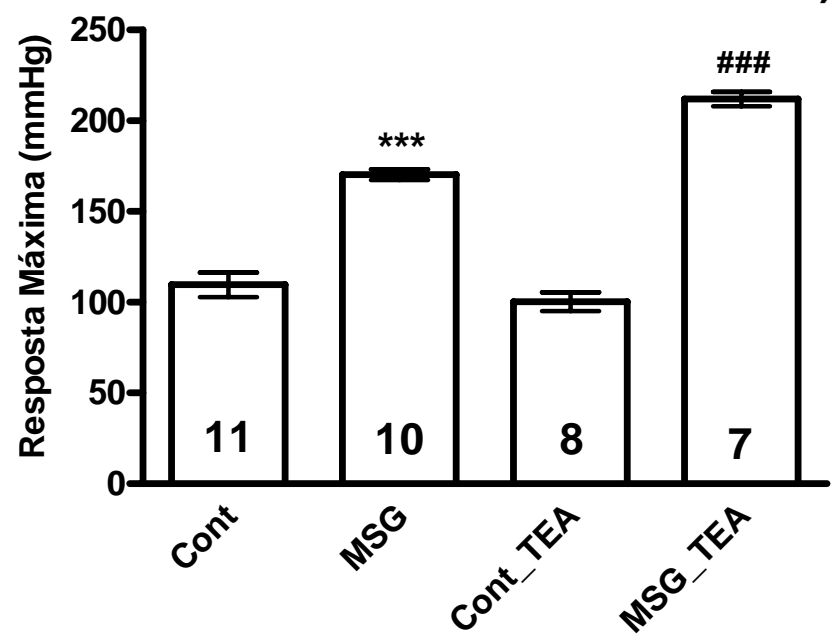

Figura 17 - Curva concentração-efeito (A) e resposta máxima vasoconstritora para noradrenalina (B) após o bloqueio inespecífico de canais de potássio com TEA (2mM) no leito arteriolar mesentérico isolado de ratos Wistar controles (Cont) e obesos-MSG (MSG) com 16 semanas de idade. Cada ponto representa a média \pm epm. $O$ número de ratos utilizados em cada grupo encontra-se dentro das barras. ${ }^{* t *} p<0,001$ vs Cont; ${ }^{\# \#} p<0,001$ vs Cont_TEA. Os sinais de significância foram omitidos nos gráficos por motivo de clareza. As diferenças estão representadas no diagrama de barras. 
Tabela 10 - Efeito do bloqueio inespecífico dos canais de potássio com TEA (2mM) sobre a resposta máxima à noradrenalina (NA) no leito arteriolar mesentérico de ratos controles e obesos-MSG (MSG) com 16 semanas de idade.

\begin{tabular}{ccccc}
\hline \hline \multicolumn{3}{c}{ Controle } & \multicolumn{3}{c}{ MSG } \\
\hline NA & $\mathrm{R}_{\mathrm{MAX}}$ & $\mathrm{pD}_{2}$ & $\mathrm{R}_{\mathrm{MAX}}$ & $\mathrm{pD}_{2}$ \\
& $109,6 \pm 6,8$ & $\mathrm{ND}$ & $170,3 \pm 2,8^{\star * \star}$ & $\mathrm{ND}$ \\
$\mathrm{NA}$ & $(11)$ & & $(10)$ & \\
+ & $100,3 \pm 5,2$ & $\mathrm{ND}$ & $211,9 \pm 4,0^{\# \ldots}$ & $\mathrm{ND}$ \\
TEA & $(8)$ & & $(7)$ & \\
\hline \hline
\end{tabular}

Os valores de $\mathrm{R}_{\mathrm{MAX}}$ (Resposta máxima) representam a média \pm epm.

$\mathrm{ND}=$ não foi determinada o pD2 por ter havido diferença significativa na resposta máxima. $\mathrm{O}$ número de ratos utilizados em cada grupo encontra-se entre parênteses. ${ }^{* * *} p<0,001$ vs Cont; ${ }^{\# \#} p<0,001$ vs Cont_TEA. 


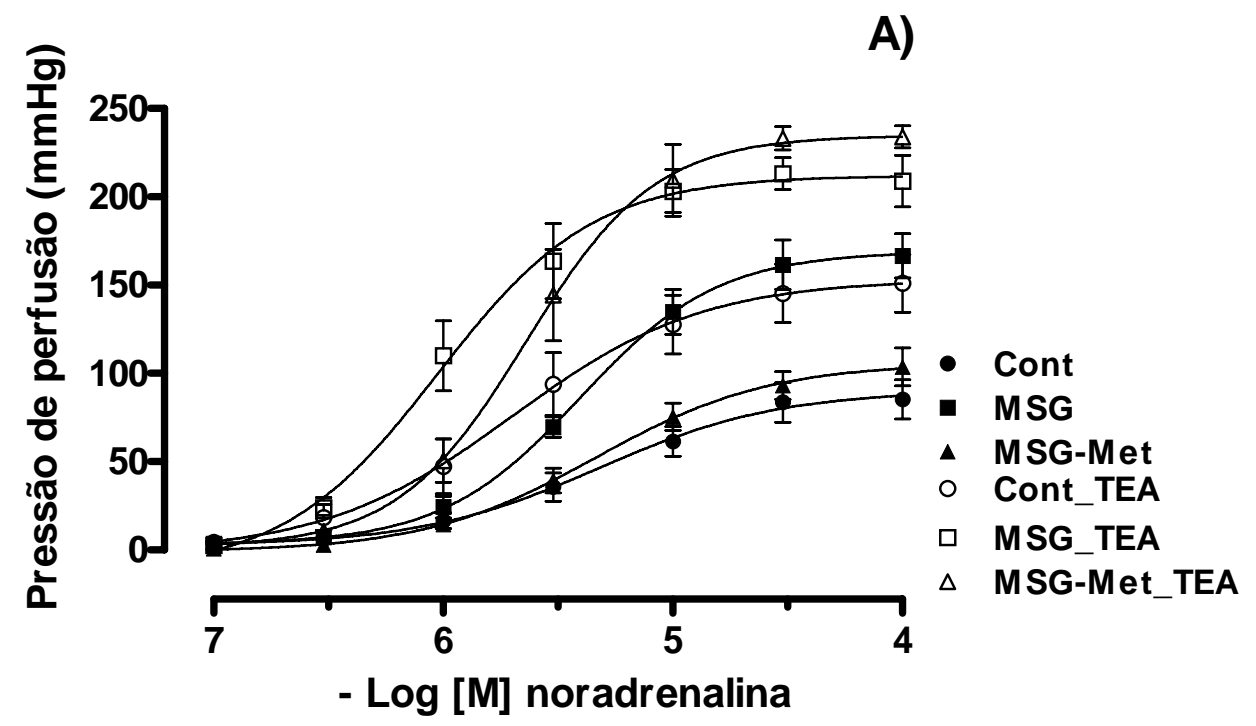

B)

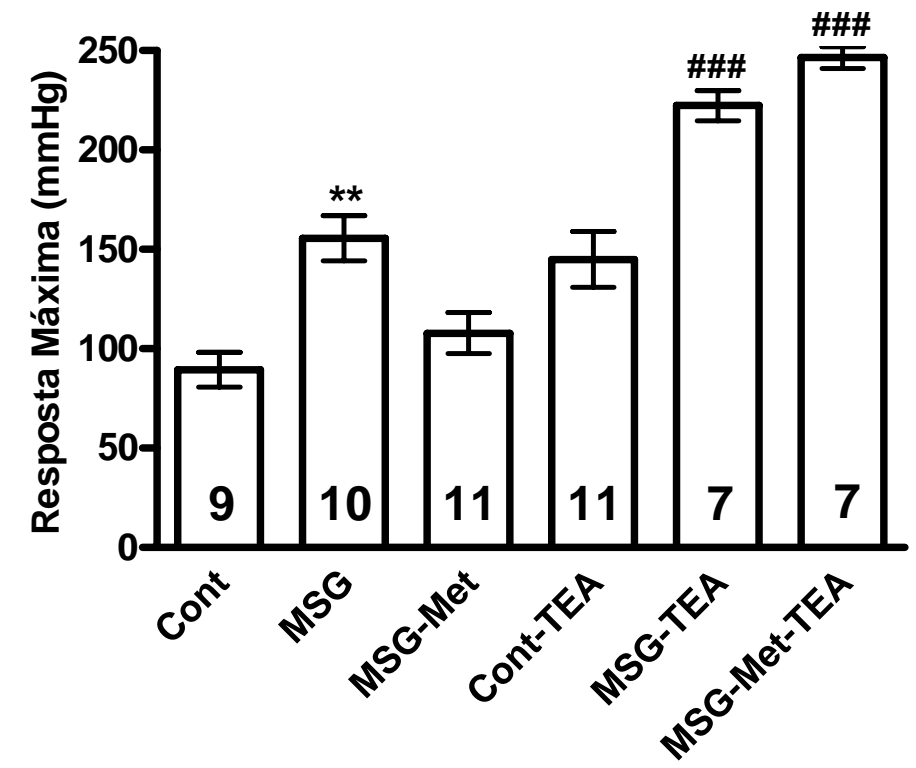

Figura 18 - Curva concentração-efeito (A) e resposta máxima vasoconstritora para noradrenalina (B) após o bloqueio inespecífico de canais de potássio com TEA $(2 \mathrm{mM})$ no leito arteriolar mesentérico isolado de ratos Wistar controles (Cont), obesos-MSG (MSG) e MSG tratados com metformina (MSG-Met) com 18 semanas de idade. Cada ponto representa a média \pm epm. O número de ratos utilizados em cada grupo encontra-se dentro das barras. ${ }^{* *} p<0,01$ vs Cont e MSG-Met; ${ }^{\# \#} p<0,001$ vs Cont_TEA;

Os sinais de significância foram omitidos nos gráficos por motivo de clareza. As diferenças estão representadas no diagrama de barras. 
Tabela 11 - Efeito do bloqueio inespecífico dos canais de potássio com TEA (2mM) sobre a resposta máxima à noradrenalina (NA) no leito arteriolar mesentérico de ratos controles, obesos-MSG (MSG) e MSG tratados com metformina (MSG-Met) com 18 semanas de idade.

\begin{tabular}{|c|c|c|c|c|c|c|}
\hline & \multicolumn{2}{|c|}{ Controle } & \multicolumn{2}{|l|}{ MSG } & \multicolumn{2}{|c|}{ MSG-Met } \\
\hline & $\mathrm{R}_{\text {MAX }}$ & $\mathrm{pD}_{2}$ & $\mathrm{R}_{\text {MAX }}$ & $\mathrm{pD}_{2}$ & $\mathrm{R}_{\text {MAX }}$ & $\mathrm{pD}_{2}$ \\
\hline NA & $\begin{array}{c}89,51 \pm 8,8 \\
(9)\end{array}$ & ND & $\begin{array}{c}155,6 \pm 11,3^{\text {** }} \\
(10)\end{array}$ & ND & $\begin{array}{c}107,9 \pm 10,3 \\
(11)\end{array}$ & ND \\
\hline NA & $145,0 \pm 14,2$ & ND & $222,4 \pm 7,6^{\# \# \#}$ & ND & $246,9 \pm 9,5^{\# \# \#}$ & ND \\
\hline+ & (11) & & (7) & & (7) & \\
\hline TEA & & & & & & \\
\hline
\end{tabular}

Os valores de $R_{\text {MAX }}$ (Resposta máxima) representam a média \pm epm.

$\mathrm{ND}=$ não foi determinada o pD2 por ter havido diferença significativa na resposta máxima. $O$ número de ratos utilizados em cada grupo encontra-se entre parênteses. ${ }^{* *} p<0,01$ vs Cont e MSG-Met; ${ }^{\# \#} p<0,001$ vs Cont_TEA; 
3.8.5 Participação dos Produtos da Ciclooxigenase na Modulação da Resposta Vasoconstritora à Noradrenalina

A inibição da COX com Indometacina reverteu o aumento da resposta contrátil à NA nos ratos MSG com 16 semanas (Figura 19A e B, Tabela 12). Resultado semelhante foi observado no grupo de 18 semanas, sem alteração da resposta no grupo MSG-Met (Figura 20A e B, Tabela 13).

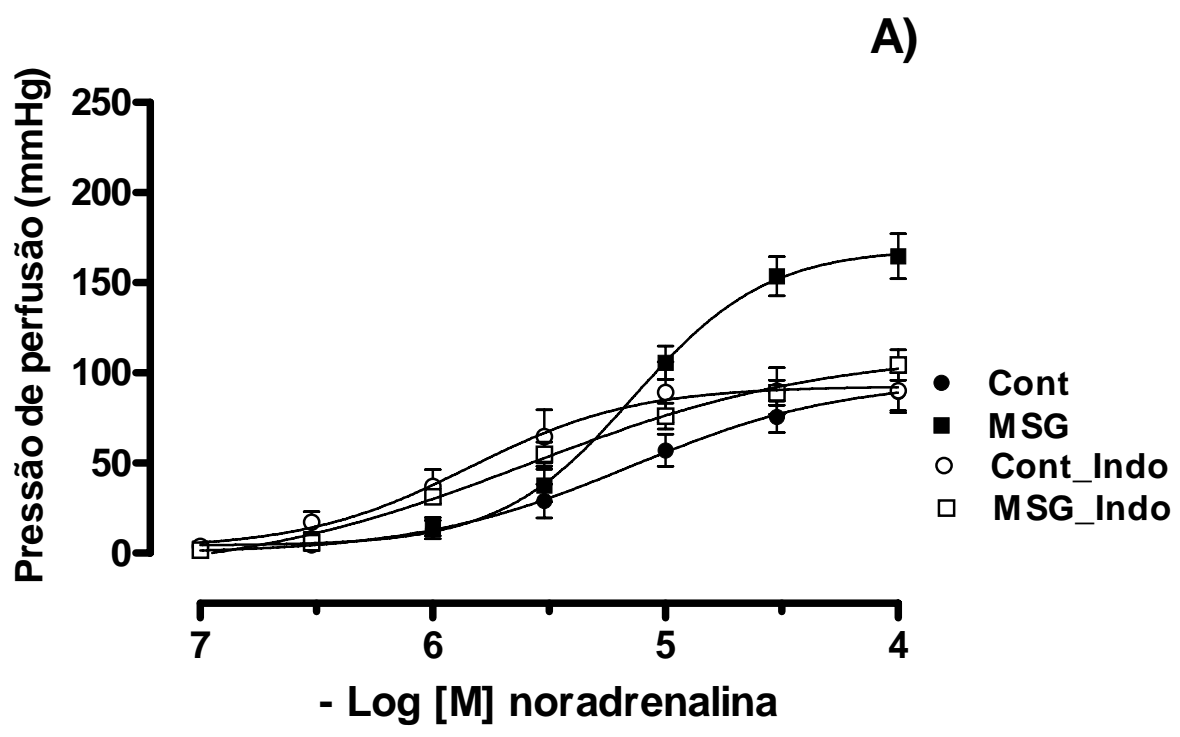

B)

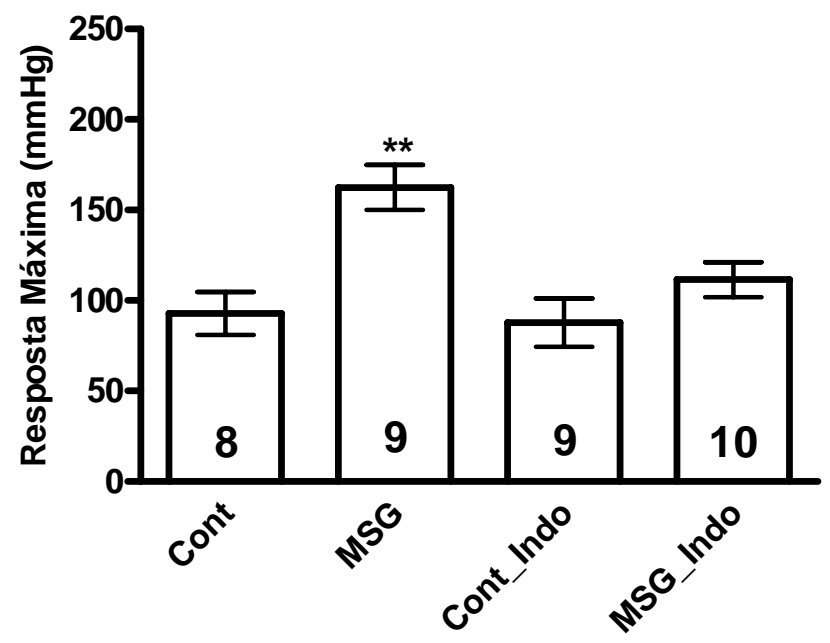

Figura 19 - Curva concentração-efeito (A) e resposta máxima vasoconstritora para noradrenalina (B) após o bloqueio da enzima ciclooxigenase com Indometacina (Indo) $(10 \mu \mathrm{M})$ no leito arteriolar mesentérico isolado de ratos Wistar controles (Cont) e obesos-MSG (MSG) com 16 semanas de idade. Cada ponto representa a média $\pm \mathrm{epm}$. O número de ratos utilizados em cada grupo encontra-se dentro das barras. " $p<0,01$ vs Cont; Os sinais de significância foram omitidos nos gráficos por motivo de clareza. As diferenças estão representadas no diagrama de barras. 
Tabela 12 - Efeito do bloqueio da enzima ciclooxigenase com Indometacina (Indo) $(10 \mu \mathrm{M})$ sobre a resposta máxima à noradrenalina (NA) no leito arteriolar mesentérico de ratos controles e obesos-MSG (MSG) com 16 semanas de idade.

\begin{tabular}{ccccc}
\hline \hline & \multicolumn{2}{c}{ Controle } & & MSG \\
& $\mathrm{R}_{\mathrm{MAX}}$ & $\mathrm{pD}_{2}$ & $\mathrm{R}_{\mathrm{MAX}}$ & $\mathrm{pD}_{2}$ \\
$\mathrm{NA}$ & $105,9 \pm 14,7$ & $\mathrm{ND}$ & $159,0 \pm 7,8^{* *}$ & $\mathrm{ND}$ \\
& $(10)$ & & $(9)$ & \\
$\mathrm{NA}$ & $84,7 \pm 9,9$ & $\mathrm{ND}$ & $105,3 \pm 7,9$ & $\mathrm{ND}$ \\
+ & $(9)$ & & $(9)$ & \\
Indo & & & & \\
\hline \hline
\end{tabular}

Os valores de $R_{\text {MAX }}$ (Resposta máxima) representam a média \pm epm.

$\mathrm{ND}=$ não foi determinada o pD2 por ter havido diferença significativa na resposta máxima. O número de ratos utilizados em cada grupo encontra-se entre parênteses.

$\mathrm{p}<0,01$ vs Controle. 


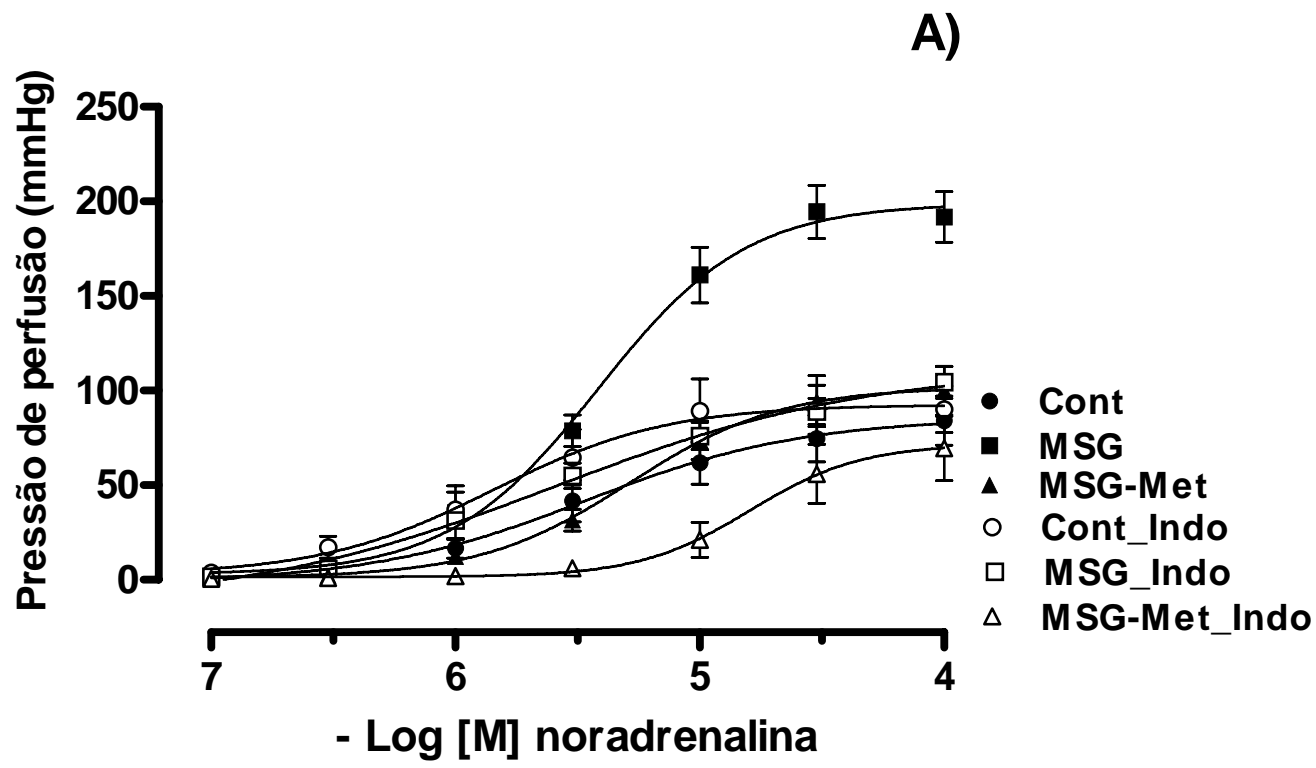

B)

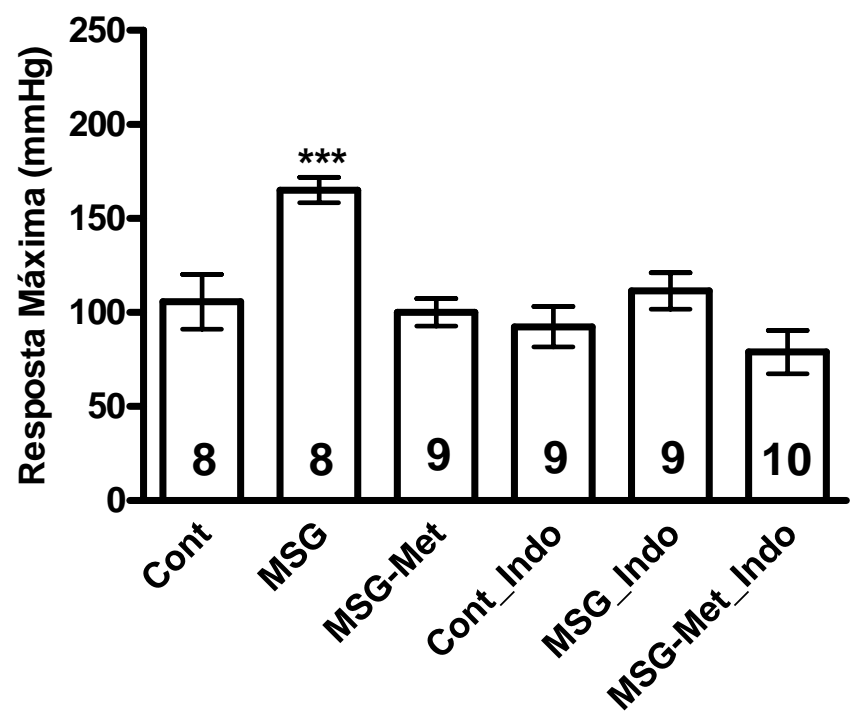

Figura 20 - Curva concentração-efeito (A) e resposta máxima vasoconstritora para noradrenalina (B) após o bloqueio da enzima ciclooxigenase com Indometacina (Indo) $(10 \mu \mathrm{M})$ no leito arteriolar mesentérico isolado de ratos Wistar controles (Cont), obesos-MSG (MSG) e MSG tratados com metformina (MSG-Met) com 18 semanas de idade. Cada ponto representa a média \pm epm. O número de ratos utilizados em cada grupo encontra-se dentro das barras.

p $<0,001$ vs Controle e MSG-Met.

Os sinais de significância foram omitidos nos gráficos por motivo de clareza. As diferenças estão representadas no diagrama de barras. 
Tabela 13 - Efeito do bloqueio da enzima ciclooxigenase com Indometacina (Indo) $(10 \mu \mathrm{M})$ sobre a resposta máxima à noradrenalina (NA) no leito arteriolar mesentérico de ratos controles, obesos-MSG (MSG) e obesos-MSG tratados com metformina (MSG-Met) com 18 semanas de idade.

\begin{tabular}{|c|c|c|c|c|c|c|}
\hline & \multicolumn{2}{|c|}{ Controle } & \multicolumn{2}{|l|}{ MSG } & \multicolumn{2}{|c|}{ MSG-Met } \\
\hline & $\mathrm{R}_{\text {MAX }}$ & $\mathrm{pD}_{2}$ & $\mathrm{R}_{\text {MAX }}$ & $\mathrm{pD}_{2}$ & $\mathrm{R}_{\text {MAX }}$ & $\mathrm{pD}_{2}$ \\
\hline NA & $\begin{array}{c}92,97 \pm 7,9 \\
(9)\end{array}$ & ND & $\begin{array}{c}164,7 \pm 6,5^{\star * *} \\
\text { (9) }\end{array}$ & ND & $\begin{array}{c}103,6 \pm 7,1 \\
(9)\end{array}$ & ND \\
\hline NA & $94,05 \pm 12,7$ & ND & $105,3 \pm 7,9$ & ND & $71,2 \pm 10,6$ & ND \\
\hline+ & (8) & & (8) & & (8) & \\
\hline Indo & & & & & & \\
\hline
\end{tabular}

Os valores de $\mathrm{R}_{\mathrm{MAX}}$ (Resposta máxima) representam a média \pm epm.

$\mathrm{ND}=$ não foi determinada o pD2 por ter havido diferença significativa na resposta máxima. O número de ratos utilizados em cada grupo encontra-se entre parênteses.

${ }^{* * *}<0,001$ vs Controle e MSG-Met. 


\subsubsection{Avaliação da Resposta Relaxante Dependente de Endotélio}

O leito arteriolar mesentérico dos ratos MSG com 16 e 18 semanas de idade apresentou diminuição da sensibilidade à Ach quando comparados aos controles com 16 (Figura 21, Tabela 14) e 18 semanas (Figura 22, Tabela 15), respectivamente. $\mathrm{O}$ tratamento com metformina restaurou a sensibilidade à Ach nos ratos MSG-Met.

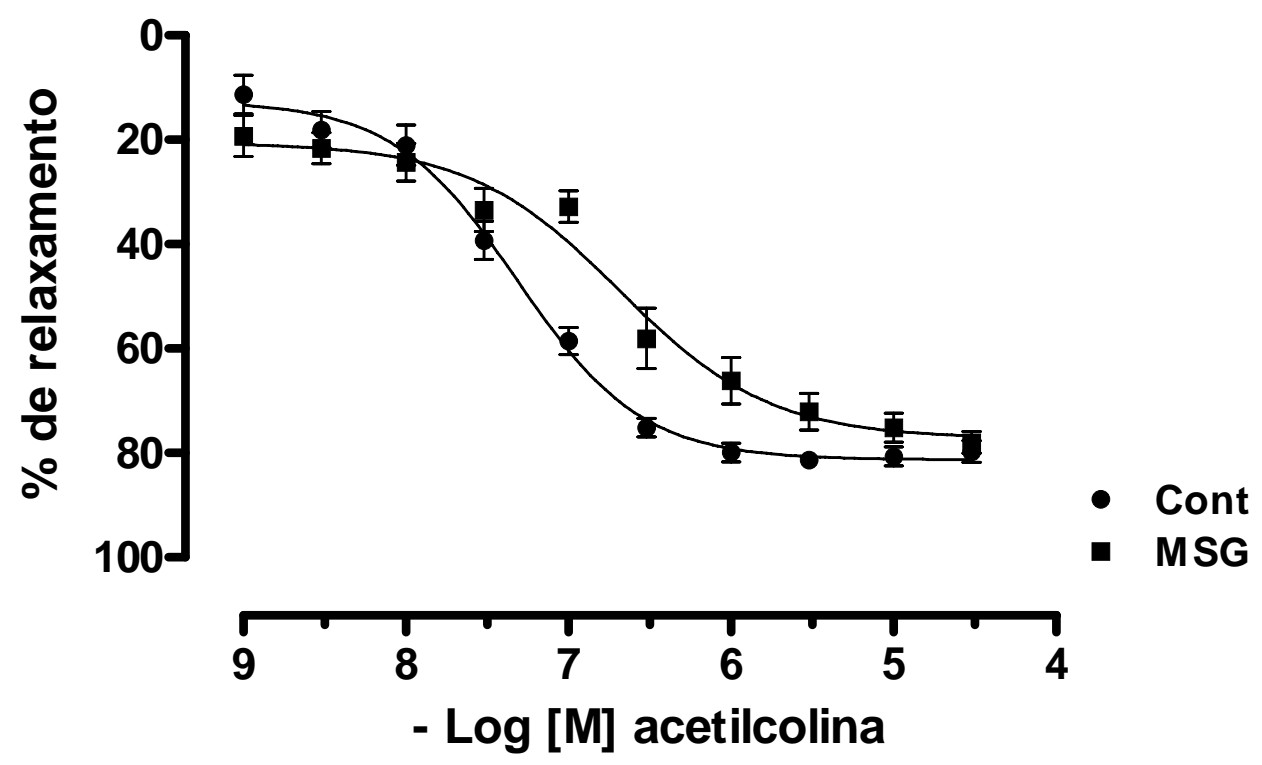

Figura 21 - Curva concentração-efeito para acetilcolina no leito arteriolar mesentérico isolado de ratos Wistar controles (Cont) e obesos-MSG (MSG) com 16 semanas de idade. Cada ponto representa a média \pm epm. Os sinais de significância foram omitidos nos gráficos por motivo de clareza. As diferenças estão representadas no diagrama de barras. 
Tabela 14 - Resposta Máxima e sensibilidade à acetilcolina (Ach) do leito arteriolar mesentérico de ratos controles e obesos-MSG (MSG) com 16 semanas de idade.

\begin{tabular}{ccccc}
\hline \hline \multicolumn{2}{c}{ Controle } & \multicolumn{2}{c}{ MSG } \\
\hline & $\mathrm{R}_{\mathrm{MAX}}$ & $\mathrm{pD}_{2}$ & $\mathrm{R}_{\mathrm{MAX}}$ & $\mathrm{pD}_{2}$ \\
\multirow{2}{*}{ Ach } & $81,78 \pm 1,8$ & $7,3 \pm 0,06$ & $81,98 \pm 2,5$ & $6,7 \pm 0,09^{* \star \star}$ \\
& $(8)$ & $(8)$ & $(8)$ & $(8)$ \\
\hline \hline
\end{tabular}

Os valores de $\mathrm{pD}_{2}$ (-log $\left.\mathrm{EC} 50\right)$ e $\mathrm{R}_{\mathrm{MAX}}$ (Resposta máxima) representam a média \pm epm. $O$ número de ratos utilizados em cada grupo encontra-se entre parênteses.

EC50- concentração que promove $50 \%$ da $\mathrm{R}_{\mathrm{MAX}}$. ${ }^{* * *} \mathrm{p}<0,001$ vs Controle. 


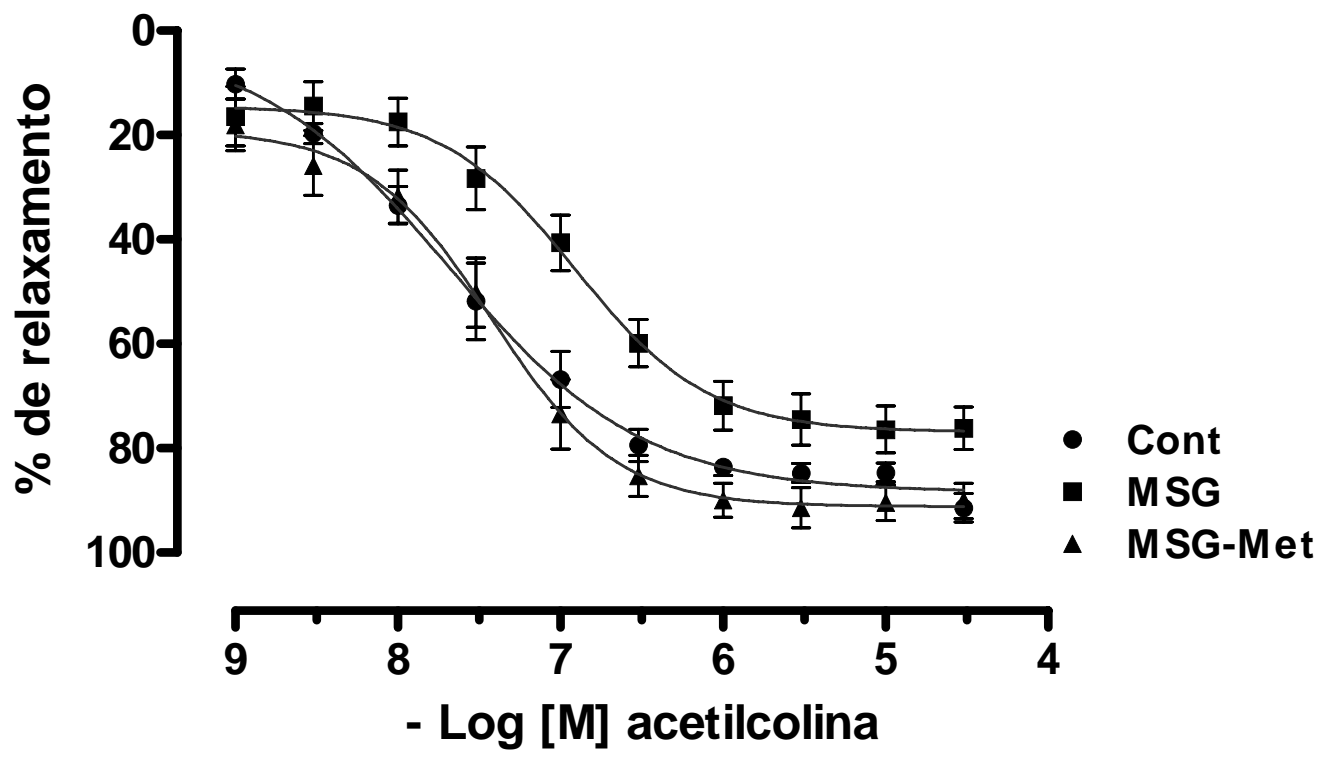

Figura 22 - Curva concentração-efeito para acetilcolina no leito arteriolar mesentérico isolado de ratos Wistar controles (Cont), obesos-MSG (MSG) e MSG-tratados com metformina (MSG-Met) com 18 semanas de idade. Cada ponto representa a média \pm epm. O número de ratos utilizados em cada grupo encontra-se dentro das barras. Os sinais de significância foram omitidos nos gráficos por motivo de clareza. As diferenças estão representadas no diagrama de barras. 
Tabela 15 - Resposta Máxima e sensibilidade à acetilcolina (Ach) do leito arteriolar mesentérico de ratos controles, obesos-MSG (MSG) e MSG tratados com metformina (MSG-Met) com 18 semanas de idade.

\begin{tabular}{ccccccc}
\hline \hline & \multicolumn{2}{c}{ Controle } & \multicolumn{2}{c}{ MSG } & \multicolumn{2}{c}{ MSG-Met } \\
\hline & $\mathrm{R}_{\mathrm{MAX}}$ & $\mathrm{pD}_{2}$ & $\mathrm{R}_{\mathrm{MAX}}$ & $\mathrm{pD}_{2}$ & $\mathrm{R}_{\mathrm{MAX}}$ & $\mathrm{pD}_{2}$ \\
\multirow{4}{*}{ Ach } & $89,48 \pm 2,0$ & $7,8 \pm 0,2$ & $84,8 \pm 3,0$ & $7,0 \pm 0,1^{\text {**}}$ & $93,6 \pm 3,3$ & $7,6 \pm 0,2$ \\
& $(9)$ & $(9)$ & $(9)$ & $(9)$ & $(7)$ & $(7)$ \\
\hline \hline
\end{tabular}

Os valores de $\mathrm{pD}_{2}$ (-log $\left.\mathrm{EC} 50\right)$ e $\mathrm{R}_{\mathrm{MAX}}$ (Resposta máxima) representam a média \pm epm. $O$ número de ratos utilizados em cada grupo encontra-se entre parênteses.

EC50- concentração que promove $50 \%$ da $\mathrm{R}_{\text {MAX }}$. ${ }^{* *} p<0,01$ vs Controle e MSG-Met. 
3.8.7 Participação do Óxido Nítrico na Resposta Vasodilatadora Dependente de Endotélio

A resposta máxima vasodilatadora à Ach foi significantemente reduzida tanto em ratos controle quanto nos obesos-MSG na presença de L-NAME. A diminuição da sensibilidade à Ach observada nos ratos MSG com 16 (Figura 23, Tabela 16) e com 18 semanas de idade (Figura 24, Tabela 17), foi revertida na presença deste bloqueio, e a correção promovida pela metformina mantida nos ratos MSG-Met.

A)

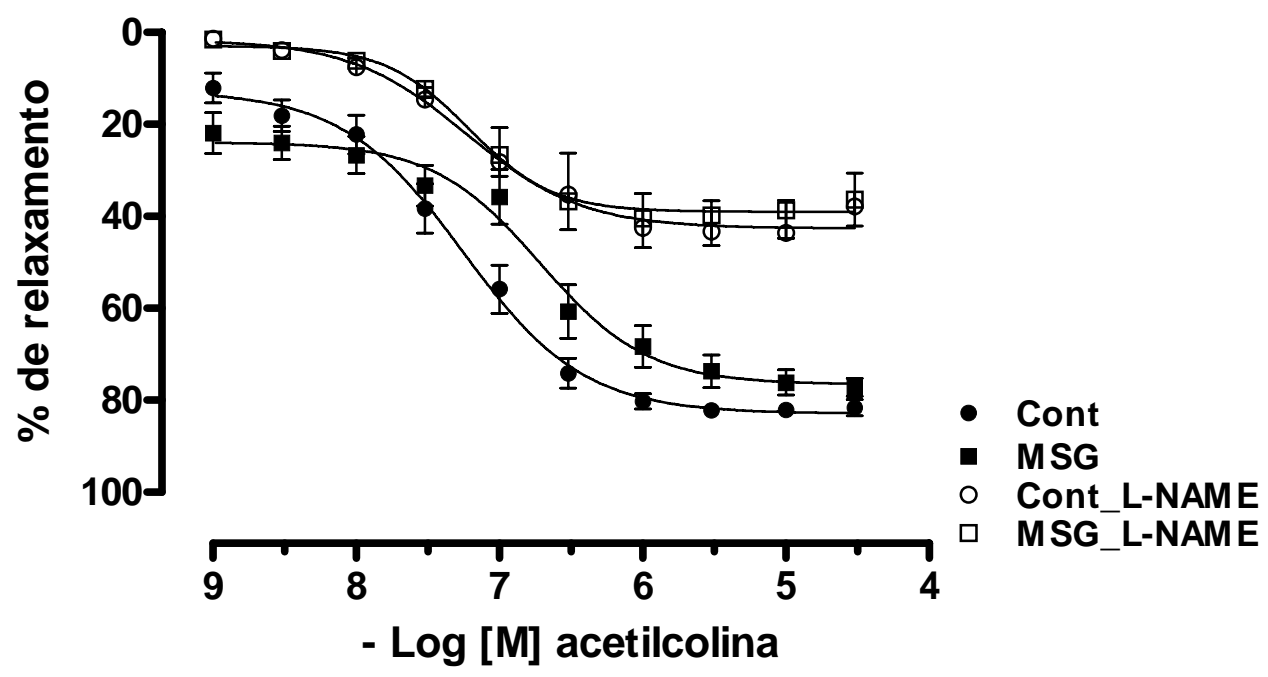

B)

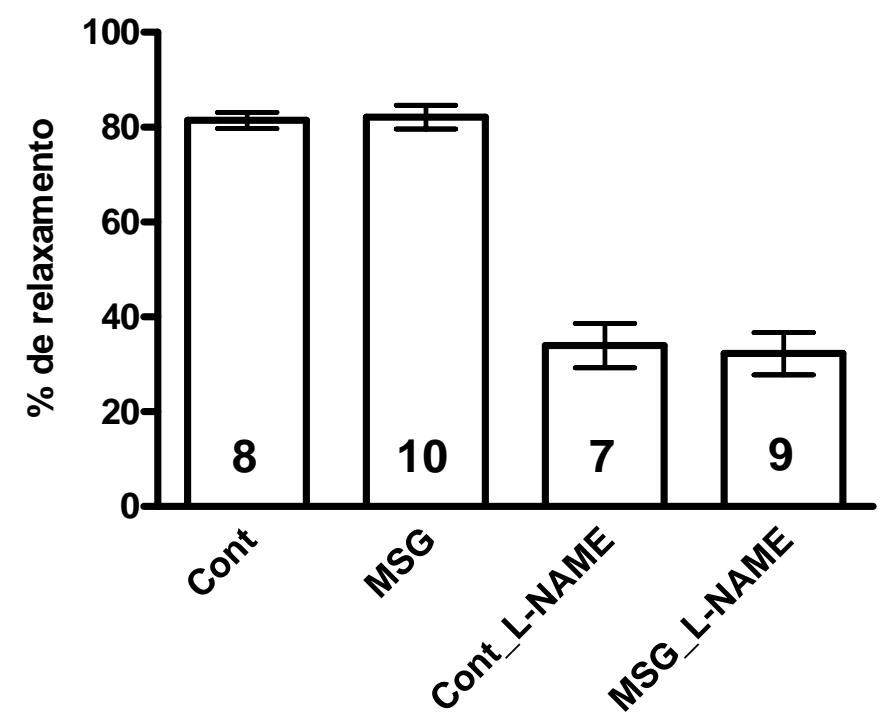

Figura 23 - Curva concentração-efeito (A) e resposta máxima vasodilatadora (B) para

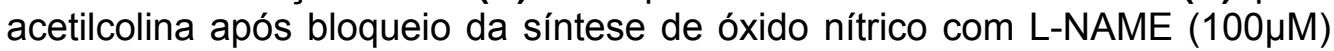
no leito arteriolar mesentérico isolado de ratos Wistar controles (Cont) e obesos-MSG (MSG) com 16 semanas de idade. Cada ponto representa a média $\pm \mathrm{epm}$. $\mathrm{O}$ número de ratos utilizados em cada grupo encontra-se dentro das barras. 


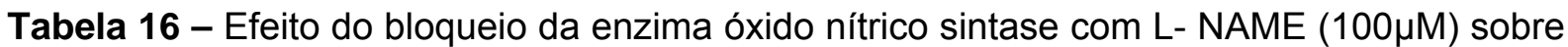
a sensibilidade $\left(\mathrm{pD}_{2}\right)$ e a resposta máxima à acetilcolina (Ach) no leito arteriolar mesentérico de ratos Wistar controles e obesos-MSG (MSG) com 16 semanas de idade.

\begin{tabular}{ccccc}
\hline \hline & \multicolumn{2}{c}{ Controle } & \multicolumn{2}{c}{ MSG } \\
\hline Rch & $81,44 \pm 1,7$ & $7,3 \pm 0,1$ & $82,12 \pm 2,5$ & $6,7 \pm 0,1^{* *}$ \\
& $(8)$ & $(8)$ & $(10)$ & $(10)$ \\
Ach & $33,95 \pm 4,6$ & $7,23 \pm 0,2$ & $32,27 \pm 4,4$ & $7,21 \pm 0,1$ \\
+ & $(7)$ & $(7)$ & $(9)$ & $(9)$ \\
L-NAME & & & & \\
\hline \hline
\end{tabular}

Os valores de $\mathrm{pD}_{2}$ (-log $\mathrm{EC} 50$ ) e $\mathrm{R}_{\mathrm{MAX}}$ (Resposta máxima) representam a média \pm epm. $O$ número de ratos utilizados em cada grupo encontra-se entre parênteses.

EC50- concentração que promove $50 \%$ da $\mathrm{R}_{\mathrm{MAX}}$. ${ }^{* *} \mathrm{p}<0,01$ vs Controle. 


\section{A)}

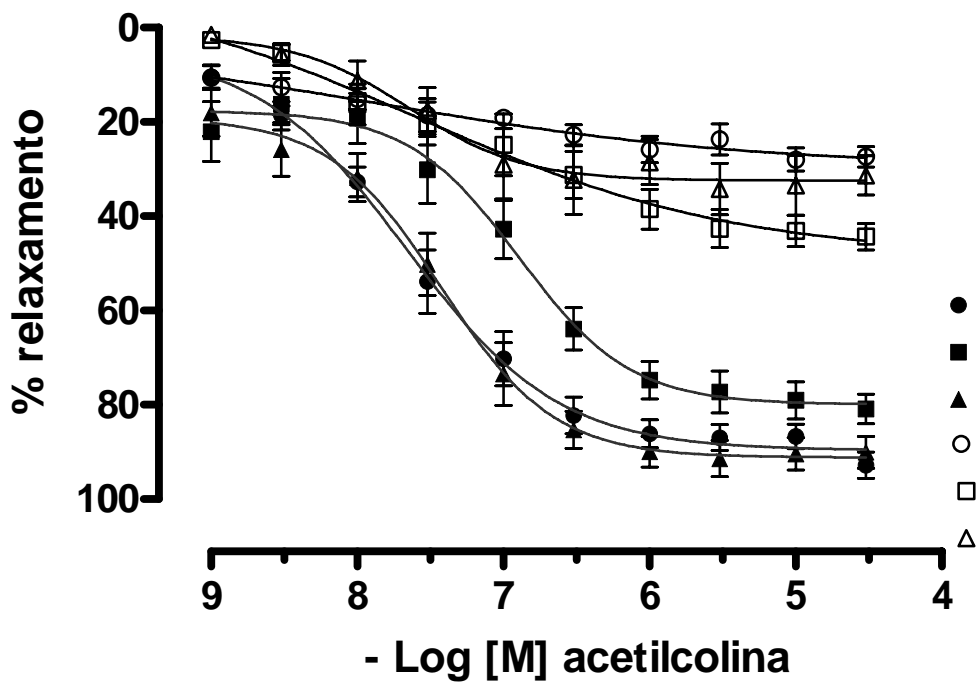

Cont

- MSG

- MSG-Met

- Cont_L-NAME

MSG_L-NAME

MSG-Met_L-NAME

B)

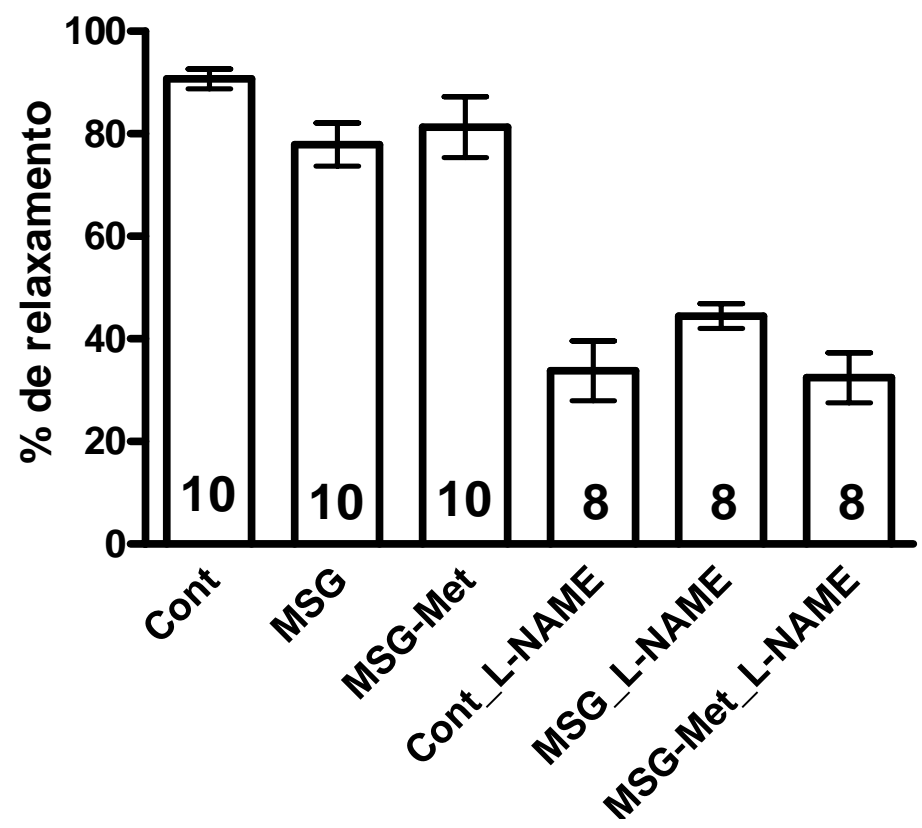

Figura 24 - Curva concentração-efeito (A) e resposta máxima vasodilatadora (B) para acetilcolina após o bloqueio da síntese de óxido nítrico com L-NAME $(100 \mu \mathrm{M})$ no leito arteriolar mesentérico isolado de ratos Wistar controles (Cont), obesos-MSG (MSG) e MSG tratados com metformina (MSG-Met) com 18 semanas de idade. Cada ponto representa a média \pm epm. O número de ratos utilizados em cada grupo encontra-se dentro das barras.

Os sinais de significância foram omitidos nos gráficos por motivo de clareza. As diferenças estão representadas no diagrama de barras. 


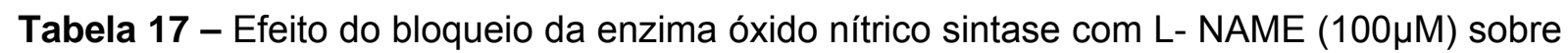
a sensibilidade $\left(\mathrm{pD}_{2}\right)$ e a resposta máxima à acetilcolina (Ach) no leito arteriolar mesentérico de ratos controles, obesos-MSG (MSG) e obesos-MSG tratados com metformina (MSG-Met) com 18 semanas de idade.

\begin{tabular}{|c|c|c|c|c|c|c|}
\hline & \multicolumn{2}{|c|}{ Cont } & \multicolumn{2}{|c|}{$\overline{\text { MSG }}$} & \multicolumn{2}{|c|}{ MSG-Met } \\
\hline & $\mathrm{R}_{\text {MAX }}$ & $\overline{p D_{2}}$ & $\mathrm{R}_{\text {MAX }}$ & $\overline{p D_{2}}$ & $\mathrm{R}_{\text {MAX }}$ & $\mathrm{pD}_{2}$ \\
\hline \multirow[t]{2}{*}{ Ach } & $90,71 \pm 1,9$ & $7,6 \pm 0,1$ & $77,90 \pm 4,2$ & $6,9 \pm 0,1^{\star \star}$ & $81,32 \pm 5,9$ & $7,4 \pm 0,1$ \\
\hline & (10) & (10) & (10) & (10) & (10) & (10) \\
\hline Ach & $33,81 \pm 5,8$ & $7,3 \pm 0,2$ & $44,44 \pm 2,4$ & $7,4 \pm 0,2$ & $32,43 \pm 4,9$ & $7,5 \pm 0,1$ \\
\hline+ & (8) & (8) & (8) & (8) & (8) & (8) \\
\hline L-NAME & & & & & & \\
\hline
\end{tabular}

Os valores de $\mathrm{pD}_{2}$ (-log $\left.\mathrm{EC} 50\right)$ e $\mathrm{R}_{\mathrm{MAX}}$ (Resposta máxima) representam a média \pm epm. $\mathrm{O}$ número de ratos utilizados em cada grupo encontra-se entre parênteses.

EC50- concentração que promove $50 \%$ da $\mathrm{R}_{\mathrm{MAX}}$.

** $p<0,01$ vs Controle e MSG-Met; 
3.8.8 Participação dos Canais de Potássio na Resposta Vasodilatadora Dependente de Endotélio

O bloqueio dos canais de $\mathrm{K}^{+}$com TEA promoveu redução significativa da resposta máxima vasodilatadora dependente de endotélio nos ratos MSG com 16 semanas (Figura 25A e B, Tabela 18), e naqueles com 18 semanas de idade (Figura 26A e B, Tabela 19). A metformina corrigiu esta redução no grupo MSG-Met.

A)

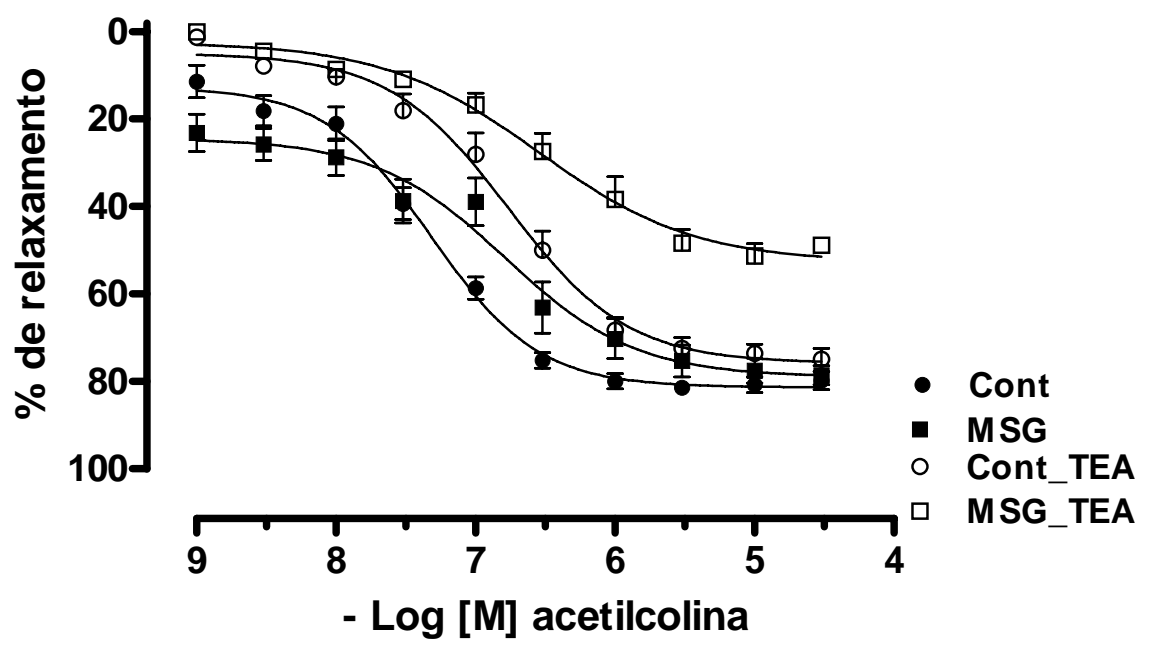

B)

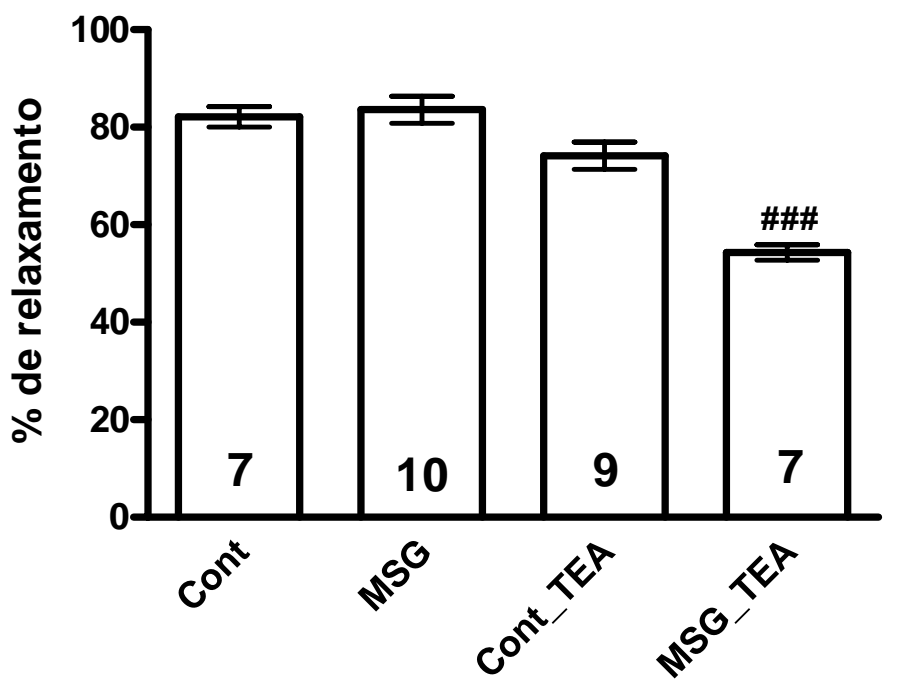

Figura 25 - Curva concentração-efeito (A) e resposta máxima vasodilatadora (B) para acetilcolina após o bloqueio inespecífico de canais de potássio com TEA $(2 \mathrm{mM})$ no leito arteriolar mesentérico isolado de ratos Wistar controles (Cont), obesos-MSG (MSG) e MSG-tratados com metformina (MSG-Met) com 18 semanas de idade. Cada ponto representa a média \pm epm. O número de ratos utilizados em cada grupo encontra-se entre parênteses. ${ }^{\#} \mathrm{p}<0,001$ vs Cont_TEA. Os sinais de significância foram omitidos nos gráficos por motivo de clareza. As diferenças estão representadas no diagrama de barras. 
Tabela 18 - Efeito do bloqueio inespecífico dos canais de potássio ativados por cálcio com TEA $(2 \mathrm{mM})$ sobre a resposta máxima à acetilcolina (Ach) no leito arteriolar mesentérico de ratos controles e obesos-MSG (MSG) com 16 semanas de idade.

\begin{tabular}{ccccc}
\hline \hline \multicolumn{2}{c}{ Controle } & \multicolumn{2}{c}{ MSG } \\
\hline & $\mathrm{R}_{\mathrm{MAX}}$ & $\mathrm{pD}_{2}$ & $\mathrm{R}_{\mathrm{MAX}}$ & $\mathrm{pD}_{2}$ \\
Ach & $82,12 \pm 2,1$ & $\mathrm{ND}$ & $83,59 \pm 2,8$ & $\mathrm{ND}$ \\
& $(7)$ & & $(10)$ & \\
Ach & $74,16 \pm 2,8$ & $\mathrm{ND}$ & $54,31 \pm 1,6^{* * *}$ & $\mathrm{ND}$ \\
+ & $(9)$ & & $(7)$ & \\
TEA & & & \\
\hline \hline
\end{tabular}

Os valores de $\mathrm{pD}_{2}$ (-log $\mathrm{EC50}$ ) e $\mathrm{R}_{\mathrm{MAX}}$ (Resposta máxima) representam a média \pm epm. $\mathrm{ND}=$ não foi determinada o pD2 por ter havido diferença significativa na resposta máxima. O número de ratos utilizados em cada grupo encontra-se entre parênteses.

EC50- concentração que promove $50 \%$ da $\mathrm{R}_{\text {MAX }}$. \#\#\# $<0,001$ vs Controle_TEA; 


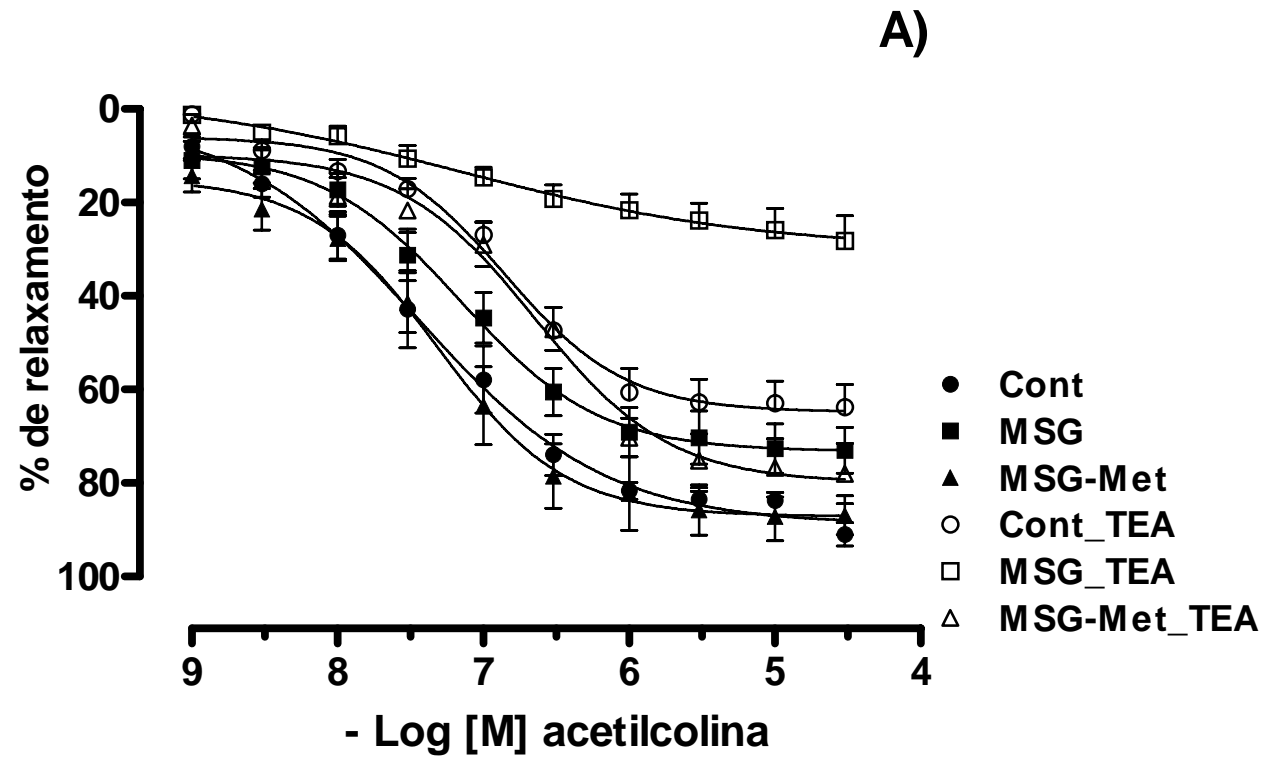

B)

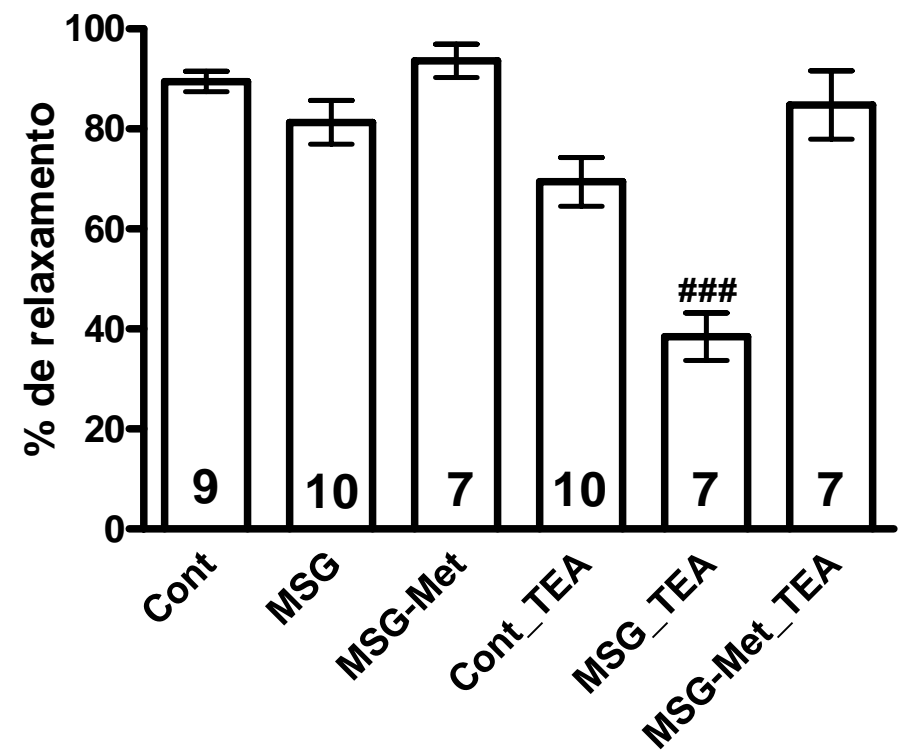

Figura 26 - Curva concentração-efeito (A) e resposta máxima vasodilatadora (B) para acetilcolina após o bloqueio inespecífico de canais de potássio com TEA $(2 \mathrm{mM})$ no leito arteriolar mesentérico isolado de ratos Wistar controles (Cont), obesos-MSG (MSG) e MSG tratados com metformina (MSG-Met) com 18 semanas de idade. Cada ponto representa a média \pm epm. $O$ número de ratos utilizados em cada grupo encontra-se no interior das barras.

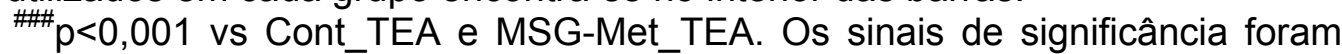
omitidos nos gráficos por motivo de clareza. As diferenças estão representadas no diagrama de barras. 
Tabela 19 - Efeito do bloqueio inespecífico dos canais de potássio ativados por cálcio com TEA $(2 \mathrm{mM})$ sobre a sensibilidade $\left(\mathrm{pD}_{2}\right)$ e a resposta máxima à acetilcolina (Ach) no leito arteriolar mesentérico de ratos controles, obesos-MSG (MSG) e obesos-MSG tratados com metformina (MSG-Met) com 18 semanas de idade.

\begin{tabular}{|c|c|c|c|c|c|c|}
\hline & \multicolumn{2}{|l|}{ Cont } & \multicolumn{2}{|l|}{ MSG } & \multicolumn{2}{|c|}{ MSG-Met } \\
\hline & $\mathrm{R}_{\text {MAX }}$ & $\mathrm{pD}_{2}$ & $\mathrm{R}_{\text {MAX }}$ & $\mathrm{pD}_{2}$ & $\mathrm{R}_{\text {MAX }}$ & $\mathrm{pD}_{2}$ \\
\hline Ach & $89,48 \pm 2,0$ & ND & $81,3 \pm 4,4$ & ND & $93,6 \pm 3,4$ & ND \\
\hline & (9) & & (10) & & (7) & \\
\hline Ach & $69,43 \pm 4,9$ & ND & $37,14 \pm 6,8^{* * *}$ & ND & $84,08 \pm 8,1$ & ND \\
\hline+ & (10) & & (7) & & (7) & \\
\hline TEA & & & & & & \\
\hline
\end{tabular}

Os valores de $\mathrm{pD}_{2}$ (-log $\left.\mathrm{EC} 50\right)$ e $\mathrm{R}_{\mathrm{MAX}}$ (Resposta máxima) representam a média \pm epm. $\mathrm{ND}=$ não foi determinada o pD2 por ter havido diferença significativa na resposta máxima. O número de ratos utilizados em cada grupo encontra-se entre parênteses.

EC50- concentração que promove $50 \%$ da $\mathrm{R}_{\mathrm{MAX}}$.

$\ldots$ p $<0,001$ vs Controle e MSG-Met_TEA. 


\subsubsection{Participação dos Produtos da Ciclooxigenase na Resposta Vasodilatadora}

Dependente de Endotélio

A inibição da COX com Indometacina reverteu a diminuição da sensibilidade à acetilcolina nos ratos MSG com 16 semanas (Figura 27A e B, Tabela 20). Resultado semelhante foi observado no grupo de 18 semanas, com a manutenção da correção promovida pela metformina no grupo MSG-Met (Figura 28A e B, Tabela 21)

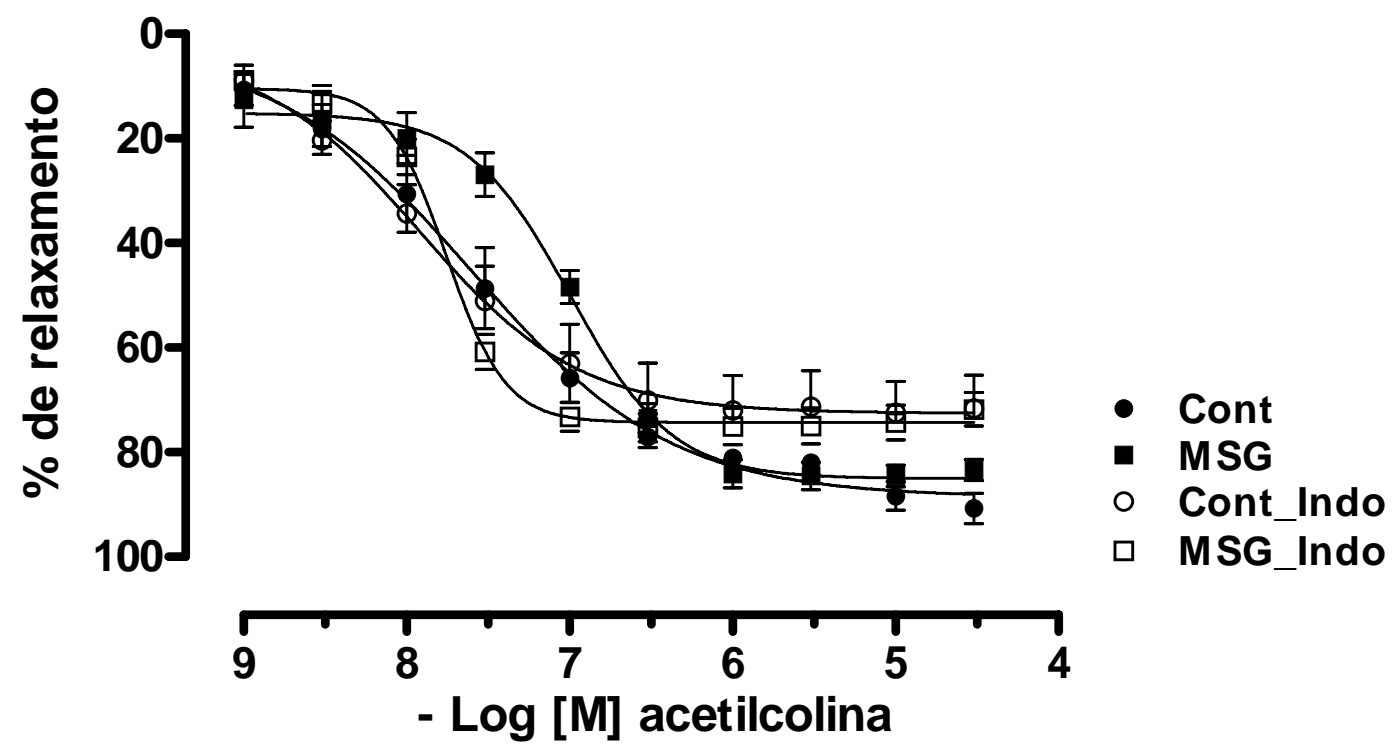

Figura 27 - Curva concentração-efeito (A) e resposta máxima vasodilatadora (B) para acetilcolina após o bloqueio da enzima ciclooxigenase com Indometacina (Indo) $(10 \mu \mathrm{M})$ no leito arteriolar mesentérico isolado de ratos Wistar controles (Cont) e obesos-MSG (MSG) com 16 semanas de idade. Cada ponto representa a média \pm epm. O número de ratos utilizados em cada grupo encontra-se dentro das barras. Os sinais de significância foram omitidos nos gráficos por motivo de clareza. As diferenças estão representadas no diagrama de barras. 


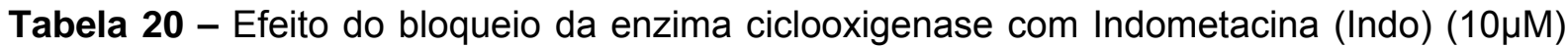
sobre a resposta máxima e a sensibilidade à acetilcolina (Ach) no leito arteriolar mesentérico de ratos Wistar controles e obesos-MSG (MSG) com 16 semanas de idade.

\begin{tabular}{ccccc}
\hline \hline & \multicolumn{2}{c}{ Controle } & & \\
& $\mathrm{R}_{\mathrm{MAX}}$ & $\mathrm{pD}_{2}$ & $\mathrm{R}_{\mathrm{MAX}}$ & $\mathrm{pD}_{2}$ \\
Ach & $81,8 \pm 1,8$ & $7,3 \pm 0,05$ & $84,8 \pm 2,0$ & $6,6 \pm 0,08^{* * \star}$ \\
& $(8)$ & $(8)$ & $(8)$ & $(8)$ \\
Ach & $83,2 \pm 2,0$ & $7,5 \pm 0,03$ & $77,3 \pm 2,2$ & $7,7 \pm 0,02$ \\
+ & $(7)$ & $(7)$ & $(7)$ & $(7)$ \\
Indo & & & & \\
\hline \hline
\end{tabular}

Os valores de $\mathrm{pD}_{2}$ (-log $\mathrm{EC} 50$ ) e $\mathrm{R}_{\mathrm{MAX}}$ (Resposta máxima) representam a média \pm epm. $\mathrm{O}$ número de ratos utilizados em cada grupo encontra-se entre parênteses.

EC50- concentração que promove $50 \%$ da $\mathrm{R}_{\mathrm{MAX}}$. ${ }^{* * *} p<0,001$ vs Controle. 


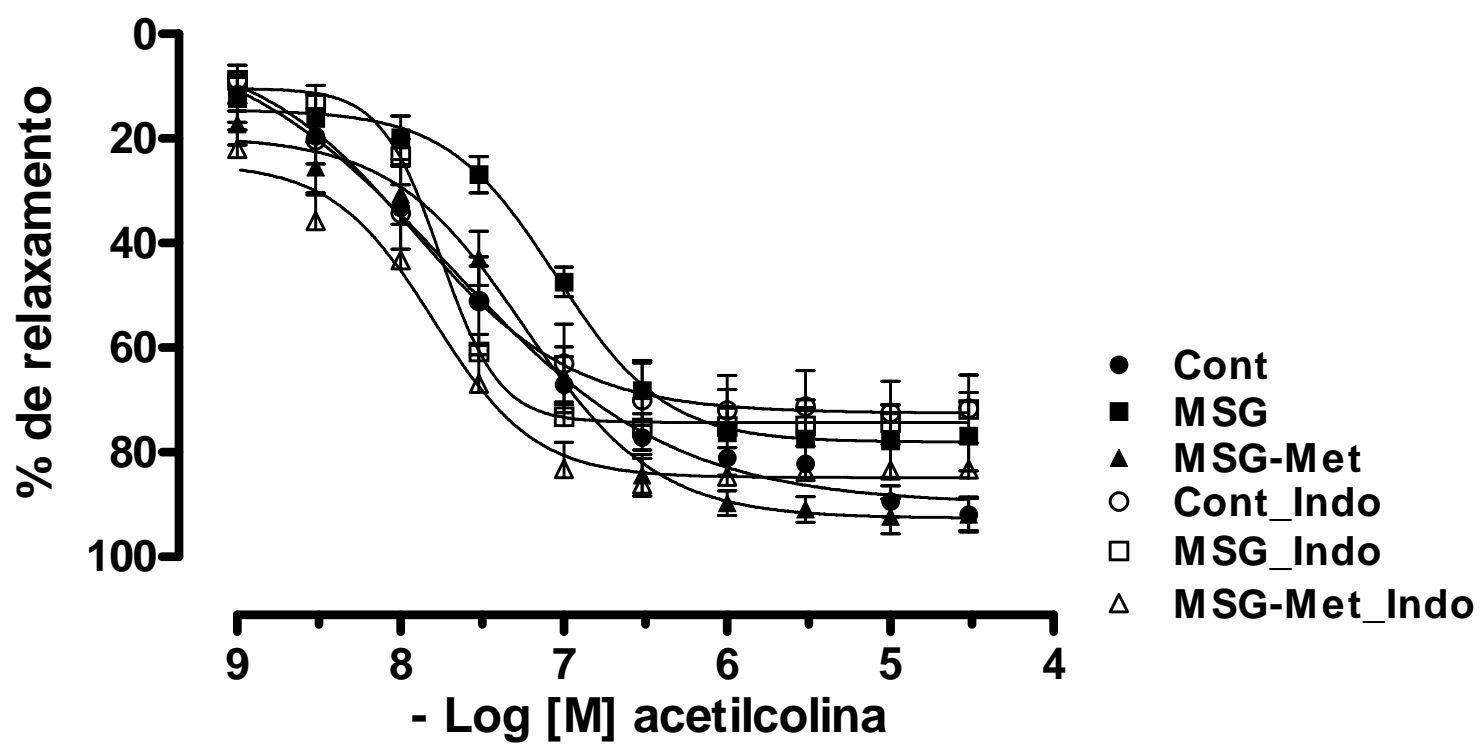

Figura 28 - Curva concentração-efeito (A) e resposta máxima vasodilatadora (B) para acetilcolina após o bloqueio da enzima ciclooxigenase com Indometacina (Indo) $(10 \mu \mathrm{M})$ no leito arteriolar mesentérico isolado de ratos Wistar controles (Cont), obesos-MSG (MSG) e MSG tratados com metformina (MSG-Met) com 18 semanas de idade. Cada ponto representa a média \pm epm. O número de ratos utilizados em cada grupo encontra-se dentro das barras. Os sinais de significância foram omitidos nos gráficos por motivo de clareza. As diferenças estão representadas no diagrama de barras. 


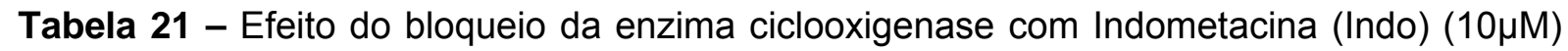
sobre a resposta máxima e a sensibilidade à acetilcolina (Ach) no leito arteriolar mesentérico de ratos Wistar controles, obesos-MSG (MSG) e obesos-MSG tratados com metformina (MSG-Met) com 18 semanas de idade.

\begin{tabular}{ccccccc}
\hline \hline & \multicolumn{2}{c}{ Cont } & \multicolumn{2}{c}{ MSG } & \multicolumn{2}{c}{ MSG-Met } \\
\hline & $\mathrm{R}_{\mathrm{MAX}}$ & $\mathrm{pD}_{2}$ & $\mathrm{R}_{\mathrm{MAX}}$ & $\mathrm{pD}_{2}$ & $\mathrm{R}_{\mathrm{MAX}}$ & $\mathrm{pD}_{2}$ \\
Ach & $88,6 \pm 2,0$ & $7,7 \pm 0,1$ & $83,7 \pm 3,1$ & $7,0 \pm 0,1^{* *}$ & $93,3 \pm 2,9$ & $7,4 \pm 0,08$ \\
& $(7)$ & $(7)$ & $(7)$ & $(7)$ & $(7)$ & $(7)$ \\
Ach & $83,2 \pm 2,0$ & $7,6 \pm 0,2$ & $75,8 \pm 2,9$ & $7,8 \pm 0,05$ & $88,8 \pm 5,3$ & $7,9 \pm 0,1$ \\
+ & $(7)$ & $(7)$ & $(8)$ & $(8)$ & $(7)$ & $(8)$ \\
Indo & & & & & & \\
\hline \hline
\end{tabular}

Os valores de $\mathrm{pD}_{2}$ (-log $\left.\mathrm{EC} 50\right)$ e $\mathrm{R}_{\mathrm{MAX}}$ (Resposta máxima) representam a média \pm epm. $\mathrm{O}$ número de ratos utilizados em cada grupo encontra-se entre parênteses.

EC50- concentração que promove $50 \%$ da $\mathrm{R}_{\text {MAX }}$.

* $p<0,01$ vs Controle e MSG-Met. 


\subsubsection{Avaliação da Resposta Relaxante Independente de Endotélio}

A resposta máxima vasodilatadora ao NPS, doador de NO, foi significantemente maior em ratos MSG com 16 semanas quando comparados ao grupo Controle (Figura 29A e B, Tabela 22). Não foi observada diferença na resposta máxima vasodilatadora ao NPS nos ratos MSG com 18 semanas de idade, com aumento na resposta vasodilatadora independente de endotélio nos ratos MSGMet, quando comparados ao grupo Controle (Figura 30A e B Tabela 23).

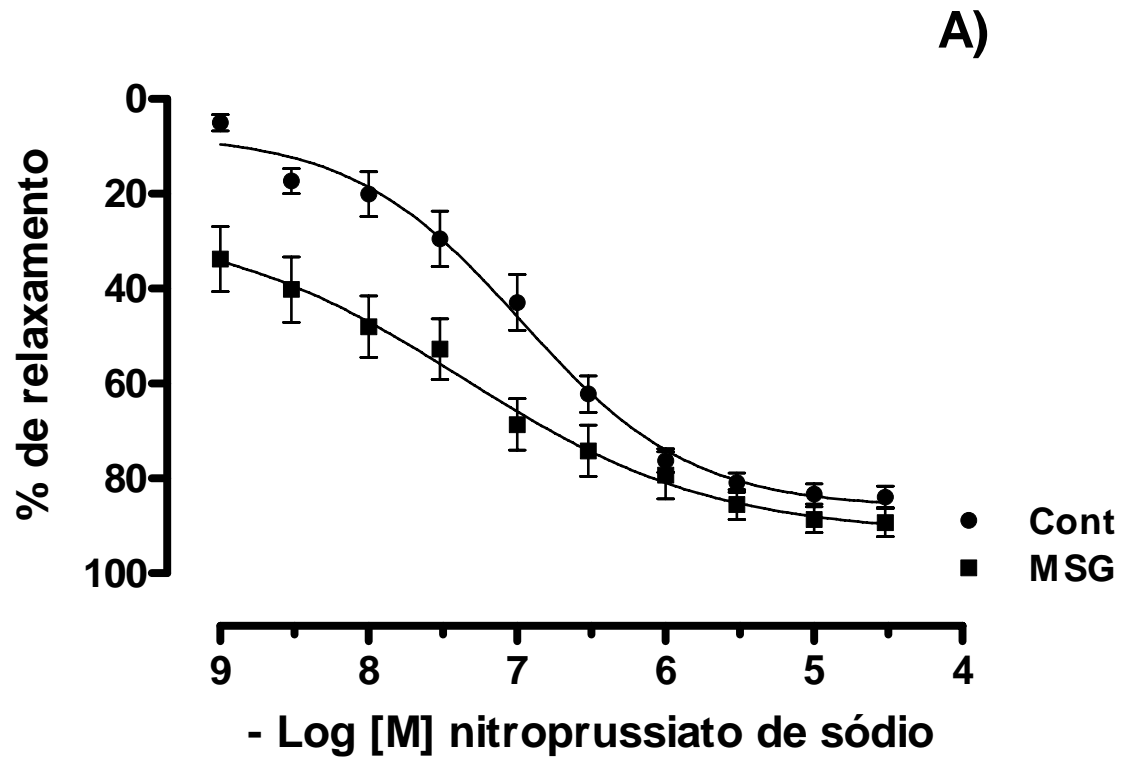

B)

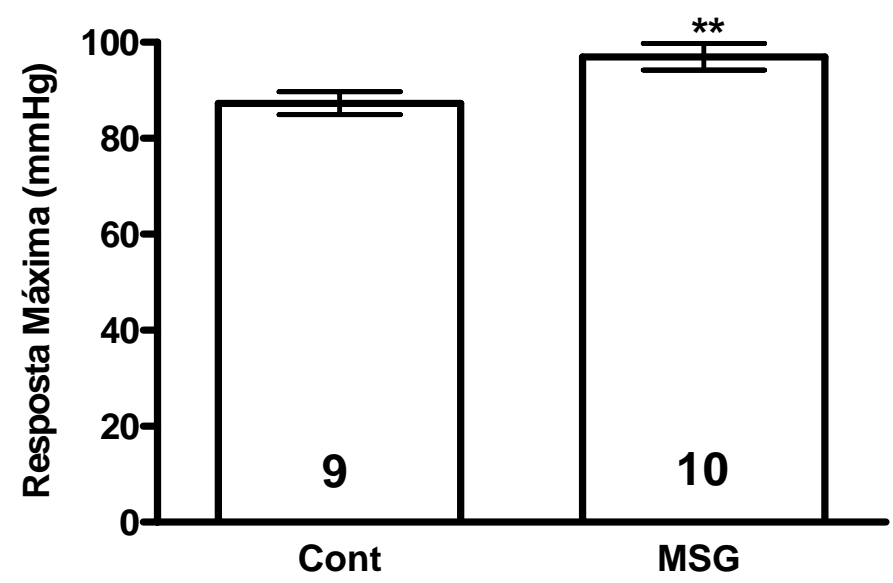

Figura 29 - Curva concentração-efeito (A) e resposta máxima vasodilatadora (B) para nitroprussiato de sódio no leito arteriolar mesentérico isolado de ratos Wistar controles (Cont) e obesos-MSG (MSG) com 16 semanas de idade. Cada ponto representa a média \pm epm. $O$ número de ratos utilizados em cada grupo encontra-se entre parênteses. " $p<0,01$ vs Cont. Os sinais de significância foram omitidos nos gráficos por motivo de clareza. As diferenças estão representadas no diagrama de barras. 
Tabela 22 - Valores de resposta máxima ao nitroprussiato de sódio (NPS) no leito arteriolar mesentérico de ratos controles e obesos-MSG (MSG) com 16 semanas de idade.

\begin{tabular}{ccccc}
\hline \hline & \multicolumn{2}{c}{ Controle } & \multicolumn{2}{c}{ MSG } \\
\hline & $\mathrm{R}_{\mathrm{MAX}}$ & $\mathrm{pD}_{2}$ & $\mathrm{R}_{\mathrm{MAX}}$ & $\mathrm{pD}_{2}$ \\
\multirow{3}{*}{ NPS } & $87,3 \pm 2,4$ & $\mathrm{ND}$ & $97,0 \pm 2,8^{\text {** }}$ & $\mathrm{ND}$ \\
& $(9)$ & & $(10)$ & \\
& & & & \\
\hline \hline
\end{tabular}

Os valores de $\mathrm{R}_{\text {MAX }}$ (Resposta máxima) representam a média \pm epm.

$\mathrm{ND}=$ não foi determinada o pD2 por ter havido diferença significativa na resposta máxima. O número de ratos utilizados em cada grupo encontra-se entre parênteses. $p<0,01$ vs Controle. 


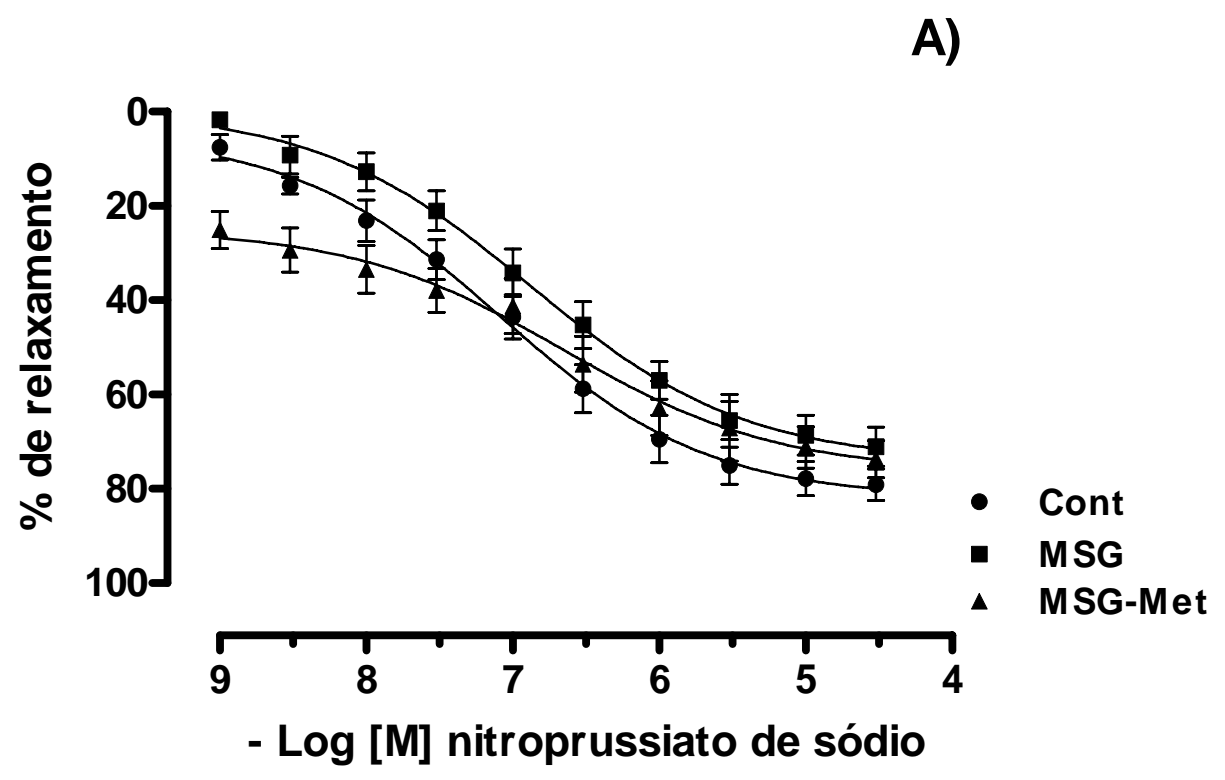

B)

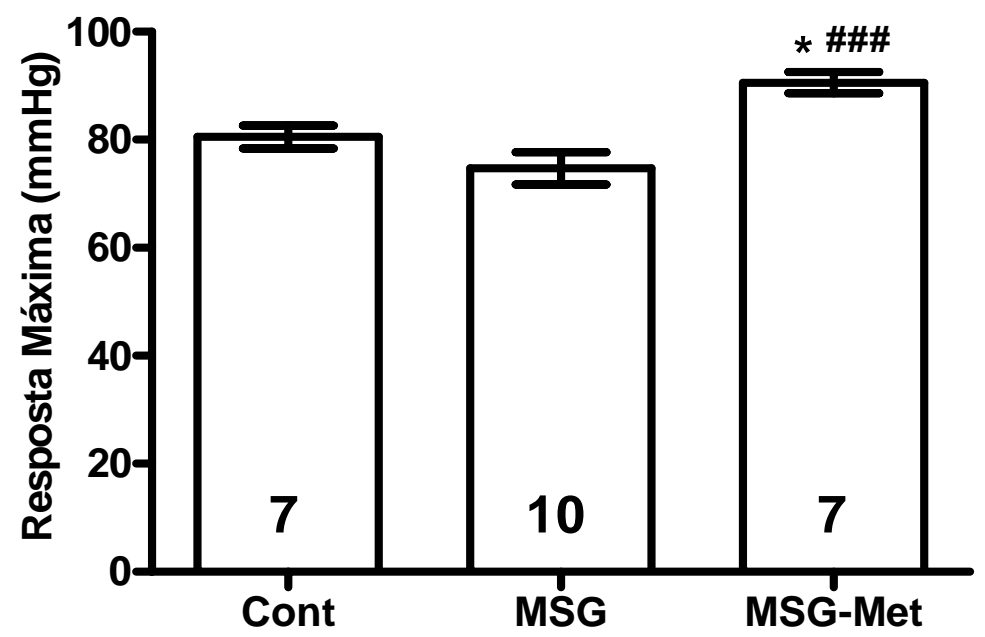

Figura 30- Curva concentração-efeito (A) e resposta máxima vasodilatadora (B) para nitroprussiato de sódio no leito arteriolar mesentérico isolado de ratos Wistar controles (Cont), obesos-MSG (MSG) e obesos-MSG tratados com metformina (MSG-Met) com 18 semanas de idade. Cada ponto representa a média \pm epm. O número de ratos utilizados em cada grupo encontra-se dentro das barras. * $p<0,05$ vs Controle; ${ }^{\# \#} p<0,001$ vs MSG.

Os sinais de significância foram omitidos nos gráficos por motivo de clareza. As diferenças estão representadas no diagrama de barras. 
Tabela 23 - Valores de resposta máxima ao nitroprussiato de sódio (NPS) no leito arteriolar mesentérico de ratos controles, obesos-MSG (MSG) e obesos-MSG tratados com metformina (MSG-Met) com 18 semanas de idade.

\begin{tabular}{ccccccc}
\hline \hline & \multicolumn{2}{c}{ Controle } & \multicolumn{2}{c}{ MSG } & \multicolumn{2}{c}{ MSG-Met } \\
\hline & $\mathrm{R}_{\mathrm{MAX}}$ & $\mathrm{pD}_{2}$ & $\mathrm{R}_{\mathrm{MAX}}$ & $\mathrm{pD}_{2}$ & $\mathrm{R}_{\mathrm{MAX}}$ & $\mathrm{pD}_{2}$ \\
\multirow{4}{*}{ NPS } & $80,3 \pm 1,8$ & $\mathrm{ND}$ & $74,72 \pm 2,9$ & $\mathrm{ND}$ & $90,6 \pm 2,0^{\# \#{ }^{*}}$ & $\mathrm{ND}$ \\
& $(7)$ & & $(10)$ & & $(7)$ & \\
\hline \hline
\end{tabular}

Os valores de $R_{\text {MAX }}$ (Resposta máxima) representam a média \pm epm.

$\mathrm{ND}=$ não foi determinada o pD2 por ter havido diferença significativa na resposta máxima. O número de ratos utilizados em cada grupo encontra-se entre parênteses. " $p<0,05$ vs Controle; ${ }^{\# \#} p<0,001$ vs MSG. 


\subsection{Produção de NO em Artérias Mesentéricas}

A produção basal de NO está reduzida em artérias mesentéricas dos ratos MSG com 16 e 18 semanas (Figura 31 A e C). O tratamento com metformina não corrigiu esta alteração. Após estímulo com Ach, a produção de NO nos ratos MSG com 16 e 18 semanas manteve-se significante menor quando comparada à de ratos controles. Quinze dias de tratamento com metformina não corrigiram a redução da produção estimulada de NO (Figura 31 B e D).

A)

B)

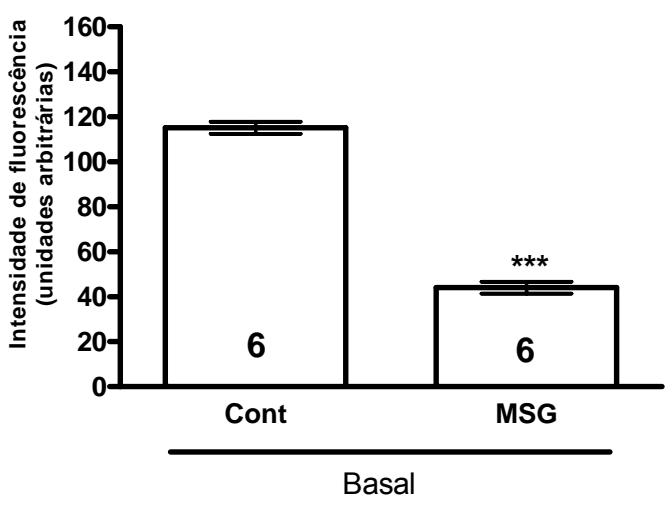

C)
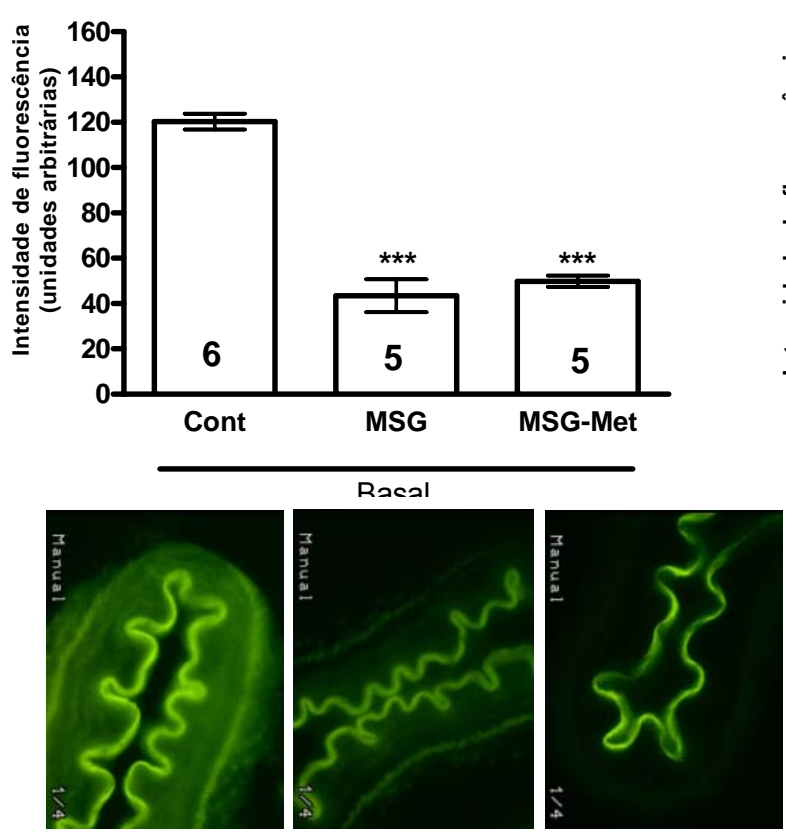

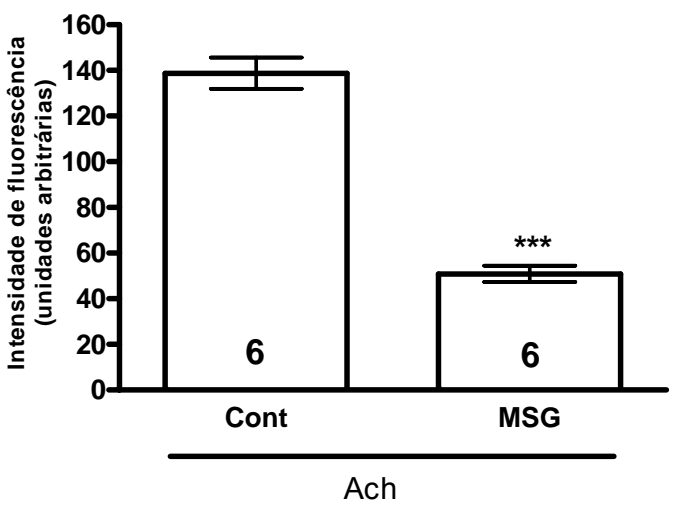

D)
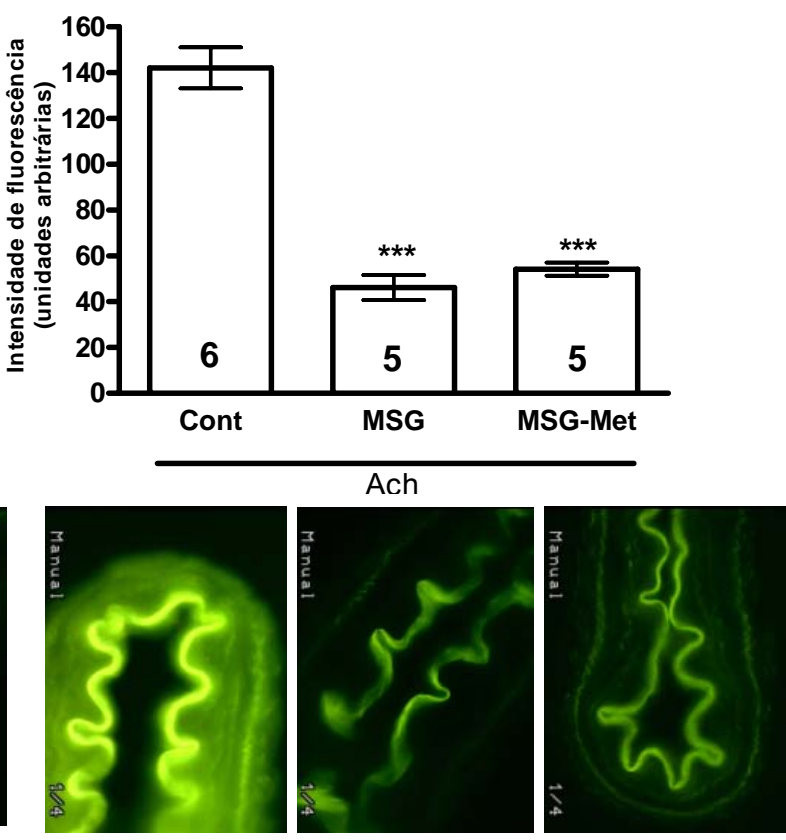

Figura 31 - Quantificação da produção de NO em artérias mesentéricas nas condições basal e estimulada com Ach dos grupos controle (Cont), obeso-MSG (MSG) com 16 semanas (A e B) e dos grupos Cont, MSG e obeso-MSG tratado com metformina (MSG-Met) com 18 semanas (C e D). Cada ponto representa a média \pm epm. $O$ número de ratos utilizados em cada grupo encontra-se dentro das barras. Os valores são expressos como média \pm epm dos valores obtidos. ${ }^{* * *} p<0,001$ vs Controle. 


\subsection{Geração de Espécies Reativas de Oxigênio em Artérias Mesentéricas}

Artérias mesentéricas de ratos MSG com 16 e 18 semanas de idade, apresentaram maior produção de EROs em relação aos controles. Quinze dias de tratamento com metformina corrigiram a aumentada geração de EROs nos ratos MSG (Figura 32 A e B).

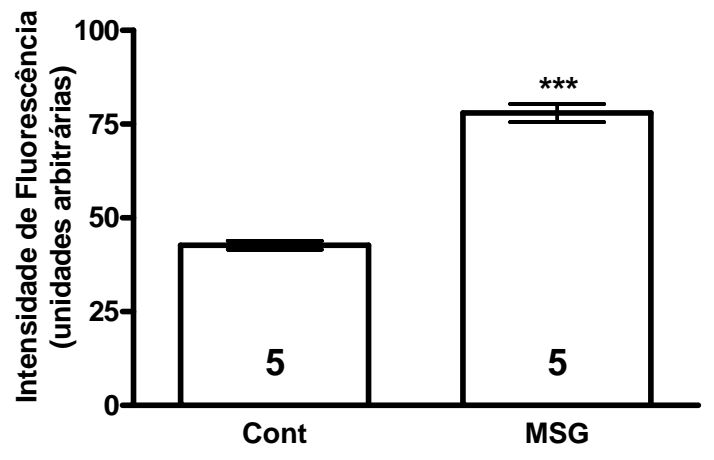

B)
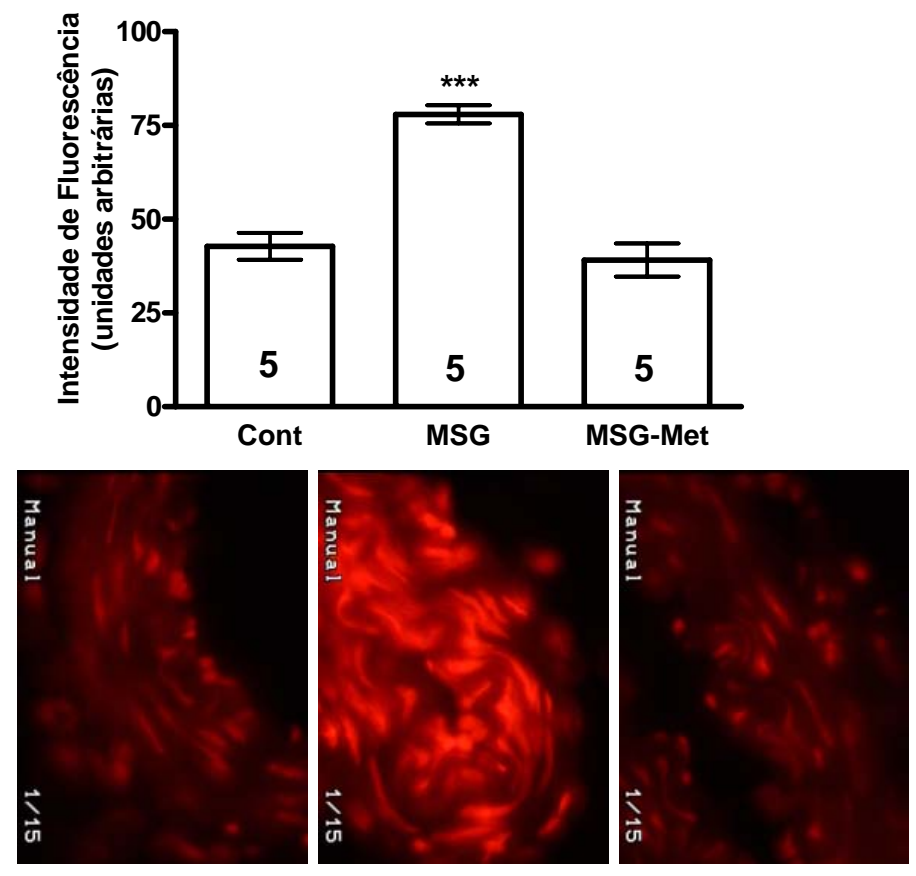

Figura 32 - Quantificação da geração espécies reativas de oxigênio em artérias mesentéricas dos grupos controle (Cont), obeso-MSG (MSG) com 16 semanas (A) e dos grupos Cont, MSG e obeso-MSG tratado com metformina (MSG-Met) com 18 semanas (B). Os valores são expressos como média \pm epm dos valores obtidos. ${ }^{* * *} p<0,001$ vs Controle. 


\section{DISCUSSÃO}

No presente trabalho demonstramos que 0 aumento da resposta vasoconstritora e a redução da resposta vasodilatadora dependente de endotélio em ratos MSG estão associados a alterações na via do NO e na geração de EROS e de produtos da via da COX, com aumento da hiperpolarização do músculo liso via canais de potássio. A metformina, além de corrigir as alterações metabólicas, reduzindo o acúmulo de gordura visceral, melhorando a sensibilidade à insulina e as alterações no perfil lipídico em ratos MSG, apresenta efeitos vasculares importantes por corrigir a resposta vasoconstritora e a resposta vasodilatadora dependente de reduzindo a geração de EROs e modulando a hiperpolarização de membrana.

\subsection{Metfomina e os Distúrbios Metabólicos na Obesidade Induzida por MSG}

A obesidade é caracterizada por alterações no perfil lipídico, estando estas associadas com o acúmulo de gordura visceral que por sua vez promove aumento das concentrações plasmáticas de ácidos graxos, liberados por meio da aumentada atividade lipolítica do tecido adiposo (BOSELLO e ZAMBONI, 2000). Além disso, está bem estabelecido que indivíduos obesos desenvolvem resistência às ações celulares da insulina, caracterizada pela diminuição da capacidade deste hormônio inibir a produção de glicose pelo fígado e promover a captação de glicose pelo músculo e tecido adiposo (SALTIEL e KAHN, 2001).

No presente estudo, utilizamos o modelo de obesidade inicialmente descrito por Olney (1969). A obesidade induzida por MSG causa, associada à redução do crescimento dos ratos, diminuição do peso corporal, e estas alterações são atribuídas às lesões que este aminoácido provoca no núcleo arqueado diminuindo os níveis do hormônio de crescimento (GH) (NEMEROFF et al., 1977; MAITER et al., 1991). Corroborando esses dados, redução significativa do peso corporal, bem como do comprimento naso-anal dos ratos MSG em relação aos controles foi observada em nosso estudo. O aumento significativo do peso das gorduras periepididimal e retroperitonial e da massa corpórea em relação ao comprimento naso-anal (Índice de Lee), associados às alterações no perfil lipídico e resistência à insulina, 
caracterizam a presença de obesidade nos ratos MSG, permitindo que os mesmos sejam considerados adequados para o presente estudo.

A obesidade é uma condição caracterizada por aumento nas concentrações plasmáticas de ácidos graxos livres não-esterificados em relação à demanda dos tecidos, que parece estar associada à expansão da massa de tecido adiposo, com consequente aumento na captação pelo fígado, aumentada lipogênese e produção de VLDL hepática, levando à hipertrigliceridemia, que pode ocorrer acompanhada ou não de aumento nos níveis de colesterol total (GINSBERG et al., 2005). De fato, observamos em nosso estudo que os ratos MSG apresentam alterações importantes no metabolismo de lipoproteínas plasmáticas, refletido pelo aumento nos níveis circulantes de colesterol total, triglicérides, colesterol LDL e VLDL. O fato de os níveis de colesterol total não estarem alterados nos ratos MSG com 16 semanas, mas estarem significantemente aumentados nos ratos com 18 semanas de idade, confirmam que as alterações metabólico-hormonais se instalam progressivamente ao longo do desenvolvimento nesses animais, assim como ocorre na obesidade humana (SALTIEL e KAHN, 2001).

Embora esteja bem estabelecido que a obesidade seja caracterizada por alterações no perfil lipídico (KISSEBAH et al., 1982), os mecanismos fisiopatológicos que explicam esta desordem são complexos e permanecem apenas parcialmente esclarecidos. Sabe-se que a resistência à insulina, característica presente na obesidade, pode contribuir para desordens no perfil lipídico (GINSBERG, 2000). A liberação de ácidos graxos livres pelo tecido adiposo para a circulação é mediada pela enzima lipase hormônio sensível. A ação dessa enzima é suprimida pela insulina em condições fisiológicas, entretanto, na resistência à insulina sua atividade encontra-se aumentada e consequentemente, ocorre aumento da concentração de ácidos graxos livres. Esses por sua vez, constituem um substrato para a síntese de VLDL no fígado, resultando em aumento nos níveis destas partículas na circulação, das quais maiores quantidades de triglicérides estarão disponíveis e serão transferidas para partículas de LDL colesterol, promovendo aumento em suas concentrações plasmáticas (COPPACK et al., 1992).

A enzima lipoproteína lipase, que participa da etapa inicial do clearance de triglicérides do plasma e armazenamento de ácidos graxos livres no tecido adiposo, também pode ter participação nas alterações do perfil lipídico na obesidade. A ação da lipoproteína lipase mediada pela insulina está diminuída na resistência à insulina, 
o que contribui para a elevação nos níveis plasmáticos de triglicerídeos (LEWIS et al., 2002). Diversas outras vias e enzimas estão envolvidas no metabolismo de lipoproteínas, sendo que alterações nessas vias/enzimas podem estar envolvidas na gênese da dislipidemia na obesidade. Uma vez que ratos MSG utilizados nesse estudo apresentaram redução da sensibilidade à insulina, alterações promovidas pela resistência à insulina no metabolismo de lipoproteínas podem ter participação na dislipidemia observada no nosso modelo.

Os efeitos benéficos da metformina corrigindo as alterações do perfil lipídico e promovendo redução significativa, embora parcial, do índice de Lee e do peso relativo das gorduras periepididimal e retroperitonial nos ratos MSG utilizados neste trabalho, estão de acordo com dados de outros estudos (RAZ et al., 2005). Em pacientes com diabetes tipo 2 a correção da dislipidemia têm sido associada com a diminuição da síntese e aumento da clearance de VLDL, podendo proporcionar uma via indireta através da qual a metformina melhora o ambiente metabólico e reduz a hiperglicemia nestes pacientes (WIERNSPERGER e BAILEY, 1999). Considerando que o próprio aumento da massa de tecido adiposo pode contribuir para as alterações no perfil lipídico presentes na obesidade através da aumentada liberação de ácidos graxos livres no plasma, o efeito da metformina reduzindo o acúmulo de gordura visceral , em adição ao seu efeito sensibilizador de insulina nos ratos MSG, pode ter contribuído para a correção das alterações no perfil lipídico observada em nosso estudo.

De modo similar ao observado em nosso trabalho, demonstrou-se que ratos alimentados com dieta rica em frutose - um modelo de resistência à insulina apresentam redução significativa do acúmulo de gordura retroperitonial, que foi atribuído por estes autores, ao aumento da atividade simpática nesta região, após tratamento com metformina por 4 semanas (BARET et al., 2002). Em adição, estudos clínicos demonstraram que pacientes diabéticos que fazem uso de metformina apresentam redução de peso que parece ser atribuída à perda de tecido adiposo, sem alterações significativas da massa magra, estando tal ação possivelmente relacionada à melhora da sensibilidade à insulina nestes pacientes (STUMVOLL et al., 1995). Aliado a isto, os efeitos diferenciais da metformina sobre o tecido adiposo e o músculo podem explicar a perda aparentemente seletiva de tecido adiposo observada nos ratos MSG. Estudos in vitro indicam que embora a metformina melhore a sensibilidade à insulina no músculo esquelético, ela não 
interfere na ação antilipolítica da insulina sobre o tecido adiposo (CIGOLINI et al., 1984). Já que as concentrações de insulina diminuem durante o tratamento com metformina, a lipólise tende a aumentar. Como a sensibilidade do músculo esquelético à insulina inclui um efeito anticatabólico sobre o metabolismo protéico, nenhuma alteração ocorre na massa magra, corroborando os resultados observados em nosso estudo.

A presença de resistência à insulina e sua importância nas alterações patológicas associadas à obesidade tem sido demonstrada em vários estudos tanto em modelos animais quanto na obesidade humana. No presente estudo, observamos que, apesar dos ratos MSG com 16 semanas apresentarem resistência à insulina, não apresentaram intolerância à glicose, diferentemente daqueles com 18 semanas de idade, que apresentaram, ambos resistência à insulina e intolerância à glicose. Estes resultados estão de acordo com estudos anteriores realizados com este modelo de obesidade, onde demonstrou-se, utilizando o teste de tolerância à glicose endovenoso (IVGTT), que estes ratos desenvolvem intolerância à glicose (HIRATA et al., 1997; MACHO et al., 2000; De MELLO et al., 2001; TOLEDO, 2005).

As diferenças observadas entre os grupos com 16 e 18 semanas em nosso estudo podem ser justificadas ao levarmos em consideração a existência de uma interação dinâmica entre a secreção de insulina pelo pâncreas e a resistência à insulina. Em condições fisiológicas os níveis de glicose sanguínea são mantidos dentro de estreitas faixas, apesar de consideráveis variações na disponibilidade de glicose, com as células $\beta$ pancreáticas sendo capazes de detectar estas alterações, respondendo rapidamente às mesmas através da modulação da síntese e liberação de insulina (para revisão ver DE FRONZO, 2004). Na intolerância à glicose, em uma etapa anterior à descompensação da célula $\beta$ e estabelecimento do diabetes tipo 2 , a secreção de insulina aumenta em resposta à resistência à insulina. À medida que as concentrações de glicose plasmáticas aumentam, os níveis de insulina no plasma também se elevam como resposta adaptativa do pâncreas para compensar a perda progressiva na homeostase glicêmica (BURKHARD, 1998). De fato, em nosso estudo, observamos este fenômeno nos ratos MSG, que apresentaram hiperinsulinemia acompanhada por aumento da capacidade secretória pancreática, avaliada pelo índice HOMA- $\beta$.

$\mathrm{Na}$ progressão do diabetes tipo 2 , as células $\beta$ tornam-se incapazes de manter a secreção de insulina elevada, inicialmente caracterizada pela redução da 
secreção de primeira fase deste hormônio em resposta a elevações na concentração de glicose, a qual é, ao menos em parte, reversivel após normalização da glicemia. Em uma fase posterior, a falência da célula $\beta$ progride e, com o declínio da capacidade secretória de insulina, as concentrações deste hormônio diminuem com consequente perda do controle glicêmico, até mesmo em jejum. Esta queda apresenta implicações fisiológicas importantes, pois é nesta fase que a produção de glicose pelo fígado começa a aumentar, com conseqüente instalação da intolerância à glicose (KASHYAP e DE FRONZO, 2007).

A partir dos dados obtidos em nosso trabalho sugerimos que, nos ratos MSG com 16 semanas de idade, a tolerância normal à glicose pode estar presente devido ao aumento das concentrações plasmáticas de insulina e da capacidade secretória pancreática, no que tange à regulação da liberação de insulina, garantindo assim a demanda do fígado, músculo esquelético e tecido adiposo destes ratos. Por outro lado, nos ratos MSG com 18 semanas, apesar da hiperinsulinemia associada ao aumento da capacidade pancreática em condições basais, que parece manter a glicemia em níveis normais, a capacidade da secreção de insulina pelas células $\beta$, quando estimulada por uma sobrecarga de glicose, encontra-se prejudicada.

A correção da hiperinsulinemia e da sensibilidade à insulina, acompanhada pela restauração da capacidade secretória pancreática nos ratos MSG tratados com metformina estão de acordo com outros estudos em modelos de resistência à insulina, utilizando este fármaco. Está bem estabelecido que o tratamento com metformina melhora a sensibilidade à insulina no diabetes tipo 2 tanto por mecanismos dependentes quanto independentes de insulina. Em concentrações terapêuticas ela suprime a gliconeogênese hepática, em parte por potencializar a ação da insulina aumentando a atividade tirosina kinase da subunidade $\beta$ do receptor de insulina e amplificando a via de sinalização pós-receptor (SEUFERT et al., 2004). Por outro lado, altas concentrações de metformina aumentam o metabolismo anaeróbico independentemente da insulina e por ação que envolve efeito sobre a cadeia respiratória mitocondrial (DETAILLE et al., 2005). A ativação da AMPK pela metformina também parece estar envolvida na melhora da sensibilidade à insulina observada com o uso deste fármaco por reduzir a atividade de tirosina fosfatases, que normalmente desativariam o receptor de insulina (BAILEY, 2007).

Estudos demonstram que o tratamento com metformina reduz os níveis de ácidos graxos livres no sangue, através da diminuição do efluxo destes a partir do 
tecido adiposo, suprimindo, deste modo, a produção de glicose hepática, constituindo este, um mecanismo indireto através do qual ela melhora a sensibilidade à insulina nos tecidos (ABBASI et al., 1998). Considerando que as concentrações de glicose sanguínea são reguladas principalmente pela produção de glicose pelo fígado e que os níveis de insulina dependem da resposta da célula $\beta$ às concentrações de glicose no sangue (MUNIYAPPA et al., 2007), a ação da metformina sobre o fígado tanto por mecanismos diretos quanto indiretos pode estar relacionada à melhora da função da célula $\beta$ e à redução da hiperinsulinemia observada nos ratos MSG.

A resistência à insulina na obesidade contribui para o desenvolvimento de uma série de alterações metabólicas e cardiovasculares, que favorecem o desenvolvimento diabetes tipo 2, dislipidemia, doença coronariana e hipertensão arterial arterial (CABALLERO et al., 2003). É bastante conhecida também a associação da obesidade como um fator de risco independente para o desenvolvimento de hipertensão arterial (KASHYAP e DE FRONZO, 2007). Diversos mecanismos explicam esta associação, dentre os quais, resistência à insulina, alterações do sistema renina angiotensina e disfunção endotelial. Associado a estes, estudos indicam que o aumento da atividade simpática está envolvido na patogênese da hipertensão arterial, não só em virtude dos efeitos hemodinâmicos, mas também das alterações renais e por indução do remodelamento vascular e cardíaco. O sistema nervoso autônomo exerce influência sobre o sistema cardiovascular por meio da liberação de neurotransmissores que mantêm o tônus vascular. Respostas reflexas do sistema nervoso simpático e parassimpático permitem ajustes do débito cardíaco e da resistência vascular periférica, contribuindo para a manutenção da pressão arterial sistêmica. Na patogênese da hipertensão arterial ocorre um desequilíbrio neste sistema com aumento na atividade simpática e conseqüente elevação da pressão arterial (WYSS, 1993).

Similarmente ao observado em trabalhos anteriores utilizando este modelo de obesidade (TOKAREV et al., 1997; MESSINA et al., 2005; TOLEDO, 2005), não verificamos alteração dos níveis de pressão arterial sistólica nos ratos MSG utilizados neste estudo. Tal resultado pode ser justificado com base nos relatos da literatura demonstrando que no modelo de obesidade induzido por MSG existe diminuição da atividade simpática (MORRIS et al., 1998; DULLOO e YOUNG, 1991) e aumento na atividade parassimpática (LUCINEI BALBO et al. 2000), que podem 
ter contribuído para a manutenção dos valores de pressão arterial normais nestes ratos, apesar das alterações vasculares apresentadas pelos mesmos.

\subsection{Efeito da Obesidade e do Tratamento com Metfomina Sobre a Reatividade Vascular}

Associadas às alterações metabólicas, doenças vasculares constituem as principais causas de morbidade e mortalidade em pacientes obesos (VAN GAAL et al., 2006). Embora esteja bem estabelecido que a obesidade é caracterizada por alterações microvasculares, os mecanismos envolvidos nessas desordens permanecem apenas parcialmente esclarecidos. $O$ entendimento destes mecanismos é de grande importância visto que pode levar ao planejamento de estratégias terapêuticas que tenham como meta impedir o desenvolvimento das desordens clínicas associadas à obesidade e, consequentemente, o desenvolvimento de diabetes tipo 2 e doenças cardiovasculares.

Embora estudos tenham demonstrado os efeitos vasculares benéficos da metformina em pacientes com diabetes tipo 2 (STEINBERG et al., 1996), estando estes associados com redução do risco de desenvolvimento de eventos cardiovasculares (BUNTING et al., 1986; SHARMA e BHALLA, 1995; DOMINGUEZ et al., 1996), o mecanismo de ação desta droga melhorando a reatividade vascular não está completamente esclarecido.

Em concordância com outros estudos realizados em humanos (STEINBERG et al., 1996) e utilizando modelos de obesidade (HE e MACLEOD, 2002; STEPP e CHANTEMELE, 2007), onde se demonstrou as complicações vasculares associadas com a obesidade e resistência à insulina (O'BRIEN et al., 1998), observamos no presente trabalho que os ratos MSG apresentam aumento da resposta vasoconstritora com 16 semanas, que se manteve nos ratos com 18 semanas de idade. Além disso, semelhantemente ao observado em outros modelos de resistência à insulina, como no diabetes tipo 2 (PEULER et al., 1997) e na hipertensão arterial (VERMA et al., 1996), demonstramos que o tratamento com metformina corrige as alterações na resposta vascular contrátil neste modelo de obesidade. 
Em estudo realizado por Majithiya e Balaraman (2006), foi demonstrado em anéis de aorta de ratos com diabetes induzido por estreptozotocina, que o tratamento com metformina restaura a aumentada resposta vasoconstritora promovida pela fenilefrina aos níveis do grupo controle, sendo esse efeito atribuído à possível ação da metformina revertendo o estresse oxidativo. Além disso, esses autores observaram que a incubação prévia de anéis de aorta de ratos diabéticos com metformina também foi capaz de reverter o aumento na resposta contrátil, sugerindo efeito direto da metformina sobre o vaso destes ratos.

Demonstramos também no presente estudo que o aumento da resposta vasoconstritora observado nos ratos MSG parece não estar associado a alterações no aparato contrátil das células do músculo liso vascular, comprovado pela curva ao $\mathrm{KCL}$. A adição de KCL à preparação permite analisar a viabilidade do músculo liso vascular ao avaliar a contração independente da ativação de receptores, visto que, aumentando a concentração de $\mathrm{K}^{+}$extracelular, reduz-se o efluxo de $\mathrm{K}^{+}$da célula muscular lisa pelos canais de $\mathrm{K}^{+}$da membrana celular, tornando assim o meio intracelular menos negativo, o que possibilita a despolarização. Essa, por sua vez, possibilita a abertura de canais de $\mathrm{Ca}^{2+}$ sensíveis a voltagem, presentes na membrana da célula muscular lisa promovendo o influxo de $\mathrm{Ca}^{2+}$ e conseqüente contração vascular (BRAYDEN, 1996).

Uma vez que o endotélio modula a reatividade vascular exercendo influência inibitória sobre o tônus do músculo liso frente a estímulos contráteis promovidos por agonistas adrenérgicos como a NA, através da liberação de EDRFs, alterações na modulação da resposta vasoconstritora mediada por estes fatores podem também ter participação nas alterações da reatividade vascular na obesidade e nos efeitos promovidos pela metformina. De fato, estudos sugerem que o aumento da resposta contrátil na obesidade está relacionado a alterações no endotélio (O'BRIEN et al., 1998), entretanto, o papel de cada um dos EDRFs nestas alterações não está totalmente esclarecido.

Considerando que o NO é um EDRF que pode ter participação importante nas alterações da reatividade vascular em modelos de resistência à insulina, investigamos a participação deste fator na alteração da resposta contrátil observada nos ratos MSG, bem como nos efeitos promovidos pela metformina. O fato, por nós verificado, de que a correção da resposta vasoconstritora promovida pela metformina foi revertida na presença do bloqueio, por L-NAME, da enzima NOS, 
leva-nos a sugerir que a via do NO tem participação importante na correção da resposta contrátil promovida pela metformina.

De modo similar ao NO, outro importante fator relaxante envolvido na modulação da resposta vasoconstritora, principalmente em vasos de resistência, é o EDHF. Embora a natureza química deste fator não tenha sido ainda elucidada, um dos mecanismos propostos para explicar sua ação vasodilatadora é a ativação inicial de canais de potássio ativados por cálcio $\left(\mathrm{K}_{\mathrm{ca}}\right)$ de condutância baixa e intermediária com conseqüente hiperpolarização do músculo liso vascular (FÉLÉTOU e VANHOUTTE, 1999). Estes canais estão presentes no endotélio e são sensíveis à inibição pelo composto TEA (Mc CULLOCH et al., 1997). Nossos resultados mostram que, similarmente ao observado com a via do NO, o componente hiperpolarizante (EDHF) tem participação importante nos efeitos promovidos pela metformina, visto que o bloqueio de canais de $\mathrm{K}^{+}$ativados por $\mathrm{Ca}^{2+}$ com TEA reverteu a correção da resposta contrátil observada nos ratos MSG-Met.

É importante ressaltar que além dos mecanismos relacionados aos EDRFs, outro componente importante envolvido na disfunção endotelial presente na resistência à insulina é o aumento na liberação de EDCFs. Uma via importante na produção destes fatores é a via da COX, que a partir do ácido araquidônico, produz prostanóides vasoconstritores como $\mathrm{TXA}_{2}$ e $\mathrm{PGF}_{2} \alpha$, ao lado de prostanóides vasodilatadores como $\mathrm{PGI}_{2}$ e $\mathrm{PGE}_{2}$, entre outros. A manutenção de um balanço entre a $\mathrm{PGI}_{2}$ e $\mathrm{O} \mathrm{TXA}_{2}$ tem importante papel na manutenção da homeostase vascular, e distúrbios neste equilíbrio podem ocorrer em determinadas doenças vasculares (MONCADA e HIGGS, 2006). Neste estudo, avaliamos a participação desta via no aumento da resposta contrátil à NA nos ratos MSG e na correção promovida pela metformina. A reversão da resposta vasoconstritora, aumentada nos ratos MSG, frente à inibição da síntese de prostanóides vasocontritores e vasodilatadores com indometacina, sem alterações no grupo tratado com metformina leva-nos a sugerir que alterações na geração e/ou no equilíbrio entre estes fatores estão envolvidas no aumento na resposta contrátil nos ratos MSG e que a metformina parece não exercer efeito sobre esta via.

Em resumo, com base nestas observações, podemos sugerir que o efeito potencializador da resposta vasoconstritora gerado pelos produtos da COX contribui para o aumento da resposta contrátil à NA nos ratos MSG e que a correção promovida pela metformina pode envolver efeito sobre o NO e o EDHF. A perda da 
função modulatória do endotélio exercida por estes fatores parece ter participação crítica no desenvolvimento das alterações vasculares neste modelo.

As desordens vasculares presentes em condições em que há resistência à insulina, como o diabetes tipo 2, estão associadas com alterações na função endotelial, incluindo diminuição da eficiência das vias de transdução dos EDRFs, diminuição da liberação ou aumento da destruição destes mediadores, além de aumento na liberação de EDCFs (DE VRIESE et al., 2000; CABALLERO, 2003), que podem contribuir para o aumento da resposta vasoconstritora e também para a redução da resposta relaxante dependente de endotélio.

A redução da sensibilidade ao agente vasodilatador dependente de endotélio Ach observada nos ratos MSG com 16 e com 18 semanas de idade utilizados em nosso trabalho está de acordo com outros estudos tanto clínicos (KREUTZENBERG et al., 2003) quanto experimentais utilizando modelos animais de obesidade (ROMANKO e STEPP, 2005). A resistência à insulina é uma característica da obesidade que tem sido bastante relacionada como fator responsável pelo desenvolvimento destas alterações (O'BRIEN et al., 1998; STEINBERG et al., 1996). Neste sentido, a melhora da sensibilidade à insulina não pode ser descartada como tendo participação na correção da resposta vasodilatadora à Ach, assim como da resposta vasoconstritora promovida pela metformina nos ratos MSG.

Estudos demonstram também que as alterações da função endotelial em condições caracterizadas por resistência à insulina, podem estar relacionadas à redução na produção dos EDRFs mediada pela ativação do receptor de Ach, que ocorre como consequência de alterações nas vias celulares pós-receptor (SOBREVIA e MANN, 1997). Entretanto, os mecanismos que contribuem para a diminuição no relaxamento mediado pelo endotélio na obesidade, principalmente no que tange à contribuição relativa de cada um dos EDRFs, ainda não estão completamente esclarecidos. Alterações na capacidade do endotélio liberar estes mediadores parecem ser os principais fatores responsáveis pelo desenvolvimento de muitos eventos cardiovasculares (FÉLÉTOU e VANHOUTTE, 2006).

No presente estudo confirmamos que a via do NO parece ter participação na alteração da reposta relaxante dependente de endotélio nos ratos MSG, visto que, a diminuição da sensibilidade à Ach observada nestes ratos foi revertida após o bloqueio da síntese de NO com L-NAME, com manutenção da correção promovida pela metformina. Embora nossos dados não permitam explicar este fenômeno, este 
resultado torna-se relevante ao levarmos em consideração que o estresse oxidativo tem papel importante na disfunção endotelial presente na obesidade e que uma fonte geradora de EROs é o desacoplamento da eNOS que, na presença, por exemplo, de níveis diminuídos de cofatores ou substrato, ao invés de oxidar a Larginina, reduz a molécula de $\mathrm{O}_{2}$ a ânion superóxido (POU et al., 1992; WEVER et al., 1997) que reage com o NO, reduzindo a vasodilatação dependente de endotélio. O desacoplamento desta enzima pode estar envolvido na redução da resposta vasodilatadora à Ach nos ratos MSG, o que justificaria a melhora da sensibilidade a este agonista frente à inibição da enzima NOS..

Embora o NO tenha sido considerado como principal mediador do relaxamento dependente de endotélio, tem se tornado evidente que a $\mathrm{PGI}_{2}$ e o EDHF, de modo similar ao NO, podem também ser importantes reguladores do tônus e da reatividade vascular, especialmente em vasos de resistência (FÉLÉTOU e VANHOUTTE, 1999). Apesar do perfil distinto de atividade que é conferido a cada um dos EDRFs, existem claras evidências demonstrando existir uma inter-relação complexa, porém bem integrada, entre estes mediadores de tal modo a garantir a manutenção da homeostase vascular. Estas inter-relações têm sido bem caracterizadas em termos de manutenção do tônus vascular, e ocorrem para garantir a regulação fisiológica do diâmetro do vaso, podendo ocorrer também como mecanismo compensatório, que é ativado quando a expressão ou atividade de um dos mediadores está deficiente (VILLAR et al., 2006).

Investigando a participação da via do EDHF na resposta vasodilatadora dependente de endotélio, verificamos que esta via tem maior participação na resposta relaxante dependente de endotélio em ratos MSG visto que a resposta máxima vasodilatadora à Ach encontra-se significantemente diminuída nestes ratos na presença de TEA, dando suporte à hipótese levantada no parágrafo anterior. $O$ papel do EDHF atuando de maneira compensatória em condições onde existe diminuição da atividade da NOS, e conseqüentemente, da produção de NO, em alguns leitos vasculares foi demonstrado em estados fisiopatológicos como a hipertensão arterial e o diabetes tipo 2 (VILLAR et al., 2006), e a ativação desta via pode justificar a manutenção da resposta máxima vasodilatadora à Ach nos ratos MSG, assim como a similaridade na reposta vasodilatadora frente à inibição da NOS com L-NAME. 
De fato, nossos resultados comprovam a hipótese levantada anteriormente, visto que observamos diminuição da produção de NO associada com aumento na geração de EROs pelas artérias mesentéricas dos ratos MSG, fatores que podem ter contribuído para a diminuição da vasodilatação dependente de endotélio e para a aumentada resposta contrátil dos ratos MSG, com consequente ativação da via do EDHF como mecanismo compensatório na tentativa de corrigir a redução da resposta vasodilatadora.

Por outro lado, o efeito da metformina corrigindo a resposta vasodilatadora à Ach nos ratos MSG foi mantido mesmo na presença de TEA, sugerindo que o componente EDHF, apesar de apresentar participação importante na correção da resposta contrátil em ratos $\mathrm{MSG}$, parece não estar envolvido na correção da resposta vasodilatadora promovida pela metformina. Em adição, embora a metformina tenha reduzido a geração de EROs, não corrigiu a produção de $\mathrm{NO}$, diminuída nos ratos MSG tanto em condições basais quanto após estímulo com a Ach. Esse resultado nos indica que o efeito benéfico da metformina restaurando as alterações na resposta vasodilatadora parecem estar associados principalmente à redução na geração de EROs em artérias mesentéricas.

Os resultados obtidos neste estudo demonstram que alterações na via dos metabólitos do ácido araquidônico estão envolvidas na redução da sensibilidade à Ach, observada nos ratos MSG, visto que a inibição desta via com indometacina reverteu a diminuição da sensibilidade à Ach nestes ratos. A correção promovida pela metformina foi mantida na presença deste bloqueio, sugerindo que esta via parece não ter participação na correção da resposta vasodilatadora pela metformina.

Além de desequilíbrio na liberação dos EDRFs e EDCFs, alterações na função vascular podem ocorrer devido a alterações no músculo liso. Estudos demonstraram que na obesidade experimental o aumento na resposta contrátil à NA em arteríolas mesentéricas se deve a alterações no músculo liso (O'BRIEN et al., 1998), e que as células musculares lisas de ratos obesos são altamente hiperplásticas e ativas (ABSHER, 1997). Embora não esteja completamente esclarecido, aumento da densidade de receptores e do influxo de cálcio extracelular para o músculo liso vascular, bem como maior atividade da proteína $G$, e ainda alterações pós-receptor têm sido relacionadas às alterações vasculares observadas na microcirculação de ratos com resistência à insulina (KARASU e ALTAN, 1993). Portanto, alterações em alguma destas vias específicas presentes no músculo liso 
vascular podem ter contribuído para as alterações na reatividade vascular observadas nos ratos MSG.

No presente estudo observamos que a resposta vasodilatadora independente de endotélio está aumentada nos ratos MSG com 16 semanas, diferentemente do observado nos ratos MSG com 18 semanas de idade. A maior parte dos estudos com modelos de resistência à insulina demonstra vasodilatação prejudicada a agonistas dependentes de endotélio sem alterações na resposta a vasodilatadores independentes de endotélio (GARLAND e MCPHERSON, 1992; SHIMOKAWA, 1996; MESSINA et al., 2005). O NPS, como os demais nitratos orgânicos, age diretamente no músculo liso vascular doando NO e por sua vez, ativando a enzima guanilato ciclase solúvel, considerada como receptor intracelular do NO (MONCADA et al., 1988). O mecanismo pelo qual houve aumento da responsividade do músculo liso ao NO (testado com o NPS) no leito arteriolar mesentérico de ratos MSG com 16 semanas e que foi perdido nos ratos com 18 semanas de idade, pode envolver alterações no sistema guanilato ciclase como efeito compensatório em virtude da diminuição da produção e/ou aumento da degradação do NO produzido pelo endotélio. De fato, em estudo realizado por Moncada e cols (1991) utilizando anéis de aorta tratados com inibidores da enzima NOS, observou-se um aumento na resposta relaxante independente de endotélio mediada pelo NPS, com aumento nos níveis de cGMP. Os autores concluiram que, na ausência da liberação de NO endógeno, ocorre uma hipersensibilidade do músculo liso vascular à aplicação exógena daquele mediador pelo aumento nas concentrações de cGMP.

O fato do aumento da resposta do músculo liso ao NO ter sido revertido em ratos com 18 semanas sem tratamento reforça a hipótese da eficácia da metformina em melhorar a resposta vascular, sugerindo também efeito desta droga sobre o músculo liso vascular. Neste sentido, estudos anteriores avaliando os efeitos da metformina in vitro em microvasos de um modelo de resistência à insulina, observaram que ela promove relaxamento do músculo liso independentemente do endotélio (KATAKAM et al., 2000). Embora o mecanismo de ação da metformina sobre o músculo liso vascular não esteja completamente esclarecido, em modelo de hipertensão arterial seus efeitos hipotensores foram também associados a um efeito direto sobre o músculo liso vascular, que parece estar relacionado à diminuição na concentração intracelular de cálcio (BHALLA et al., 1996). Estes autores demonstraram ainda que a metformina amplifica o fenômeno de oxidação de $\mathrm{OH}-\mathrm{L}-$ 
arginina no músculo liso vascular, para formar $\mathrm{NO}$ e nitrito, processo que é dependente do citocromo p450. Futuros estudos são necessários para investigar os mecanismos envolvidos nestes efeitos da metformina sobre o músculo liso vascular dos ratos $M S G$.

Em resumo, os resultados por nós obtidos enfatizam a importância do NO e dos produtos da COX para a manutenção da homeostase vascular, especialmente em situações em que há resistência à insulina e obesidade, características apresentadas pelo modelo utilizado para este estudo. Nossos resultados demonstram também que o componente EDHF representa papel importante neste modelo de obesidade ao produzir vasodilatação sob condições onde existe diminuição na produção e/ou biodisponibilidade de NO e desequilibrio na geração de prostanóides. Apesar da importância deste fator em condições onde existe disfunção endotelial, como a obesidade, não estar bem caracterizada, seu papel no sistema vascular de ratos MSG parece ser relevante. Demonstramos ainda no presente estudo que o tratamento com metformina, além de corrigir as alterações metabólicas, reduzindo o acúmulo de gordura visceral, melhorando a sensibilidade à insulina e as alterações no perfil lipídico em ratos MSG, corrige a aumentada resposta vasoconstritora e a diminuida resposta vasodilatadora dependente de endotélio, atuando sobre a via do NO, do EDHF e reduzindo a geração de EROs, além de interferir sobre a resposta do músculo liso vascular ao NO. 


\section{CONCLUSÕES}

Os resultados do presente estudo permitem-nos concluir que, em ratos MSG:

O aumento da resposta vasoconstritora e a diminuição da resposta vasodilatadora dependente de endotélio estão relacionados com alterações na via do NO e da COX, associados com aumento na geração de EROs;

Há maior participação da via do EDHF na resposta vasodilatadora que pode constituir mecanismo compensatório frente à redução da resposta vasodilatação dependente de NO nos ratos MSG;

A metformina restaura a aumentada resposta vasoconstritora e a diminuída resposta vasodilatadora dependente de endotélio, atuando na via do NO e do EDHF, bem como, reduzindo a geração de EROs, restabelecendo assim o equilíbrio na geração dos EDRFs/ EDCFs;

$>\mathrm{O}$ aumento da resposta do músculo liso vascular ao NO pode constituir mecanismo compensatório à remoção do tônus vasodilatador dependente de NO;

A metformina interfere com a resposta do músculo liso vascular promovendo aumentada responsividade ao NO. 


\section{REFERÊNCIAS BIBLIOGRÁFICAS ${ }^{*}$}

ABBASI, F.; CARANTONI, M.; CHEN, Y. D. I.; REAVEN G. M. Further evidence for a central role of adipose tissue in the antihyperglycemic effect of metformin. Diabetes care, v. 21, n. 8, p. 1301-1305, 998.

ABSHER, P. M.; SCHNEIDER, D.J.; BALDOR, L. C.; RUSSELL, J. C.; SOBEL, B. E. Increased proliferation of explanted vascular smooth muscle cells: a marker presaging atherogenesis. Atherosclerosis, v. 131, n. 2, p. 187-194, 1997.

AVOGARO, A.; KREUTZENBERG, S. V. Mechanisms of endothelial dysfunction in obesity. Clin. Chim. Acta, v. 360, n. 1-2, p. 9-26, 2005.

BAILEY, C. J. Treating insulin resistance: future prospects. Diab. Vasc. Dis. Res., v. 4, n.1, p. 20-31, 2007.

BANDYOPADHYAY, G.; STANDAERT, M. L.; ZHAO, L. Y. ; AVIGNON, A.; GALLOWAY, L.; KARNAM, P.; MOSCAT, J.; FARESE, R. V. Activation of protein kinase $C$ (alpha, beta, and zeta) by insulin in 3T3/L1 cells. Transfection studies suggest a role for PKC-zeta in glucose transport. J. Biol. Chem., v. 272, n. 4, p. 2551-2558, 1997.

BARET, G.; PEYRONNET, J.; GRASSI-KASSISSE, D.; DALMAZ, Y.; WIERNSPERGER, N.; GÉLOËN, A. Increased intraabdominal adipose tissue mass in fructose fed rats: correction by metformin. Exp. Clin. Endocrinol. Diabetes, v. 110, n. 6, p. 298-303, 2002.

BHALLA, R. C.; TOTH, K. F.; TAN, E.; BHATTY, R. A.; MATHIAS, E.; SHARMA, R. $V$. Vascular effects of metformin. Possible mechanisms of its antihypertensive action in the spontaneously hypertensive rat. A.J.H., v. 9, n. 6, p. 570-576, 1996.

BODEN, G. Role of Fatty Acids in the Pathogenesis of Insulin Resistance and NIDDM. Diabetes, v. 46, n. 1, p. 3-10, 1997.

*De acordo com:

ASSOCIAÇÃO BRASILEIRA DE NORMAS TÉCNICAS. NBR 6023: informação e documentação: referências: elaboração. Rio de Janeiro, 2002. 
BOSELLO, O.; ZAMBONI, M. Visceral obesity and metabolic syndrome. Obes. Rev., v. 1, n. 1, p. $47-56,2000$.

BRAYDEN, J. E. Potassium channels in vascular smooth muscle. Clin. Exp. Pharmacol. Physiol., v. 23, n. 12, p. 1069-1076, 1996.

BUNTING, C. E.; KOSCHINSKY, T.; RIITTER, R.; GRIES, F. A. Metformin inhibits the growth of human vascular cells: a new potentially anti atherogenic drug effect. Diabetologia, v. 29, n. 1, p. 523, 1986.

BURKHARD, G. Implications of blood glucose, insulin resistance and $\beta$-cell function in impaired glucose tolerance. Diabetes Res. Clin. Pract., v. 40, n. 1, p. 15-20, 1998.

CABALLERO, A. E. Endothelial Dysfunction in Obesity and Insulin Resistance: A Road to Diabetes and Heart Disease. Obes. Res., v. 11, p. 1278-1289, 2003.

CIGOLINI, M.; BOSELLO, O.; ZANCANARO, C.; ORLANDI, P. G.; FEZZI, O.; SMITH, U. Influence of metformin on metabolic effect of insulin in human adipose tissue in vitro. Diabetes Metab., v. 10, p. 311-5, 1984.

COHEN, R. A.; VANHOUTTE, P. M. Endothelium-dependent hyperpolarization. Beyond nitric oxide and cyclic GMP. Circulation, v. 92, n. 11, p. 3337-3349, 1995.

COPPACK, S. W.; EVANS, R. D.; FISHER, R. M.; FRAYN, K. N.; GIBBONS, G. F.; HUMPHREYS, S. M.; KIRK, M. L.; POTTS, J. L.; HOCKADAY, T. D. Adipose tissue metabolism in obesity: lipase action in vivo before and after mixed meal. Metab. Clin. Exp., v. 41, n. 3, p. 264-72, 1992.

DE FRONZO, R. A. Pathogenesis of type 2 diabetes mellitus. Med. Clin. North. Am., v. 88, n. 1-2, p. 787-835, 2004. Review.

DE MELLO, M. A.; DE SOUZA, C. T.; BRAGA, L. R.; DOS SANTOS, J. W.; RIBEIRO, I. A.; GOBATTO, C. A. Glucose tolerance and insulin action in monosodium glutamate (MSG) obese exercise-trained rats. Physiol. Chem. Phys. Med., v. 33, n. 1, p. 63-7, 2001.

DE VRIESE, A. S.; VERBEUREN, T. J.; VOORDE, J. V.; LAMEIRE, N.H.; VANHOUTTE, P. M. Endothelial dysfunction in diabetes. Br. J. Pharmacol., v. 130, n. 5, p. 963-974, 2000. 
DELARUE, J.; MAGNAN, C. Free fatty acids and insulin resistance. Curr. Opin. Clin. Nutr. Metab. Care, v.10, n. 2, p. 142-8, 2007.

DETAILLE, D.; GUIGAS, B.; CHAUVIN, C.; BATANDIER, C.; FONTAINE, E.; WIERNSPERGER, N.; LEVERVE, X. Metformin prevents high-glucose-induced endothelial cell death through a mitochondrial permeability transition-dependent process. Diabetes, v. 54, n. 7, p. 2179-2187, 2005.

DOMINGUEZ, L. J.; DAVIDOFF, A. J.; SRINIVAS, P. R.; STANDLEY, P.R.; WALSH, M. F.; SOWERS, J.R. Effects of Metformin on Tyrosine Kinase Activity, Glucose Transport, and Intracellular Calcium in Rat Vascular Smooth Muscle. Endocrinology, v. 137, n. 1, p. 113-121, 1996.

DULLOO, A. G.; YOUNG, J. B. Effects of monosodium glutamate and gold thioglucose on dietary regulation of sympathetic nervous system activity in rodents. Metabolism, v. 40, n. 2, p. 113-121, 1991.

ENGELI, S.; JANKE, J.; GORZELNIAK, K.; BÖHNKE, J.; GHOSE, N.; LINDSCHAU, C.; LUFT, F. C.; SHARMA, A. M. Regulation of the nitric oxide system in human adipose tissue. J. Lipid. Res., v. 45, n. 9, p. 1640-8, 2004.

FÉLETOU, M.; VANHOUTTE, P. M. The third pathway: endothelium-dependent hyperpolarization. J. Physiol. Pharmacol., v. 50, n. 4, p. 525-34, 1999.

FÉLÉTOU, M.; VANHOUTTE, P. M. Endothelial dysfunction: a multifaceted disorder. Am. J. Physiol. Heart Circ. Physiol., v. 291, n. 3, p. 985-1002, 2006.

FONSECA, V. A. Management of diabetes mellitus and insulin resistance in patients with cardiovascular disease. Am. J. Cardiol., v. 92, n. 4, p. 50-60, 2003.

FORMIGUERA, X.; CANTÓN, A. Obesity: edipemiology and clinical aspects. Baillieres Clin. Gastroenterol., v. 18, n. 6, p. 1125-1146, 2004.

FREIDENBERG, G. R.; REICHART, D.; OLEFSKY, J. M.; HENRY, R. R. Reversibility of defective adipocyte insulin receptor kinase activity in non-insulin-dependent diabetes mellitus. Effect of weight loss. J. Clin. Invest., v. 82, n. 4, p. 1398-406, 1988. 
FURCHGOTT, R. F.; VANHOUTTE, P. M. Endothelium-derived relaxing and contracting factors. FASEB J., v. 3, p. 2007-2018, 1989.

GARLAND, J. G.; McPHERSON, G. A. Evidence that nitric oxide does not mediate the hyperpolarization and relaxation to acetylcholine in the rat small mesenteric artery. Br. J. Pharmacol., v. 105, p. 429-435, 1992.

GINSBERG, H. N.; ZHANG. Y. L.; HERNANDEZ-ONO, A. Regulation of plasma triglycerides in insulin resistance and diabetes. Arch. Med. Res., v. 36, n. 3, p. 232240, 2005.

GINSBERG, H. N. Insulin resistance and cardiovascular disease. J. Clin. Invest., v. 106, p. 453-458, 2000.

GREENFIELD, J.; CAMPBELL, L. Insulin resistance and obesity. Clin. Derm., v. 22, n. 4, p. 289-295, 2004.

HE, Y.; MACLEOD, K. M. Modulation of noradrenaline-induced vasoconstriction in isolated perfused mesenteric arterial beds from obese Zucker rats in the presence and absence of insulin. Can. J. Physiol. Pharmacol., v. 80, n. 3, p. 171-179, 2002.

HILL, J. O. Understanding and addressing the epidemic of obesity: an energy balance perspective. Endocr. Rev., v. 27, n. 7, p. 750-761, 2006.

HIRATA, A. E.; ANDRADE, I. S.; VASKEVICIUS, P.; DOLNIKOFF, M. S. Monosodium glutamate (MSG)-obese rats develop glucose intolerance and insulin resistance to peripheral glucose uptake. Braz. J. Med. Biol. Res., v. 30, p. 671-674, 1997.

HOLZWARTH-MCBRIDE, M. A.; SLADEK, K. M.; KNIGGE, J. R. Monosodium glutamate induced lesions of the arcuate nucleus. II. Fluorescence histochemistry of catecholamines. Anat. Rec., v. 186, p. 197-206, 1976.

JOHNSON, J. A.; MAJUMDAR, S. R.; SIMPSON, S. H.; et al. Decreased mortality associated with the use of metformin compared with sulfonylurea monotherapy in type 2 diabetes. Diabetes Care, v. 25, p. 2244-2248, 2002.

KARASU, C.; ALTAN, V. M. The role of endothelial cells on the alterations in vascular reactivity induced by insulin-dependent diabetes mellitus: effects of insulin treatment. Gen. Pharmacol., v. 24, n. 3, p. 743-755, 1993. 
KASHYAP, S. R.; DE FRONZO, R.A. The insulin resistance syndrome: physiological considerations. Diab. Vasc. Dis. Res., v. 4, n. 1, p. 13-19, 2007.

KATAKAM, P. V. G.; UJHELYI, M. R.; HOENIG, M.; Miller, A. W. Metformin Improves Vascular Function in Insulin-Resistant Rats. Hypertension, v. 35, p. 108-112, 2000.

KELISHADI, R. Childhood Overweight, Obesity, and the Metabolic Syndrome in Developing Countries. Epidemiol. Rev., v. 3, p. 1-15, 2007.

KEMP, B. E.; MITCHELHILL, K. I.; STAPLETON, D.; MICHELL, B. J.; CHEN, Z. P.; WITTERS, L. A. Dealing with energy demand: the AMP-activated protein kinase. Trends. Biochem. Sci., v. 24 p. 22-25, 1999.

KIM, J.; MONTAGNAMI, M.; KOH, K. K.; QUON, M.J. Reciprocal relationships between insulin resistance and endothelial dysfunction: molecular and pathophysiological mechanisms. Circulation, v. 113, p. 1888-1904, 2006.

KIZER, J. S.; NEMEROFF, C. B.; YOUNGBLOOD, W. W. Neurotoxic amino acids and structurally related analogs. Pharmacol. Rev., v. 29, n. 4, p. 301-318, 1977.

KISSEBAH, A.H.; VYDELLNGUM, N.; MURRAY, R.; et al. Relation of body fat distribution to metabolic complications of obesity. J. Clin. Endocrinol. Metab., v. 54, p. 254-260, 1982.

KOHN, A. D.; SUMMERS, S. A.; BIRNBAUM, M. J.; ROTH, R.A. Expression of a constitutively active Akt ser/thr kinase in 3T3-L1 adipocytes stimulates glucose uptake and glucose transporter 4 translocation. J. Biol. Chem., v. 27, p. 3137231378, 1996.

KRENTZ, A. J.; BAILEY, C. J. Oral antidiabetic agents: current role in type 2 diabetes mellitus. Drugs, v. 65, n. 3, p. 385-411, 2005. Review.

KREUTZENBERG, S. V. E.; KIWANUKA, A.; TIENGO, A.; AVOGARO, A. Visceral obesity is characterized by impaired nitric oxide-independent vasodilation. Eur. Heart J., v. 24, n. 13, p. 1210-1215, 2003.

LARSEN, P. J.; MIKKELSEN, J. D.; JESSOP, D.; LIGHTMAN, S. L.; CHOWDREY, $\mathrm{H}$. S. Neonatal monosodium glutamate treatment alters both the activity and the 
sensitivity of the rat hypothalamo-pituitary-adrenocortical axis. J. Endocrinol., v. 141, v. 3, p. 497-503, 1994.

LI, Z.; BOWERMAN, S.; HEBER, D. Health Ramifications of the Obesity Epidemic. Surg. Clin. N. Am., v. 85, n. 4, p. 681-701, 2005.

LUCINEI-BALBO, S.; GRAVENA, C.; BONFLEUR, M. L.; DE FREITAS, M. P. C. Insulin secretion and acetylcholinesterase activity in monosodium I-glutamateinduced obese mice. Horm. Res., v. 54, n. 4, n. 186-191, 2000.

MACHO, L.; FICKOVA, M.; JEZOVA, ZORAD, S. Late effects of postnatal administration of monosodium glutamate on insulin action in adult rats. Physiol. Res., v. 49, n. 1, p. S79-85, 2000.

MAITER, D.; UNDERWOOD, L. E.; MARTIN, J. B.; KOENIG, J. I. Neonatal treatment with monosodium glutamate: effects of prolonged growth hormone $(\mathrm{GH})$-releasing hormone deficiency on pulsatile $\mathrm{GH}$ secretion and growth in female rats. Endocrinology, v. 128, n. 2, p. 1100-1106, 1991.

MAJITHIYA, J.; BALARAMAN, R. Metformin reduces blood pressure and restores endothelial function in aorta of streptozotocin-induced diabetic rats. Life Sci., v. 78, p. 2615-2624, 2006.

McGREGOR, D. D. The effect of sympathetic nerve stimulation of vasoconstrictor responses in perfused mesenteric blood vessels of the rat. J. Physiol., v. 177, p. 21-30, 1965.

MARIN, P.; DARIN, N.; AMEMIYA, T.; ANDERSSON, B.; JERN, S.; BJORNTORP, $P$. Cortisol secretion in relation to body fat distribution in obese premenopausal women. Metabolism, v. 41, n. 8, p. 882-886, 1992.

MARMO, M. R.; DOLNIKOFF, M. S.; KETTELHUT, I. C.; MATSUSHITA, D. M.; HELL, N. S.; LIMA, F. B. Neonatal monosodium glutamate treatment increases epididymal adipose tissue sensitivity to insulin in three-month old rats. Braz. J. Med. Biol. Res., v. 27, n. 5, p. 1249-1253, 1994.

MATHER, K. J.; MIRZAMOHAMMADI, B.; LTEIF, A.; STEINBERG, H. O.; BARON, A. D. Endothelin Contributes to Basal Vascular Tone and Endothelial Dysfunction in Human Obesity and Type 2 Diabetes. Diabetes, v. 51, n. 12, p. 3517-3523, 2002. 
MATSUZAWA, Y. Therapy insight: adipocytokines in metabolic syndrome and related cardiovascular disease. Nat. Clin. Pract. Cardiovasc. Med., v. 3, p. 35-42, 2006.

MATTHEWS, D. R.; HOSKER, J. P.; RUDENSKI, A. S.; NAYLOR, B. A.; TREACHER, D. F.; TURNER, R. C. Homeostasis model assessment: insulin resistance and beta-cell function from fasting plasma glucose and insulin concentrations in man. Diabetologia, v. 28, n. 7, p. 412-419, 1985.

McCULLOCH, A. I.; BOTTRILL, F. E.; RANDALL, M. D.; HILEY, C. R. Characterization and modulation of EDHF-mediated relaxations in the rat isolated superior mesenteric arterial bed. Br. J. Pharmacol., v. 120, n. 8, p. 1431-1438, 1997.

McGIFF, J. C.; CARROLL, M. A.; ESCALANTE, B. Arachidonate metabolites and kinins in blood pressure regulation. Hypertension, v. 18, n. 5, p. 150-157, 1991.

MESSINA, M.M.; EVANS, S. A.; SWOAP, S. J.; OVERTON, J. M. Perinatal MSG treatment attenuates fasting-induced bradycardia and metabolic suppression. Physiol. Behav., v. 86, n. 3, p. 324-330, 2005.

MONCADA, S.; GRYGLEWSKI, R.; BUNTING, S.; VANE, J. R. An enzyme isolated from arteries transforms prostaglandin endoperoxides to an unstable substance that inhibits platelet aggregation. Nature, v. 263, n. 5579, p. 663-65, 1976.

MONCADA, S.; REES, D. D.; SCHULZ, R.; PALMER, R. M. Development and mechanism of a specific supersensitivity to nitrovasodilators after inhibition of vascular nitric oxide synthesis in vivo. Proc. Natl. Acad. Sci. USA, v. 88, n. 6, p. 2166-2170, 1991.

MONCADA, S.; RADOMSKI, M. W; PALMER, R. M. J. Endothelium-derived relaxing factor. Identification as nitric oxide and role in the control of vascular tone and platelet function. Biochem. Pharmacol., v. 37, n. 13, p. 2495-2501, 1988.

MONCADA, S.; HIGGS, E. A. The discovery of nitric oxide and its role in vascular biology. Br. J. Pharmacol., v. 147, p. S193-S201, 2006.

MONTEIRO, J. C. Obesidade: diagnóstico, métodos e fundamentos. In: MONTEIRO, J. C. Obesidade. São Paulo: Lemos Editorial, 1998.

MORRIS, M. J.; TORTELLI, C. F.; FILIPPIS, A.; PROIETTO, J. Reduced BAT 
function as a mechanism for obesity in the hypophagic, neuropeptide $\mathrm{Y}$ deficient monosodium glutamate-treated rat. Regul. Pept., v. 25, n. 75, p. 441-447, 1998.

MUNIYAPPA, R.; MONTAGNANI, M.; KOH, K. K.; QUON, M. J. Cardiovascular Actions of Insulin. Endocrinol. Rev., v. 28, n. 5, p. 463-491, 2007.

MYKKANEN, L.; HAFFNER, S.M.; RONNEMAA, T.; BERGMAN, R.N.; LAAKSO, M. Low insulin sensitivity is associated with clustering of cardiovascular disease risk factors. Am. J. Epidemiol., v. 146, n. 4, p. 315-21, 1997.

NEMEROFF, C. B.; GRANT, L. D.; BISSETTE, G.; ERVIN, G. N.; HARRELL, L. E.; PRANGE, A. J. Growth, endocrinological and behavioral deficits after monosodium Lglutamate in the neonatal rat: possible involvement of arcuate dopamine neuron damage. Psychoneuroendocrinology, v. 2, n. 2, p. 179-96, 1977.

O'BRIEN, S. F.; MCKENDRICK, J. D.; RADOMSKI, M. W.; DAVIDGE, S. T.; RUSSELL, J. C. Vascular wall reactivity in conductance and resistance arteries: differential effects of insulin resistance. Can. J. Physiol. Pharmacol., v. 76, n. 1, p. 72-6, 1998.

OLNEY, J. W. Brain lesions, obesity, and other disturbances in mice treated with monosodium glutamate. Science, v. 164, p. 719-721, 1969.

OUSLIMANI, N.; PEYNET, J.; ROUSSELOT, DB.; THE'ROND, P.; LEGRAND, A.; BEAUDEUX, J. L. Metformin decreases intracellular production of reactive oxygen species in aortic endothelial cells. Metabolism, v. 54, p. 829-834, 2005.

PASQUALI, R.; ANCONETANI, B.; CHATTAT, R.; BISCOTTI, M.; SPINUCCI, G.; CASIMIRRI, D. F. Hypothalamic-pituitary-adrenal axis activity and its relationship to the autonomic nervous system in women with visceral and subcutaneous obesity: effects of the corticotropin-releasing factor/arginine-vasopressin test and of stress, Metabolism, v. 45, n. 3, p. 351-356, 1996.

PERTICONE, F.; CERAVOLO, R.; CANDIGLIOTA, M.; VENTURA, G.; IACOPINO, S.; SINOPOLI, F.; MATTIOLI, P. L. Obesity and body fat distribution induce endothelial dysfunction by oxidative stress protective effect of vitamin C. Diabetes, v. 50, p. 159-165, 2001.

PESSIN, J. E.; SALTIEL, A. R. Signaling pathways in insulin action: molecular targets of insulin resistance. J. Clin. Invest., v. 106, n. 2, p. 165-9, 2000. 
PEULER, J. D.; MILLER, J. A.; BOURGHLI, M.; ZAMMAM, H. Y.; SOLTIS, E. E.; SOWERS, J. R. Disparate effects of antidiabetic drugs on arterial contraction. Metabolism, v. 46, p. 1199-1205, 1997.

POU, S.; POU, W.; BREDT, D. S.; SNYDER, S. H.; ROSEN, G. M. Generation of superoxide by purified brain nitric oxide synthase. J. Biol. Chem., v. 267, p. 2417324176, 1992.

POWERS, K.; REHRIG, S.; JONES, D. Financial Impact of Obesity and Bariatric Surgery. Med. Clin. N. Am., v. 91, n. 3, p. 321-338, 2007.

QATANANI, M.; LAZAR, M. A. Mechanisms of obesity-associated insulin resistance: many choices on the menu. Genes Dev., v. 21, n. 12, p. 1443-55, 2007.

RAZ. I.; ELDOR, R.; CERNEA, S.; SHAFRIR, E. Diabetes: insulin resistance and derangements in lipid metabolism. Cure through intervention in fat transport and storage. Diabetes Metab. Res. Rev., v. 21, n. 1, p. 3-14, 2005.

REAVEN, G. M. Role of insulin resistance in human disease. Diabetes, v. 37, p. 1595-1607, 1988.

RODRIGUEZ-SIERRA, J. F.; SRIDARAN, R.; BLAKE, C. A. Monosodium glutamate disruption of behavioral and endocrine function in the female rat. Neuroendocrinology, v. 31, n. 3, p. 228-35, 1980.

ROMANKO, O. P.; STEPP, D. W. Reduced constrictor reactivity balances impaired vasodilation in the mesenteric circulation of the obese Zucker rat. Am. J. Physiol. Heart Circ. Physiol., v. 289, p. H2097-H2102, 2005.

ROSMOND, R.; DALLMAN, M. F.; BJORNTORP, P. Stress-related cortisol secretion in men: relationships with abdominal obesity and endocrine, metabolic and hemodynamic abnormalities. J. Clin. Endocrinol. Metab., v. 83, n. 6, p. 1853-1859, 1998.

SALTIEL, A. R.; KAHN, C. R. Insulin signalling and the regulation of glucose and lipid metabolism. Nature, v. 414, p. 799-806, 2001.

SARTIN, J. L.; LAMPERTI, A. A.; KEMPPAINEN, R. J. Alterations in insulin and glucagon secretion by monosodium glutamate lesions of the hypothalamic arcuate nucleus. Endocr. Res., v. 11, n. 3-4, p. 145-55, 1985. 
SARTORETTO, J. L.; MELO, G. A. N.; CARVALHO, M. H. C.; NIGRO, D.; PASSAGLIA, R. T.; SCAVONE, C.; CUMAN, R. K. N.; FORTES, Z. B. Metformin treatment restores the microvascular reactivity in neonatal streptozocin-induced diabetic rats increasing NOS activity, but not NOS expression. Life Sci., v. 77, p. 2676-2689, 2005.

SCHERER, P. E. Adipose tissue: from lipid storage compartment to endocrine organ. Diabetes, v. 55, n. 6, p. 1537-45, 2006.

SCHIMMACK, G.; DEFRONZO, R. A.; MUSI, N. AMP-activated protein kinase: Role in metabolism and therapeutic implications. Diabetes Obes. Metab., v. 8, n.6, p.591602, 2006.

SEUFERT, J.; LÜBBEN, G.; DIETRICH, K.; BATES, P. C. A comparison of the effects of thiazolidinediones and metformin on metabolic control in patients with type 2 diabetes mellitus. Clin. Ther., v. 26, n. 6, p. 805-18, 2004.

SHARMA, R. V.; BHALLA, R. C. Metformin attenuates agonist stimulated calcium transients in vascular smooth muscle cells. Clin. Exp. Hypertens., v. 17, p. 913-929, 1995.

SHIMOKAWA, H.; YASUTAKE, H.; FUJII, K.; OWADA, M. K.; NAKAIKE, R.; FUKUMOTO, Y.; TAKAYANAGI, T.; NAGAO, T.; EGASHIRA, K.; FUJISHIMA, M.; TAKESHITA, A. The importance of the hyperpolarizing mechanism increases as the vessel size decreases in endothelium dependent relaxations in rat mesenteric circulation. J. Cardiovasc. Pharmacol., v. 28, p. 703-711, 1996.

SOBREVIA; MANN, G. E. Dysfunction of the endothelial nitric oxide signalling pathway in diabetes and hyperglycaemia. Exp. Physiol., v. 82, p. 423-452, 1997.

STEINBERG, H. O.; CHAKER, H.; LEAMING, R.; JOHNSON, A.; G. BRECHTEL, AND ALAIN D. BARON. Obesity/insulin resistance is associated with endothelial dysfunction. J. Clin. Invest., v. 97, p. 2601-2610, 1996.

STEPP, D. W.; CHANTEMELE, E. J. B. Structural Remodeling in the Limb Circulation: Impact of Obesity and Diabetes. Microcirculation, v. 14, p. 311-316, 2007.

STUMVOLL, N.; NURJHAN, N.; PERRIELLO, G.; DAILEY, G.; GERICH, J. E. Metabolic effects of metformin in non-insulin-dependent diabetes mellitus. N. Engl. J. Med., v. 333, p. 550-554, 1995. 
TOKAREV, D.; KRISTOVA, V.; KRISKA, M.; JEZOVA, D. Treatment of Neonatal Rats with Monosodium Glutamate Attenuates the Cardiovascular Reactivity to Phenylephrine and Angiotensin II. Physiol. Res., v. 46, n. 3, p. 165-171, 1997.

TOLEDO, D. P. Estudo da resposta inflamatória aguda e crônica e reatividade microvascular em modelo de resistência à insulina (obesidade em ratos). 2005. Tese (doutorado) - Instituto de Ciências Biomédicas, Universidade de São Paulo, 2005.

TUOMILEHTO, J.; LINDSTRÖM, J.; ERIKSSON, J. G.; VALLE, T. T.; HÄMÄLÄINEN, H.; ILANNE-PARIKKA, P.; KEINÄNEN-KIUKAANNIEMI, S.; LAAKSO, M.; LOUHERANTA, A.; RASTAS, M.; SALMINEN, V.; UUSITUPA, M. Prevention of type 2 diabetes mellitus by changes in lifestyle among subjects with impaired glucose tolerance. N. Engl. J. Med., v. 344, n. 18, p. 1343-50, 2001.

VAN GAAL, L. F.; MERTENS, I. L.; DE BLOCK, C. E. Mechanisms linking obesity with cardiovascular disease. Nature, v. 444, n. 7121, p. 875-80, 2006.

VEJA, G. L. Cardiovascular Outcomes for Obesity and Metabolic Syndrome. Obes. Res., v. 10, n. 1, p. 27S-32S, 2002.

VERMA, S.; BHANOT, S.; MCNEILL, J. H. Decreased vascular reactivity in metformin-treated fructose-hypertensive rats. Metabolism, v. 45, p. 1053-1055, 1996.

VILLAR, I. C.; FRANCIS, S.; WEBB, A.; HOBBS, A. J.; AHLUWALIA, A. Novel aspects of endothelium-dependent regulation of vascular tone. Kidney Int.. v. 70, n. 5, p. 840-53, 2006. Review.

WEVER, R. M.; VAN DAM, T.; VAN RIJN, H. J.; DE GROOT, F.; RABELINK, T. J. Tetrahydrobiopterin regulates superoxide and nitric oxide generation by recombinant endothelial nitric oxide synthase. Biochem. Biophys. Res. Commun., v. 237, p. 340-344, 1997.

WHITE, M. F. The IRS-signalling system: A network of docking proteins that mediate insulin action. Mol. Cell. Biochem., v. 182, n. 1-2, p. 3-11, 1998.

WIERNSPERGER, N. F.; BAILEY, C. J. The antihyperglycaemic effect of metformin: therapeutic and cellular mechanisms. Drugs, v. 58, n. 1, p. 31-9, 1999. 
WILCOX, G. Insulin and insulin resistance. Clin. Biochem. Rev., v. 26, p. 19-27, 2005.

WILD, S.; ROGLIC, G.; GREEN, A.; SICREE, R.; KING, H. Global prevalence of diabetes: estimates for the year 2000 and projections for 2030. Diabetes Care, v. 27, p. 1047-1053, 2004.

WYSS, J. M. The role of the sympathetic nervous system in hypertension. Curr. Opin. Nephrol. Hypertens., v. 2, p. 265-73, 1993.

XAVIER, F. E.; ROSSONI, L.V.; ALONSO, M.J.; BALFAGÓN, G.; VASSALLO, D.V.; SALAICES, M. Ouabain-induced hypertension alters the participation of endothelial factors in alpha-adrenergic responses differently in rat resistance and conductance mesenteric arteries. Brit. J. Pharmacol., v. 143, p. 215-225, 2004.

ZHOU, G.; MYERS, R.; LI, Y.; CHEN, Y.; SHEN, X.; FENYK-MELODY, J.; WU, M.; VENTRE, J.; DOEBBER, T.; FUJII, N.; MUSI, N.; HIRSHMAN, M. F.; GOODYEAR, L. J.; MOLLER, D. E. Role of AMP-activated protein kinase in mechanism of metformin action. J. Clin. Invest., v. 108, n. 8, p. 1167-74, 2001.

ZIMMET, P.; ALBERTI, K. G.; SHAW, J. Global and societal implications of the diabetes epidemic. Nature, v. 414, p. 782-787, 2001. 